\title{
Transcutaneous electrical nerve stimulation for patients with chronic pain
}

Citation for published version (APA):

Köke, A. J. A. (2012). Transcutaneous electrical nerve stimulation for patients with chronic pain. [Doctoral Thesis, Maastricht University]. Maastricht University. https://doi.org/10.26481/dis.20120119ak

Document status and date:

Published: 01/01/2012

DOI:

10.26481/dis.20120119ak

Document Version:

Publisher's PDF, also known as Version of record

\section{Please check the document version of this publication:}

- A submitted manuscript is the version of the article upon submission and before peer-review. There can be important differences between the submitted version and the official published version of record.

People interested in the research are advised to contact the author for the final version of the publication, or visit the DOI to the publisher's website.

- The final author version and the galley proof are versions of the publication after peer review.

- The final published version features the final layout of the paper including the volume, issue and page numbers.

Link to publication

\footnotetext{
General rights rights.

- You may freely distribute the URL identifying the publication in the public portal. please follow below link for the End User Agreement:

www.umlib.nl/taverne-license

Take down policy

If you believe that this document breaches copyright please contact us at:

repository@maastrichtuniversity.nl

providing details and we will investigate your claim.
}

Copyright and moral rights for the publications made accessible in the public portal are retained by the authors and/or other copyright owners and it is a condition of accessing publications that users recognise and abide by the legal requirements associated with these

- Users may download and print one copy of any publication from the public portal for the purpose of private study or research.

- You may not further distribute the material or use it for any profit-making activity or commercial gain

If the publication is distributed under the terms of Article $25 \mathrm{fa}$ of the Dutch Copyright Act, indicated by the "Taverne" license above, 


\section{Transcutaneous electrical nerve stimulation for patients with chronic pain}

Albère J.A. Köke 
(c) Albère Jacobus Antonio Köke, Maastricht 2011 ISBN XXX-XX-XXXXXXX-X

Typesetting: Michał Sławiński

Printed in Poland 


\title{
Transcutaneous electrical nerve stimulation for patients with chronic pain
}

\author{
Proefschrift \\ Ter verkrijging van de graad van doctor \\ aan de Universiteit Maastricht, \\ op gezag van de Rector Magnificus, \\ Prof. Mr. G.P.M.F.Mols,
}

volgens het besluit van het College van Decanen,

in het openbaar te verdedigen

op 19 januari 2012 om 14.00 uur

door

\section{Albère Jacobus Antonio Köke}

Geboren 06-06-1961 te Sittard 


\section{Promotoren}

Prof. dr. M. van Kleef

Prof. dr. R.J.E.M. Smeets

\section{Co-promotor}

Dr. J. Patijn

\section{Beoordelingscommissie}

Prof. dr. M.L. Peters (voorzitter)

Prof. dr. J.W.S. Vlaeyen

Prof. dr. R. de Bie

Prof. dr. H.C.W. de Vet

Prof. dr. W. Zuurmond 




\section{Contents of the thesis}

Chapter 1

General introduction

9

Chapter 2

Pain reducing effect of three types of Transcutaneous Electrical

Nerve Stimulation (TENS) in patients with chronic pain:

A randomized cross-over trial

Chapter 3

Can we 'predict'long term outcome

for Transcutaneous Electrical Nerve Stimulation?

Chapter 4

Why chronic pain patients use transcutaneous

electrical nerve stimulation (TENS) on long term?

63

Chapter 5

Psychometric evaluation of the Dutch Chronic

Pain Self efficacy Scale: a two-factor solution

79

Chapter 6

Minimal clinically important change and minimal

detectable change of pain. Do clinicians and patients agree?

Chapter 7

General discussion

Chapter 8

Summary

133

Samenvatting

139

Dankwoord

145

About the author

149

Publications 



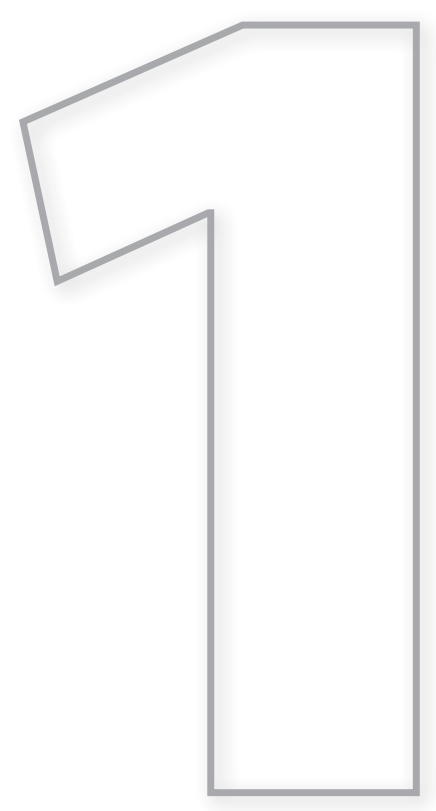

General introduction 



\section{Chronic pain}

Optimizing the treatment for patients with chronic pain, due to modest effects of current treatment, poses a great challenge to clinicians and researchers. Chronic pain disrupts quality of life and becomes a disease in its own right. Patient with chronic pain not only suffer from persistent, recurrent pain, they also endure substantial reductions in everyday activities, limited social and occupational functioning, and disrupted lifestyles [45].

Research in the past decades has made progress on the elucidation of causal mechanism, assessment and treatment. It is widely believed that the prevalence of chronic pain remains stable [55].

Comparing studies on the prevalence of chronic impairing pain however, do not confirm this belief. Von Korff et al. [89] conducted (in 1988) one of the first epidemiological studies on chronic pain. The results showed prevalence of $41 \%$ for back pain, $26 \%$ for headache, $17 \%$ for abdominal pain, $12 \%$ for chest pain, and $12 \%$ for facial pain. Since then many prevalence studies of chronic pain have been published showing that chronic pain is a very common condition, and is even increasing throughout the past decade. Harkness et al. [38] found a two- to four fold increase in prevalence of low back pain, shoulder pain and chronic wide spread pain over a 40 year period (1950-1994) in England. Two population based estimates of pain (1992-2006) in the United States, showed an increase of musculoskeletal pain from 14 to 20\% [32]. Palmer et al. [67] found a 12.7\% rise in the 1-year prevalence of low back pain (LBP) over a 10-year period (1990-2000), and recently Leijon et al. [51] reported the prevalence of chronic, impairing LBP over a 16-year interval. In this time period, prevalence rose from 3.9\% (95\% Cl, 3.4\%-4.4\%) in 1992, to 10.2\% (95\% Cl, 9.3\%-11.0\%). Increases were seen for all adult age strata, in men and women and in white and black race.

Reasons for this increase in chronic pain are unclear. Although chronic musculoskeletal pain significantly affects populations of working age, there is clear evidence that musculoskeletal pain, in particular, increases with age. With an ageing population it is therefore likely that musculoskeletal pain in the community will increase. Another factor that may lead to an increasing burden of musculoskeletal pain is obesity, an epidemic which is occurring around the world [10]. Self-reported work-restricting pain in the neck and back area and in lower extremity joints was more common in obese subjects than in a general Swedish population [26].

Another important finding is that although symptom severity and general health were similar for both study periods, the proportion of individuals who sought care from a health care provider in the past year increased from 73\% to 84.0\% [52]. In a European study Breivik et al. [8] found that two-thirds of patients, who suffered from chronic pain during many years, were currently under treatment; such as massage (30\%), physical therapy (21\%) and acupuncture (13\%). Almost half of all patients were taking non-prescription analgesics such as; over the counter NSAIDs, weak opioids, and two-thirds were taking prescription medication [8].

Although chronic pain patients persist in seeking treatment, the effectiveness of all somatic treatments aimed at pain relief, such as medication, alternative medicine, invasive pain 
treatment and exercises offered today remains limited $[48 ; 72 ; 85-86]$. Prospective cohort studies in patients with chronic pain showed only limited numbers of patients recovering from their complaints. For example, Papageorgiou et al. [68] reported that, 7 years after the initial diagnosis, $77 \%$ of the patients still suffered from chronic pain. In another cohort study, Anderson et al. [1] found among those with initial chronic pain, 85\% still reporting chronic pain after 12 years.

Chronic pain therefore is a highly treatment resistant health problem resulting in increasing healthcare costs and prolonged patient suffering. Chronic pain costs Europe billions of Euros every year, with national costs ranging from $€ 1.1$ billion to nearly $€ 50$ billion [57; 96]. Musculoskeletal diseases are the fifth most expensive disease category regarding hospital care, and the most expensive regarding work absenteeism and disability (1.7\% of GNP) in the Netherlands [87]. The total cost of neck pain in the Netherlands in 1996 was estimated to be US \$686 million [6]. Although these numbers are impressive, there is a paucity of literature assessing specifically the health care costs of chronic pain, so the exact impact of chronic pain on economics still remains uncertain [36].

It seems therefore that since Von Korff et al. [89] published his results of the first epidemiologic study on pain, little has changed. Because of today's high prevalence and still unclear aetiology of chronic pain, there is a pressing need for effective low cost treatment with no or minor side effects. As Transcutaneous Electrical Nerve Stimulation (TENS) is a noninvasive, inexpensive, safe, non-addictive, easy to use treatment with no or minor side effects (skin irritation); it seems worthwhile to examine its effectiveness. As chronic pain is a multidimensional problem, effectiveness of TENS should not only be assessed in domain of pain relief but should include a broader range of domains such as physical and emotional functioning, health care use/costs, work capacity and disability. Therefore the topic of this thesis is the effectiveness of Transcutaneous Electrical Nerve Stimulation (TENS) within patients with chronic pain complaints covering a broad range of relevant outcome domains.

\section{Transcutaneous Electrical Nerve Stimulation (TENS)}

TENS is probably one of the oldest treatments for pain relief and is still being used. In her book "TENS Clinical Applications and Related Theory", Walsh [91] presented a case-report, originally published in 1759 in the book 'The Desideratum: or Electricity made Plain and Useful'. In this book, John Wesley described a case-report about a woman with shoulder pain for more than 2 years and no satisfactory treatment results so far. After three consecutive days of treatments with strong electric shocks, her chronic shoulder pain had completely resolved. But despite this first promising case report as well as others presented thereafter, electroanalgesia wasn't accepted as a therapeutic tool within the field of medicine at those days [79]. However, at the end of the $19^{\text {th }}$ century a lot of effort was put in the production of a portable electrotherapy 
device. In 1919 the first TENS-machine (the Electreat) was available for purchase in the United States of America. In 1941 the sale of this Electreat was forbidden by the American FDA because the company couldn't prove her slogan 'Electreat relieves pain' [91].

It then took over 25 years for TENS to become popular again. First, the gate control theory, published in 1965, provided a neurophysiologic explanatory working mechanism; it's explained how large fiber stimulation can produce pain relief by 'closing the gate'. Not long thereafter Wall \& Sweet [90] published their case-reports of successful electric pain treatments in eight patients with treatment resistant chronic neuropathic pain disorders. According to Walsh [91], a second contributing factor for the renewed interest in TENS was the fact that Shealy et al. [74] used TENS as a screening tool for dorsal column stimulation (DCS) to treat chronic pain. In several cases TENS appeared to be more effective than DCS, and so TENS was also used as a solo treatment for pain.

Secondly, the discovery of opioid neuropeptides with pain reducing effect in the animal brain, called enkephalines and/or endorphins (an abbreviation of "endogenous morphine", which literally means "morphine produced naturally in the body"), provided a second explanatory working mechanism for TENS. In a study of Solomon et al. [80] it appeared that the analgesic effect of TENS for postoperative pain was reduced in patients who had used narcotics prior to surgery. The results suggested that the cross-tolerance phenomenon between TENS and opioids found in rodents [77] was also present in humans. Since then many animal studies demonstrated that TENS produces hypoalgesic effects through opioids receptors in the spinal cord [77].

In general two major theories or mechanism have been described and used in daily care and research until today. The first mechanism is transcutaneous stimulation of large afferent nerve fibres resulting in segmental pain inhibition (gate control theory). The second mechanism is based on transcutaneous stimulation of small afferent nerve fibres which leads to pain relief by the release of endogenous opioids (supra-segmental effect) [79].

Today TENS is the most widely used afferent electrical nerve stimulation technique for pain relief, commonly used as an immediate and adjunct treatment to control pain [22; 37]. TENS is a portable device and therefore applicable in many different situations by the patient at home, work and leisure. So it can be used as a self management approach and as such it might increase patient's compliance and response to the treatment. TENS is used for pain relief in many different pain syndromes. Several types of TENS can be applied based on different setting of TENS parameters: pulse frequency, pulse duration, pulse amplitude (intensity), and style of output. 


\section{Different types of TENS}

A TENS unit allows the parameters of frequency, pulse duration, pulse amplitude (intensity), and modulation type (constant, burst, modulated) to be manipulated based on presumed mechanism for pain relief. After setting up the parameters, peripheral nerves are electrically stimulated by surface electrode placed on the skin. Based on a combination of specific TENS parameters, different types of TENS can be distinguished. Effectiveness is thought to be due to the specific settings of these parameters.

Frequency of stimulation is broadly classified as high frequency TENS (HFT) $(>50 \mathrm{~Hz})$ or low frequency (LFT) $(<10 \mathrm{~Hz})$. HFT is assumed to work by stimulation of large diameter afferents inhibiting nociceptive fiber evoked responses in the dorsal horn (gate control theory), and LFT is assumed to work due to the release of endogenous opioids [79].

Pulse duration and stimulus intensity could also be factors responsible for the differing effect of TENS. Longer pulse duration is experienced as a more pleasant sensation, fitting the idea of specific stimulation of large afferent fibres which results in closing the "gate" in the dorsal horn. Longer pulse duration and higher stimulus intensity results probably stimulates more deep tissue large diameter afferents, which is important to produce a pain reduction [70].

Modulation of the stimulus intensity and/or frequency is typically used to overcome fading away of current sensation due to adaptation or habituation to electrical stimulation [25]. This fading away might be caused by a decrease in frequency of action potentials (adaptation) or decrease in central subjective awareness of the sensation (habituation). Therefore most TENS devices have an option of modulation in order to vary in pulse duration, frequency or amplitude parameters in a cyclic fashion. The effectiveness of these modulation options remains unclear [91].

In summary two main theories for TENS are used to explain the pain reducing effects of TENS. On one hand the gate control theory is used to explain how and why TENS is working and on the other hand the release of 'endorphines' by TENS. However the precise mechanism of action and the precise relevance of stimulation parameters to hypoalgesic effects are still unclear. As a consequence no consensus on optimum stimulation parameters (frequency, pulse duration, intensity and modulation) exists [19].

\section{What do we know about evidence for effectiveness of TENS?}

Effectiveness of TENS has been systematically reviewed for chronic LBP $[12 ; 46 ; 60]$, neck pain [47], chronic musculoskeletal pain [43], chronic pain [13; 58; 64], chronic/recurrent headache [9; 11], rheumatoid arthritis $[5 ; 11 ; 65 ; 73]$, osteoarthritis $[5 ; 65 ; 73]$, acute postoperative pain [4; 14], labour pain [15; 27], adult cancer pain [71], shoulder pain in stroke patients [69], and a diverse group of acute pain problems/situations [93], and angina pectoris [7; 61]. Despite the large numbers of randomised controlled trials, evidence from systematic 
reviews and meta-analysis has been inconsistent in demonstrating clear benefits. Evidence is conflicting for acute pain [4; 14], more positive for chronic pain [43; 65], although many are inconclusive [46-47; 58; 64].

Long term follow up studies report high rates of percentages of patients continuing TENS; $55 \%$ at 3 months, $13-74 \%$ at 6 months, 20\%-66\% at 1 year, $25-43 \%$ at $3-4$ years, and $58 \%$ after 10 years $[31 ; 54 ; 59 ; 88]$. But reasons for the continuation of TENS on long term or knowledge about characteristics of this subgroup of long term responders are not well known.

Most frequently mentioned comments in systematic reviews about TENS are that the studies were heterogeneous with respect to study population, sample size, study design, methodological quality, mode of TENS and frequency or duration of TENS treatment. This situation has been interpreted as one in which there is a lack of evidence of effect, rather than reliable evidence of a lack of effect. 


\section{Possible explanations for lack of evidence regarding TENS}

Before planning a new trial with TENS, discussing possible explanations for the lack of consistent evidence to support the use of TENS is warranted. Several reasons that might explain the lack of effect presented by the systematic reviews are; type of TENS, heterogeneity of pain population, underpowerment of studies, outcome domains, and outcome measures. These reasons will be discussed in more detail, in the next paragraphs.

\section{Type of TENS}

As no consensus on the optimal stimulation parameters (frequency, pulse duration, intensity) exists [19], every clinician and researcher is free to choose his/her own TENS-parameters. This is reflected by the high percentages of trials which used different parameters. Traditionally HFT (50-100 Hz) and LFT (1-10 HZ) are used most frequently, but accompanying parameters of pulse duration and/or intensity are highly variable. Although frequency could be the main parameters that determines the presumed effect this is still unclear. Studies comparing HFT and LFT, found no differences in pain reducing effect [35; 39-40; 62; 82-83]. Only one study reported a difference in favour of HFT [56] and one in favour of LFT [83]. An explanation might be that both types of TENS, more or less could be effective on the basis of the same or mutual influencing mechanisms. Sluka et al. [78] have shown that low frequency TENS delivered below motor threshold acts by mu-opioid receptors, whereas high frequency TENS acts by delta-opioid receptors in an animal study. However, animal research permits better control over the variables that affect pain perception. Specifically, the affective-motivational component of pain is minimized. Whether these frequency depended effects in animal studies therefore translate into differences in hypoalgesia in humans remains a matter of debate [20]. In healthy humans some studies found no frequency depended hypoalgesic effect of TENS with experimental pain, when its pulse intensity, pulse pattern, and pulse duration were kept constant [18].

Other stimulus parameters presumed responsible for treatment effect are stimulus intensity and pulse duration. Both, animal and human studies, shown better pain relief with increasing intensity [34; 75-76; 95; 97] and longer pulse duration [34; 92; 94]. Although stimulation just below or above sensory thresholds are often recommended for TENS, especially for HFT, this could result in non optimal stimulus intensity. Bjordal et al. [4] compared TENS-trials with an assumed optimal treatment dose ( stimulus intensity $<15 \mathrm{~mA}$ [3]), to those with a nonoptimal treatment dosage in post-operative pain. They found a significant effect on analgesic consumption in favour of TENS with an optimal dosage.

Besides optimal stimulus intensity there are also large differences of frequency of TENS stimulation over a day, week or months. In several studies, included in the reviews, TENS 
was given as one single treatment of approximate 30 minutes. One can question whether this 'treatment' reflects a valid and effective treatment, as chronic pain is a long lasting problem and TENS is only a symptomatic treatment (by inhibiting and/or modulating nociceptive stimulus transport).

An optimal treatment dosage containing sufficient intensity and long pulse duration (> $200 \mu \mathrm{sec}$ ) of stimulation over time seems to be a critical success factors for effectiveness [79]. This treatment must not be offered as a single stimulation, but continued over a period of time to assess whether successful pain reduction occurs.

\section{Study population}

The inconclusive results could also be due to the heterogeneity of chronic pain patients and types of pain included in the trials. Although a medical diagnosis is often used as an inclusion criterion, this does not mean that complexity of the pain problem is the same in all patients with the same medical diagnosis. The contribution of psychosocial factors to the pain complaints differs between patients and could influence outcome of TENS.

Patients with pain without clear signs of an organic lesion and signs of psychiatric disturbance (psychogenic pain) had higher failure rates compared to patients with neuropathic pain mostly of peripheral origin [42]. Also pathological personality traits (hysteric neurosis, paranoia), mental illness (depressive state, psychosis) [41; 50; 63], social isolation and analgesic abuse [50] seem to be associated with poor outcome. Therefore one cannot expect that each individual patient responds equally to treatment.

The different aetiology of the pain in the study populations may be another explanation for differences in success rates. For example, Meyler et al. [59] found at 6 months follow up different positive success rates for TENS in conditions such as; ischemic heart pain (75\%), pain due to skeletal degenerative causes (69\%), peripheral nerve injuries (53\%) and pain caused by central and autonomic nervous dysfunction (10-25\%). Verdouw et al. [88] reported the highest success rate in patients with pain on more than one location (53\%) compared to cervicobrachialgia (43\%), facial pain/headache (43\%), LBP (39\%), peripheral deafferentiation pain (29\%), CRPS (25\%) and intercostal neuralgia (25\%).

The outcome of TENS seems therefore to be influenced by medical as well as psychosocial factors which is in line with the multidimensional definition of pain. For clinical practice and for selecting patients to participate in randomised trials on the effectiveness for TENS it is therefore very important to identify possible subgroups of patients on the basis of the biopsychosocial model who will benefit from TENS. The more efficient patient selection probably is an important factor to improve the effectiveness of treatment in the field of TENS. 


\section{Underpowerment of TENS trials}

Most meta-analysis included not only a small number of studies, but also most RCT's had small sample sizes. This could be a problem for overall results as large sample sizes are necessary to overcome problems with effects with large standard deviations in the included studies relative to the scale on which pain is measured [43]. Johnson et al. [43] stated that the disparity in the results of previous reviews and meta-analysis is explained by lack of statistical power in many of those studies. In 2003 Bjordal et al. [4] conducted a meta-analysis with sufficient power (1350 patients) in postoperative pain, and concluded that TENS significantly reduced analgesic consumption post-operatively. The question is whether TENS in those patients effectively reduced the pain as patients took pain medication as well. Therefore Johnson et al. [43] reviewed the literature about effectiveness of electric nerve stimulation (including TENS) compared to placebo in chronic musculoskeletal pain. To enhance power, contrary to most meta-analysis, a variety of anatomic locations (e.g. back, neck) were included. As TENS effect depends on inhibiting nociceptive transmission to the brain, this mechanism is likely the critical factor for effective treatment. Anatomic location of the pain is therefore not a relevant factor for success. A total of 1227 patients were included in the analysis (29 studies). On average the pain relief provided by electric nerve stimulation was nearly three times higher than pain relief by placebo. HFT and LFT produced both significant effects, where acupuncture-like TENS and combinations of HLT and LFT did not.

\section{Type of outcome}

As pain is a multidimensional phenomenon measuring effectiveness solely by the amount of pain reduction seems to be inadequate. Patients suffer not only from pain, but also experience problems in emotional and physical functioning and health related quality of life. Therefore a core set has been recommended including 6 core outcome domains; (1) pain; (2) physical functioning; (3) emotional functioning; (4) participant ratings of improvement and satisfaction with treatment; (5) symptoms and adverse events; and (6) participant disposition, when designing chronic pain clinical trials [84].

The finding that there are chronic pain patients reporting no or minor pain relief, but still use TENS [44] could be due to other effects of TENS besides pain reduction. However, why patients continue TENS despite no pain relief is not clear. There might be other potential effects why they continue TENS, but there are hardly studied [31]. Results from a literature search on other effects of TENS show; reduction of medication intake [31], joint mobility [60; 65], increase in activity level [31; 60; 81], socialization [29], improved work capacity and sleep pattern [33], reduction of interference with work, improved activity inside home and social activity [31] and reduction of use of other therapy and medical costs [16]. So in general, less information on other effects besides pain relief by TENS exists. 
The question therefore is what other possible benefits patients might gain from using TENS, and how these effects can be explained. Supposed working mechanisms for TENS however, only explain pain reduction. In our opinion TENS has positive effects on daily physical functioning, as a secondary effect due to pain reduction. We also think that patients would use TENS as a substitute for other pain treatment attended with more side effects such as medication [4].

Furthermore, we think that the TENS working mechanism is not only based on neurophysiologic effects by closing the gate or increased release of endorphins due to strong stimulus intensity. We hypothesize that TENS might also be successful due to more psychological mechanisms. As TENS is a self-administered treatment it might help patients to better cope with their pain complaints. Physiologically, psychological processes such as perceived control over pain or self-efficacy beliefs on coping with chronic pain also influence the release of catecholamines and endogenous opioids [49]. It may be that the effectiveness of TENS is also due to changes in psychological factors associated with pain, pain control and negative consequences of pain. This however, has never been studied. 


\section{Pain measurement: statistically significant versus clinically relevant change}

Our inability to measure pain effectively [17], might be a reason why the effectiveness of TENS remains inconclusive. Although pain is common, the measurement of intensity of pain and the determination of the extent to which a certain amount of pain reduction corresponds with successful therapy can be far from simple. Unlike unidimensional parameters such as body weight or length which can be easily quantified, pain is a complex multidimensional phenomenon. Pain includes physiologic, psychological, emotional and behavioural dimensions.

Most pain scales used in TENS research are one-dimensional, self report pain scales which only focus on pain intensity. This might result in an increased risk of oversimplification of the experience. However, self report of pain is momentarily the most reliable indicator for the intensity of pain or pain relief.

In interpreting the results of RCTs, emphasizing statistical significance rather than clinical importance is common. Assessing statistically significant differences between treatments in clinical trials or changes over time in a patient are necessary, but not sufficient to prove effectiveness of the treatment [30]. Statistical significance of a treatment effect, because of its partial dependency on sample size, does not always correspond to the clinical relevance of the effect [24].

In TENS the same results of trials were differently interpreted by different reviewers because they used different definitions of success [4]. The lack of emphasis on clinical relevance or importance seems to contribute to misconceptions and disagreement when interpreting results of clinical trials. The concept of 'minimal clinically important change' (MCIC) might be a way to overcome the shortcomings of interpreting results/effects on the basis of statistically significant difference [21]. A MCIC represents a change that would be considered meaningful and worthwhile by the patient such that he/she would consider repeating the intervention if it were his/her choice to make again [21]. The MCIC represents the lower boundary or threshold of an effect that is important for the patient or clinician.

In the field of pain, a 30\% decrease in pain intensity is recommended by the IMMPACTgroup [28] as a reasonable primary standard (MCIC) to asses a clinical relevant change in chronic pain trials. The idea of having one universal MCID for a (pain) instrument is tempting as it can be used for determination of sample size in research or for interpreting the results of trials.

The question is whether such a recommendation of 30\% decrease in pain can be used for all type of pain reducing treatment, and/or pain scales. At first, these recommendations are based on studies using a numeric (pain) rating scale (NRS) [30]. Litcher-Kelly et al. [53] reviewed 50 original research papers (out of 7 well-known pain magazines) addressing chronic musculoskeletal pain to find out what pain assessments are commonly used. Their results showed that in 49 studies, 30 times a single item VAS pain measurement was used compared to six times a numeric rating scale (NRS). 
Secondly, there is no consensus in the literature on the most appropriate technique for determining the $\mathrm{MCIC}$; different methods to estimate the $\mathrm{MCIC}$ result in different values [66]. Most MCIC are estimated from a researchers or clinicians perspective. One can question whether patient's perception of important change is the same.

Furthermore, it seems that an $\mathrm{MCIC}$ is a context-specific value rather than a fixed number [2]. It is therefore necessary to estimate $\mathrm{MCIC}$ for each intervention separately as each intervention has specific side effects, costs or unconviences that should be integrated in a MCIC. Moreover, it is important to make a distinction between MCIC (smallest difference perceived as important by the patient) and a minimal detectable difference (MDC). The MDC is the smallest difference that can be detected that can be detected by the instrument beyond measurement error [23-24]. MCIC and MDC are therefore two different concepts, both important for better interpreting effect from interventional studies. Estimating such treatment specific MCIC and MDC is important for comparing results of studies on the effectiveness of interventions in pain.

One can question whether a 30\% pain reduction is an appropriate cut-off point for defining success for TENS, as TENS is a low cost treatment with no or minor side effects. Whether the recommendation of MCID for pain reduction as indicator for treatment success, must be based on a researchers or a patients perspective, also needs further investigation. 


\section{Outline of this thesis}

Based on the different reasons for the lack of evidence, as discussed above, we defined the research questions for this thesis.

To diminish the impact of heterogeneity within chronic pain populations a cross-over design was chosen were the same patient is randomly using two types of TENS in different time periods. A cross-over design also increases power for statistical analysis, so the problem of underpowerment can be solved. As no consensus exists on optimal treatment parameters we hypothesize that the intensity of TENS might be a crucial factor for success. So our first research question is to examine the effectiveness in reducing severity of pain of three different types of TENS (high frequency/low intensity vs. high frequency/high intensity vs. a control group (TENS)) in patients with chronic pain referred to a tertiary pain clinic (Chapter 2).

We do not expect that TENS is effective for all chronic pain patients. Finding which patients respond (positive or negative) to TENS is important to identify subgroups of patients, which allow for optimal selection of patients in research and daily practice in the future? As pain is a multidimensional phenomenon, assessing predictive factors for long term outcome of TENS, must be done from a biomedical as well as a psychosocial perspective. A combination of pain related variables and psychological factors are used to explain what characteristic of patients and/or complaints predict successful outcome. Successful outcome can be defined as continuation of TENS over a period of 6 months or as a clinically important pain reduction. The second research question is: "What pain related factors and psychosocial factors can predict long term use of TENS or clinically important pain reduction on long term?" (Chapter 3).

As pain is a multidimensional phenomenon we hypothesise that TENS also has secondary effects, in the field of physical functioning and psychological factors such as pain catastrophizing and self-efficacy beliefs, contributing to successful continuation of TENS on long term by patients. We specifically hypothesize that psychological factors, such as decreased pain catastrophizing beliefs and increased self efficacy and/or perceived control contribute to the successful use of TENS on long term. The third research question is whether improvements in physical functioning and/or improvements in self-efficacy and catastrophizing after the use of TENS are associated with the continuation of TENS on long term (Chapter 4).

As we hypothesize that increased self-efficacy might be an important factor for the use and success of TENS we must measure changes in self-efficacy with a valid instrument. As no valid Dutch measurement for self-efficacy in chronic pain exist, we have translated the English Chronic Pain Self-efficacy Scale into Dutch version and want to examine the psychometric 
qualities this Dutch translation. The fourth research question therefore is what the psychometric qualities in terms of the factor structure, test-retest reliability and construct validity of the Dutch Chronic Pain Self-efficacy Scale (CPSS-DLV) are (Chapter 5).

At last, success of treatment in pain is quantified by the amount of pain relief provided by the treatment. A definition for MCIC in pain treatments is a minimal reduction of $30 \%$ pain intensity. However no MDC is calculated to see whether or not this improvement is beyond measurement error. Therefore we want to calculate both, MCIC and MDC, within the same study population to gain insight in measurement properties of VAS pain scales for evaluation TENS. Also the recommended 30\% pain reduction is based on a cut-off point selected by researchers and clinicians. As MCIC should reflect patient's perspective rather than a researchers perspective we want to examine the difference between $\mathrm{MCIC}$ based on both perspectives and the validity of measurement scale (global perceived effect) used for estimating MCIC's. At last the $30 \%$ pain reduction is regarded to be applicable to all type of pain treatments. So we question whether this recommendation of $30 \%$ pain reduction is also applicable to TENS. As TENS is a treatment with minor side effects, low costs and unconviences in use, we hypothesise that patients with chronic pain rate a pain reduction below 30\% as successful. Therefore our last research questions are; 1) whether a MCIC for pain relief by TENS, measured by VAS pain scales, exceeds the MDC, 2) whether a global perceived effect scale is a valid measure to establish a MCIC based on VAS pain scales and 3) what change in pain reduction by TENS in chronic pain is defined as successful using patients perspective (Chapter 6). 


\section{References}

[1] Andersson HI. The course of non-malignant chronic pain: a 12-year follow-up of a cohort from the general population. Eur J Pain 2004;8(1):47-53

[2] Beaton DE, Boers M, Wells GA. Many faces of the minimal clinically important difference (MCID): a literature review and directions for future research. Curr Opin Rheumatol 2002;14(2):109-114

[3] Bjordal JM, Greve G. What may alter the conclusions of reviews? Phys Ther Rev 1998;3(3):121-132

[4] Bjordal JM, Johnson MI, Ljunggreen AE. Transcutaneous electrical nerve stimulation (TENS) can reduce postoperative analgesic consumption. A meta-analysis with assessment of optimal treatment parameters for postoperative pain. Eur J Pain 2003;7(2):181-188

[5] Bjordal JM, Johnson MI, Lopes-Martins RA, Bogen B, Chow R, Ljunggren AE. Short-term efficacy of physical interventions in osteoarthritic knee pain. A systematic review and meta-analysis of randomised placebo-controlled trials. BMC Musculoskelet Disord 2007;8:51

[6] Borghouts JA, Koes BW, Vondeling H, Bouter LM. Cost-of-illness of neck pain in The Netherlands in 1996. Pain 1999;80(3):629-636

[7] Borjesson M. Visceral chest pain in unstable angina pectoris and effects of transcutaneous electrical nerve stimulation. (TENS). A review. Herz 1999;24(2):114-125

[8] Breivik H, Collett B, Ventafridda V, Cohen R, Gallacher D. Survey of chronic pain in Europe: prevalence, impact on daily life, and treatment. Eur J Pain 2006;10(4):287-333

[9] Bronfort G, Nilsson N, Haas M, Evans R, Goldsmith CH, Assendelft WJ, Bouter LM. Non-invasive physical treatments for chronic/recurrent headache. Cochrane Database Syst Rev 2004(3):CD001878

[10] Brooks P. Issues with chronic musculoskeletal pain. Rheumatology (Oxford) 2005;44(7):831-833

[11] Brosseau L, Judd MG, Marchand S, Robinson VA, Tugwell P, Wells G, Yonge K. Transcutaneous electrical nerve stimulation (TENS) for the treatment of rheumatoid arthritis in the hand. Cochrane Database Syst Rev 2003(3):CD004377

[12] Brosseau L, Milne S, Robinson V, Marchand S, Shea B, Wells G, Tugwell P. Efficacy of the transcutaneous electrical nerve stimulation for the treatment of chronic low back pain: a meta-analysis. Spine (Phila Pa 1976) 2002;27(6):596-603

[13] Caroll D, Moore RA, McQuay HJ, Fairman F, Tramer M, Leijon G. Transcutaneous electrical nerve stimulation (TENS) for chronic pain (Cochrane review). The Cochrane Library 2002(4)

[14] Caroll D, Tramer M, McQuay H, Nye B, Moore A. Randomization is important in studies with pain outcomes: systematic review of transcutaneous electrical nerve stimulation in acute postoperative pain. Br J Anaesth 1996;77:798-803

[15] Carroll D, Tramer M, McQuay H, Nye B, Moore A. Transcutaneous electrical nerve stimulation in labour pain: a systematic review. Br J Obstet Gynaecol 1997;104(2):169-175

[16] Chabal C, Fishbain DA, Weaver M, Heine LW. Long-term transcutaneous electrical nerve stimulation (TENS) use: impact on medication utilization and physical therapy costs. Clin J Pain 1998;14(1):66-73

[17] Chapman CR. Pain perception and assessment. Minerva Anestesiol 2005;71(7-8):413-417 
[18] Chen C, Tabasam G, Johnson MI. Does the pulse frequency of transcutaneous electrical nerve stimulation (TENS) influence hypoalgesia? A systematic review of studies using experimental pain and healthy human participants. Physiotherapy 2008;94:11-20

[19] Chesterton LS, Barlas P, Foster NE, Lundeberg T, Wright CC, Baxter GD. Sensory stimulation (TENS): effects of parameter manipulation on mechanical pain thresholds in healthy human subjects. Pain 2002;99(1-2):253-262

[20] Claydon LS, Chesterton LS, Barlas P, Sim J. Effects of simultaneous dual-site TENS stimulation on experimental pain. Eur J Pain 2008;12(6):696-704

[21] Copay AG, Subach BR, Glassman SD, Polly DW, Jr., Schuler TC. Understanding the minimum clinically important difference: a review of concepts and methods. Spine J 2007;7(5):541-546

[22] Cruccu G, Aziz TZ, Garcia-Larrea L, Hansson P, Jensen TS, Lefaucheur JP, Simpson BA, Taylor RS. EFNS guidelines on neurostimulation therapy for neuropathic pain. Eur J Neurol 2007;14(9):952-970

[23] de Vet HC, Ostelo RW, Terwee CB, van der Roer N, Knol DL, Beckerman H, Boers M, Bouter LM. Minimally important change determined by a visual method integrating an anchor-based and a distributionbased approach. Qual Life Res 2007;16(1):131-142

[24] de Vet HC, Terwee CB, Ostelo RW, Beckerman H, Knol DL, Bouter LM. Minimal changes in health status questionnaires: distinction between minimally detectable change and minimally important change. Health Qual Life Outcomes 2006;4:54

[25] Defrin R, Ariel E, Peretz C. Segmental noxious versus innocuous electrical stimulation for chronic pain relief and the effect of fading sensation during treatment. Pain 2005;115(1-2):152-160

[26] Deltonen M, Lindross AK, Torgerson JS. Musciloskeletal pain in the obese: a comparison with a general population and long-term changes after conventional and surgical obesity treatment. Pain 2003; 104:549-557

[27] Dowswell T, Bedwell C, Lavender T, Neilson JP. Transcutaneous electrical nerve stimulation (TENS) for pain relief in labour. Cochrane Database Syst Rev 2009(2):CD007214

[28] Dworkin RH, Turk DC, Farrar JT, Haythornthwaite JA, Jensen MP, Katz NP, Kerns RD, Stucki G, Allen RR, Bellamy N, Carr DB, Chandler J, Cowan P, Dionne R, Galer BS, Hertz S, Jadad AR, Kramer LD, Manning DC, Martin S, McCormick CG, McDermott MP, McGrath P, Quessy S, Rappaport BA, Robbins W, Robinson JP, Rothman M, Royal MA, Simon L, Stauffer JW, Stein W, Tollett J, Wernicke J, Witter J. Core outcome measures for chronic pain clinical trials: IMMPACT recommendations. Pain 2005;113(1-2):919

[29] Eriksson MB, Sjolund BH, Nielzen S. Long term results of peripheral conditioning stimulation as an analgesic measure in chronic pain. Pain 1979;6(3):335-347

[30] Farrar JT, Young JP, Jr., LaMoreaux L, Werth JL, Poole RM. Clinical importance of changes in chronic pain intensity measured on an 11-point numerical pain rating scale. Pain 2001;94(2):149-158

[31] Fishbain DA, Chabal C, Abbott A, Heine LW, Cutler R. Transcutaneous electrical nerve stimulation (TENS) treatment outcome in long-term users. Clin J Pain 1996;12(3):201-214

[32] Freburger JK, Holmes GM, Agans RP, Jackman AM, Darter JD, Wallace AS, Castel LD, Kalsbeek WD, Carey TS. The rising prevalence of chronic low back pain. Arch Intern Med 2009;169(3):251-258 
[33] Fried T, Johnson R, McCracken W. Transcutaneous electrical nerve stimulation: its role in the control of chronic pain. Arch Phys Med Rehabil 1984;65(5):228-231

[34] Garrison DW, Foreman RD. Effects of transcutaneous electrical nerve stimulation (TENS) on spontaneous and noxiously evoked dorsal horn cell activity in cats with transected spinal cords. Neurosci Lett 1996;216(2):125-128

[35] Grimmer KA. A controlled double blind study comparing effects of strong burst mode TENS and high rate TENS on painful osteoarthritic knees. Australian Journal of Physiotherapy 1992;48:49-56

[36] Gupta A, Mehdi A, Duwell M, Sinha A. Evidence-based review of the pharmacoeconomics related to the management of chronic nonmalignant pain. J Pain Palliat Care Pharmacother 2010;24(2):152-156

[37] Hansson PT, Attal N, Baron R, Cruccu G. Toward a definition of pharmacoresistant neuropathic pain. Eur J Pain 2009;13(5):439-440

[38] Harkness EF, Macfarlane GJ, Silman AJ, McBeth J. Is musculoskeletal pain more common now than 40 years ago?: Two population-based cross-sectional studies. Rheumatology (Oxford) 2005;44(7):890895

[39] Hseuh TC, Kuan P, Hong C. The immediate effectiveness of electrical nerve stimulation and electrical muscle stimulation on myofascial triggerpoints The American Journal of Physical Medicine and Rehabilitation 1997;76:471-476

[40] Jensen H, Zesler R, Christensen T. Transcutaneous electrical nerve stimulation (TNS) for painful osteoarthrosis of the knee. Int J Rehabil Res 1991;14(4):356-358

[41] Johansson F, Almay BG, von Knorring L. Personality factors related to the outcome of treatment with transcutaneous nerve stimulation. Psychiatr Clin (Basel) 1981;14(2):96-104

[42] Johansson F, Almay BG, Von Knorring L, Terenius L. Predictors for the outcome of treatment with high frequency transcutaneous electrical nerve stimulation in patients with chronic pain. Pain 1980;9(1):5561

[43] Johnson M, Martinson M. Efficacy of electrical nerve stimulation for chronic musculoskeletal pain: a meta-analysis of randomized controlled trials. Pain 2007;130(1-2):157-165

[44] Johnson MI, Ashton CH, Thompson JW. An in-depth study of long-term users of transcutaneous electrical nerve stimulation (TENS). Implications for clinical use of TENS. Pain 1991;44(3):221-229

[45] Kato K, Sullivan PF, Evengard B, Pedersen NL. Chronic Widespread pain and its Comorbidities. A population based study. Arch Intern Med 2006;166:1649-1654

[46] Khadilkar A, Milne S, Brosseau L, Robinson V, Saginur M, Shea B, Tugwell P, Wells G. Transcutaneous electrical nerev stimulation (TENS) for chronic low back pain ( Cohrane review). Cochrane Database Syst Rev 2006;3

[47] Kroeling P, Gross A, Goldsmith CH, Burnie SJ, Haines T, Graham N, Brant A. Electrotherapy for neck pain. Cochrane Database Syst Rev 2009(4):CD004251

[48] Kuijpers T, van Middelkoop M, Rubinstein SM, Ostelo R, Verhagen A, Koes BW, van Tulder MW. A systematic review on the effectiveness of pharmacological interventions for chronic non-specific lowback pain. Eur Spine J 2011;20(1):40-50 
[49] Lackner JM, Carosella AM. The relative influence of perceived pain control, anxiety, and functional self efficacy on spinal function among patients with chronic low back pain. Spine (Phila Pa 1976) 1999;24(21):2254-2260; discussion 2260-2251

[50] Lampl C, Kreczi T, Klingler D. Transcutaneous electrical nerve stimulation in the treatment of chronic pain: predictive factors and evaluation of the method. Clin J Pain 1998;14(2):134-142

[51] Leijon O, Mulder M. Prevalence of low back pain and concurrent psychological distress over a 16-year period. Occup Environ Med 2009;66(2):137-139

[52] Leijon O, Wahlstrom J, Mulder M. Prevalence of self-reported neck-shoulder-arm pain and concurrent low back pain or psychological distress: time-trends in a general population, 1990-2006. Spine (Phila Pa 1976) 2009;34(17):1863-1868

[53] Litcher-Kelly L, Martino SA, Broderick JE, Stone AA. A systematic review of measures used to assess chronic musculoskeletal pain in clinical and randomized controlled clinical trials. J Pain 2007;8(12):906913

[54] Long DM. The current status of electrical stimulation of the nervous system for the relief of chronic pain. Surg Neurol 1998;49(2):142-144

[55] Manchikanti L, Singh V, Datta S, Cohen SP, Hirsch JA. Comprehensive review of epidemiology, scope, and impact of spinal pain. Pain Physician 2009;12(4):E35-70

[56] Mannheimer C, Carlsson CA. The analgesic effect of transcutaneous electrical nerve stimulation (TNS) in patients with rheumatoid arthritis. A comparative study of different pulse patterns. Pain 1979;6(3):329-334

[57] Mantyselka PT, Kumpusalo EA, Ahonen RS, Takala JK. Direct and indirect costs of managing patients with musculoskeletal pain-challenge for health care. Eur J Pain 2002;6(2):141-148

[58] McQuay HJ, Moore RA, Eccleston C, Morley S, Williams AC. Systematic review of outpatient services for chronic pain control. Health Technol Assess 1997;1(6):i-iv, 1-135

[59] Meyler WJ, de Jongste MJ, Rolf CA. Clinical evaluation of pain treatment with electrostimulation: a study on TENS in patients with different pain syndromes. Clin J Pain 1994;10(1):22-27

[60] Milne S, Welch V, Brosseau L, Saginur M, Shea B, Tugwell P, Wells G. Transcutaneous electrical nerve stimulation (TENS) for chronic low back pain. Cochrane Database Syst Rev 2001(2):CD003008

[61] Murray S, Collins PD, James MA. Neurostimulation treatment for angina pectoris. Heart 2000;83(2):217220

[62] Nash TPW, D. M. TENS: does type of stimulus really matter? Pain Clinics 1990;3:161-168

[63] Nielzen S, Sjolund BH, Eriksson MB. Psychiatric factors influencing the treatment of pain with peripheral conditioning stimulation. Pain 1982;13(4):365-371

[64] Nnoaham KE, Kumbang J. Transcutaneous electrical nerve stimulation (TENS) for chronic pain. Cochrane Database Syst Rev 2008(3):CD003222

[65] Osiri M, Welch V, Brosseau L, Shea B, McGowan J, Tugwell P, Wells G. Transcutaneous electrical nerve stimulation for knee osteoarthritis (Cochrane Review). The Cochrane Library 2002(4)

[66] Ostelo RW, de Vet HC. Clinically important outcomes in low back pain. Best Pract Res Clin Rheumatol 2005;19(4):593-607 
[67] Palmer KT, Walsh K, Bendall H, Cooper C, Coggon D. Back pain in Britain: comparison of two prevalence surveys at an interval of 10 years. BMJ 2000;320(7249):1577-1578

[68] Papageorgiou AC, Silman AJ, Macfarlane GJ. Chronic widespread pain in the population: a seven year follow up study. Ann Rheum Dis 2002;61(12):1071-1074

[69] Price Cl, Pandyan AD. Electrical stimulation for preventing and treating post-stroke shoulder pain. Cochrane Database Syst Rev 2000(4):CD001698

[70] Radhakrishnan R, Sluka KA. Deep tissue afferents, but not cutaneous afferents, mediate transcutaneous electrical nerve stimulation-Induced antihyperalgesia. J Pain 2005;6(10):673-680

[71] Robb K, Oxberry SG, Bennett MI, Johnson MI, Simpson KH, Searle RD. A cochrane systematic review of transcutaneous electrical nerve stimulation for cancer pain. J Pain Symptom Manage 2009;37(4):746753

[72] Rubinstein SM, van Middelkoop M, Kuijpers T, Ostelo R, Verhagen AP, de Boer MR, Koes BW, van Tulder MW. A systematic review on the effectiveness of complementary and alternative medicine for chronic non-specific low-back pain. Eur Spine J 2010;19(8):1213-1228

[73] Rutjes AW, Nuesch E, Sterchi R, Kalichman L, Hendriks E, Osiri M, Brosseau L, Reichenbach S, Juni P. Transcutaneous electrostimulation for osteoarthritis of the knee. Cochrane Database Syst Rev 2009(4):CD002823

[74] Shealy CN. Transcutaneous electrical stimulation for control of pain. Clin Neurosurg 1974;21:269-277

[75] Sjolund BH. Peripheral nerve stimulation suppression of C-fiber-evoked flexion reflex in rats. Part 1: Parameters of continuous stimulation. J Neurosurg 1985;63(4):612-616

[76] Sjolund BH. Peripheral nerve stimulation suppression of C-fiber-evoked flexion reflex in rats. Part 2: Parameters of low-rate train stimulation of skin and muscle afferent nerves. J Neurosurg 1988;68(2):279283

[77] Sluka KA, Bailey K, Bogush J, Olson R, Ricketts A. Treatment with either high or low frequency TENS reduces the secondary hyperalgesia observed after injection of kaolin and carrageenan into the knee joint. Pain 1998;77(1):97-102

[78] Sluka KA, Deacon M, Stibal A, Strissel S, Terpstra A. Spinal blockade of opioid receptors prevents the analgesia produced by TENS in arthritic rats. J Pharmacol Exp Ther 1999;289(2):840-846

[79] Sluka KA, Walsh D. Transcutaneous electrical nerve stimulation: basic science mechanisms and clinical effectiveness. J Pain 2003;4(3):109-121

[80] Solomon RA, Viernstein MC, Long DM. Reduction of postoperative pain and narcotic use by transcutaneous electrical nerve stimulation. Surgery 1980;87(2):142-146

[81] Sternbach RA, Ignelzi RJ, Deems LM, Timmermans G. Transcutaneous electrical analgesia: a follow-up analysis. Pain 1976;2(1):35-41

[82] Tulgar M, McGlone F, Bowsher D, Miles JB. Comparative effectiveness of different stimulation modes in relieving pain. Part I. A pilot study. Pain 1991;47(2):151-155

[83] Tulgar M, McGlone F, Bowsher D, Miles JB. Comparative effectiveness of different stimulation modes in relieving pain. Part II. A double-blind controlled long-term clinical trial. Pain 1991;47(2):157-162

[84] Turk DC, Dworkin RH, Allen RR, Bellamy N, Brandenburg N, Carr DB, Cleeland C, Dionne R, Farrar JT, Galer BS, Hewitt DJ, Jadad AR, Katz NP, Kramer LD, Manning DC, McCormick CG, McDermott MP, McGrath 
P, Quessy S, Rappaport BA, Robinson JP, Royal MA, Simon L, Stauffer JW, Stein W, Tollett J, Witter J. Core outcome domains for chronic pain clinical trials: IMMPACT recommendations. Pain 2003;106(3):337345

[85] van Middelkoop M, Rubinstein SM, Kuijpers T, Verhagen AP, Ostelo R, Koes BW, van Tulder MW. A systematic review on the effectiveness of physical and rehabilitation interventions for chronic non-specific low back pain. Eur Spine J 2011;20(1):19-39

[86] van Middelkoop M, Rubinstein SM, Verhagen AP, Ostelo RW, Koes BW, van Tulder MW. Exercise therapy for chronic nonspecific low-back pain. Best Pract Res Clin Rheumatol 2010;24(2):193-204

[87] van Tulder MW, Koes BW, Bouter LM. A cost-of-illness study of back pain in The Netherlands. Pain 1995;62(2):233-240

[88] Verdouw BC, Zuurmond WWA, deLange JJ, Metz GCH, Wagemans MFM. Long-term use and effectiveness of transcutaneous electrical nerve stimulation in treatment of chronic pain patients. Pain Clinic 1996;8(4):341-346

[89] Von Korff M, Dworkin SF, Le Resche L, Kruger A. An epidemiologic comparison of pain complaints. Pain 1988;32(2):173-183

[90] Wall PD, Sweet WH. Temporary abolition of pain in man. Science 1967;155(758):108-109

[91] Walsh DM. TENS: Clinical Applications and Related Theory. New York: Churchill Livingstone, 1997

[92] Walsh DM, Foster NE, Baxter GD, Allen JM. Transcutaneous electrical nerve stimulation. Relevance of stimulation parameters to neurophysiological and hypoalgesic effects. Am J Phys Med Rehabil 1995;74(3):199-206

[93] Walsh DM, Howe TE, Johnson MI, Sluka KA. Transcutaneous electrical nerve stimulation for acute pain. Cochrane Database Syst Rev 2009(2):CD006142

[94] Walsh DM, Lowe AS, McCormack K, Willer JC, Baxter GD, Allen JM. Transcutaneous electrical nerve stimulation: effect on peripheral nerve conduction, mechanical pain threshold, and tactile threshold in humans. Arch Phys Med Rehabil 1998;79(9):1051-1058

[95] Wang B, Tang J, White PF, Naruse R, Sloninsky A, Kariger R, Gold J, Wender RH. Effect of the intensity of transcutaneous acupoint electrical stimulation on the postoperative analgesic requirement. Anesth Analg 1997;85(2):406-413

[96] Wenig CM, Schmidt CO, Kohlmann T, Schweikert B. Costs of back pain in Germany. Eur J Pain 2009;13(3):280-286

[97] Woolf CJ. Transcutaneous electrical nerve stimulation and the reaction to experimental pain in human subjects. Pain 1979;7(2):115-127 



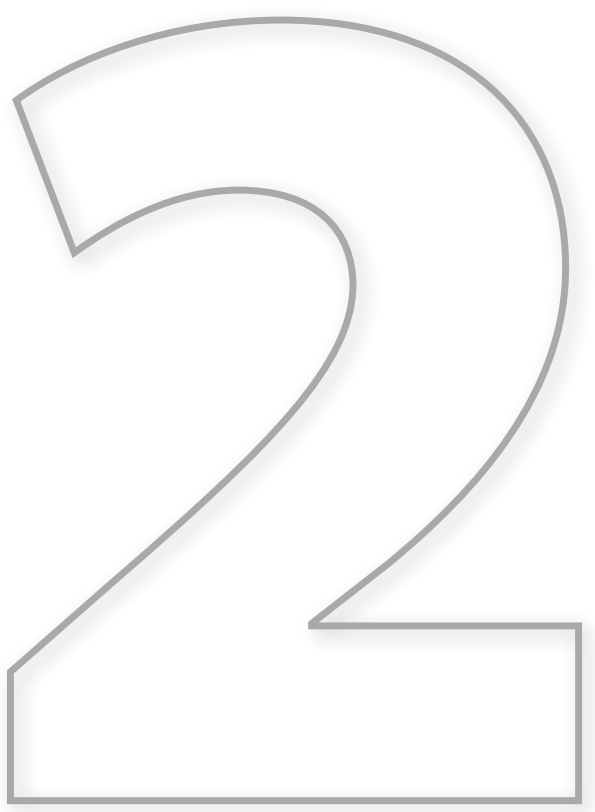

\title{
Pain reducing effect of three types
} of Transcutaneous Electrical Nerve Stimulation (TENS) in patients with chronic pain: A randomized cross-over trial

\author{
Albère J.A. Köke ${ }^{a, b}$, Jan S.A.G. Schouten ${ }^{d}$, \\ Myriam J.H. Lamerichs-Geelen', Jos S.M. Lipsch', \\ Ed M.H. Waltjec, Maarten van Kleefa, Jacob Patijn ${ }^{a}$ \\ aPain Management and Research Center, University Hospital Maastricht \\ ${ }^{\text {b} A d e l a n t e ~ C e n t r e ~ o f ~ E x p e r t i s e ~ i n ~ R e h a b i l i t a t i o n, ~ H o e n s b r o e k ~}$ \\ cDepartment of Physical Therapy, University Hospital Maastricht \\ dDepartment of Epidemiology, University Maastricht
}




\section{Abstract}

Background. Transcutaneous electrical nerve stimulation (TENS) is a frequently applied therapy in chronic pain although evidence for effectiveness is inconclusive. Several types of TENS, based on different combination of frequency, pulse duration and intensity, exist. The precise mechanism of action and the relevance of combinations of stimulus parameter are still unclear.

Methods. To compare the effectiveness of three types of TENS we conducted a randomized, single blinded crossover trial. Patients received two times a two weeks period of daily TENS treatment, separated by a washout period of two weeks. In total 180 chronic pain patients were randomized into three groups. In group 1 high frequency, low intensity TENS (HFT) was compared with high frequency, high intensity TENS (HIT). In group 2 and 3, HFT and HIT was compared with a control TENS (COT). The order of TENS-type in each group was also randomized. Primary outcome was patient overall judgment on effectiveness and pain reduction (VAS).

Results. No differences were found in patient's judgment or pain reducing effect within all three groups, indicating no superiority of one type of TENS.

Fifty-six \% of the patients continued TENS after the two weeks treatment period. At 6 months $42 \%$ of all patients still used TENS.

Conclusion. We concluded that there were no differences in effectiveness for the three types of TENS used in this study. Because no placebo group was included no definite conclusions on effectiveness of TENS in general in the treatment of chronic pain can be made. 


\section{Introduction}

Transcutaneous electrical nerve stimulation (TENS) is a non-invasive therapy mainly used for pain relief for a variety of pain syndromes. Despite its frequent use and theoretical rationale the evidence from RCTs for treatment of chronic pain with TENS is still inconclusive [2]. Theoretically high frequency and low intensity TENS (HFT) are assumed to work through segmental pain inhibition processes (gate control theory). In contrast, low frequency and high intensity TENS (LFT) is assumed to be effective by the release of endogenous opioids (supra-segmental effect) [25].

Although the frequency of TENS may be the decisive factor in the above-mentioned working mechanism, the results of studies are still inconclusive. Five studies comparing HFT and LFT found no differences in pain reducing effect [7-9; 18; 23]. Only one study reported a difference in favor of HFT [15] and one in favor of LFT [22].

Pulse duration and stimulus intensity differ in HFT and LFT and could also be decisive factor for efficacy. Animal and human studies have shown higher analgesic effects by increasing the stimulus intensity [6; 20-21; 28-29] or longer pulse duration [6; 26-27]. Combining stimulus parameters of both working mechanism increases the hypoalgesic effect of TENS [26].

The precise mechanism of action and the precise relevance of stimulus parameters to hypoalgesic effects are therefore still unclear. As a consequence the most effective combination of stimulus parameters (frequency, pulse duration, intensity) is still unknown [3].

Combining high frequency with high stimulus intensity might act as well on segmental as on supra-spinal levels of pain inhibition systems and therefore can prohibit larger hypoalgesic effects. To test this hypothesis we conducted a randomized crossover trial to compare the hypoalgesic effects of high frequency conventional TENS (HFT) and a combination high frequency high intensity TENS (HIT). However, not only neurophysiologic stimuli influence the endogenous pain inhibition pain system. Physiologically, psychological processes such as perceived control over pain or self-efficacy beliefs on coping with chronic pain influence levels of catecholamines and endogenous opioids [14]. It can be hypothesized that hypoalgesic effects of TENS are also due to enhanced feelings of control over pain by using TENS.

To test this second hypothesis we conducted also a randomized cross over trial in groups to compare the hypoalgesic effects of high frequency conventional TENS (HFT) and a combination type high frequency high intensity TENS (HIT) with a 'control'TENS (COT), in which patients were free to use TENS as they preferred. We hypothesized that the HIT has greater hypoalgesic effects than HFT, and that both HFT and HIT are more effective than COT.

\section{Methods}

Out-Patients from the Pain Clinic at the University Hospital Maastricht were screened for eligibility. Inclusion criteria were: a) patients referred for TENS treatment by pain physicians, b) duration of pain $>6$ months, c) age above 18, d) no current other treatment for pain. Exclu- 
sion criteria were a) pain due to cancer, b) the use of a cardiac pacemaker, c) pregnancy, d) neurological sensory deficits, e) language and/or cognitive inability to complete the health assessment questionnaires and f) previous TENS for pain relief. After providing an informed consent the patient was included in the study. The ethical committee approved the research protocol. Three different methods of TENS were compared in a randomized, single blinded crossover design. Patients received two times a 2-weeks period of daily TENS treatment, separated by a washout period of 2 weeks. The subjects were randomly assigned to one of the three groups (group 1: HFT-HIT, group 2 HIT-COT, group 3 HFT-COT) Random assignment was performed by means of a table of random numbers prepared, independently by computer. Therapy assignment was drawn from sealed opaque envelops by an independent person.

\section{Intervention}

Three physical therapists, experienced with TENS, conducted the treatment. Patients received their TENS-unit after verbal and written instruction. Based on diagnosis, medical history and physical examination the physical therapist located for each patient 3 potential sides for stimulation; a) in area of painful sensation, b) in the region of the peripheral innervation of the painful area and c) according to the segmental innervation of the painful area. Patients were instructed to experiment with electrode positions (stimulation sites), as given by therapist in order to discover the optimal site for pain relief. Self-adhering, reusable electrodes type PALS Platinum $895220(5 \times 5 \mathrm{~cm})$ were used

Patients kept a daily record of stimulation site used and severity of pain. No co-interventions, besides existing pain medication, were allowed.

In the high frequency conventional TENS group (HFT; frequency $80 \mathrm{~Hz}$, pulse duration $80 \mu \mathrm{S}$ ) patients were instructed to use TENS 4-6 times a day for 1 hour periods at sensory threshold intensity. In the high frequency high-intense TENS group (HIT; frequency $80 \mathrm{~Hz}$, pulse duration $250 \mu \mathrm{S}$ ) were instructed to use TENS 4-6 times a day for 30 minutes periods at maximum tolerance intensity level. In control TENS group (COT; frequency $30 \mathrm{~Hz}$, pulse duration $250 \mu \mathrm{S}$ ) patients were free to choose stimulus duration and stimulus intensity as they preferred. Two of TENS-devices were used: TWIN-STAR (van Lent Systems B.V. Netherlands), TENStem (Schwa Medico Netherlands).

\section{Outcome measurement}

Primary outcome variables were patients' global judgment on overall result (positive or negative) and reduction of severity of pain. Global judgment is based on patient decision to continue TENS in the future. It can be regarded as an assessment of the patients' integration of the benefits (efficacy) of the treatment versus its side effects (risks, problems in handling), providing a patient based evaluation of the effect of treatment [5]. 
The success of each treatment period (TENS-type) was rated by the patient indicating his/her willingness to continue treatment with specific TENS-type (positive) or not (negative).

Average severity of pain during the past week is measured on a $100 \mathrm{~mm}$ visual analogue scale (VAS), which is a valid and reliable measurement [1].

Baseline measurements consisted of demographic data: such as age, gender, marriage, education, work-status, location of pain, medical diagnosis, and severity of pain (VAS). Following each 2-week treatment period, and at the start of the second treatment period, pain severity (VAS) was measured by a blinded observer. Also patient judgment of result was assessed at end of each treatment period. At 6 months follow up patients received a postal questionnaire, containing questions about continuation of TENS and severity of pain (VAS).

\section{Statistical analyses}

The prognostic similarity of the TENS groups at baseline was determined for all baseline variables. Therefore, measures of central tendency and dispersion were calculated.

Patients' assessments of outcome were described and compared per group by means of Chi-square tests. A difference in severity of pain within groups was analyzed by paired t-test. Severity of pain (VAS) is also analyzed using a mixed linear regression model to compare the effects of all three types of TENS. The outcome measures in the short term (period 1 and 2) were dependent variables. The intervention allocation (TENS-type) was a dichotomous independent (dummy) variable and the baseline values of the outcome measures were incorporated in the mixed model as covariates. Because of the crossover design the treatment periods also are incorporated in the model as a fixed factor. In case of differences in baseline characteristic ( $p>0.05)$, these variables were also incorporated in the model in order to control for possible confounding. All patients were entered in the analysis, according to the intention-to- treat principle. Analysis was performed by SPSS 11.0 for windows.

\section{Results}

In the period of April 2000 until March 2001, 228 patients were referred for TENS treatment. A total of 180 were randomized over the three groups. After the first treatment period, there were nine dropouts, who refused further treatment. A total of 171 patients completed both treatment periods. At 6 months follow up 151 patients returned their questionnaires (see Figure 1). Baseline characteristics of all baseline measurements are presented in Table 1. No statistical differences were found at baseline. 


\section{Washout period}

Severity of pain was comparable at the start of both treatment periods in all groups. In group 1 (HFT-HIT), mean difference pain start period 1 and period 2 was $3.6 \mathrm{~mm}(\mathrm{SD}=19.9, \mathrm{p}=0.19)$. Group 2 (HIT-COT) mean difference pain start period 1 and period 2 was $0.4 \mathrm{~mm}$ (SD $=15$, $\mathrm{p}=0.84$ ). Group 3 (HFT-COT) mean difference pain start period 1 and period 2 was $2.5 \mathrm{~mm}$ $(S D=16.8, p=0.26)$.

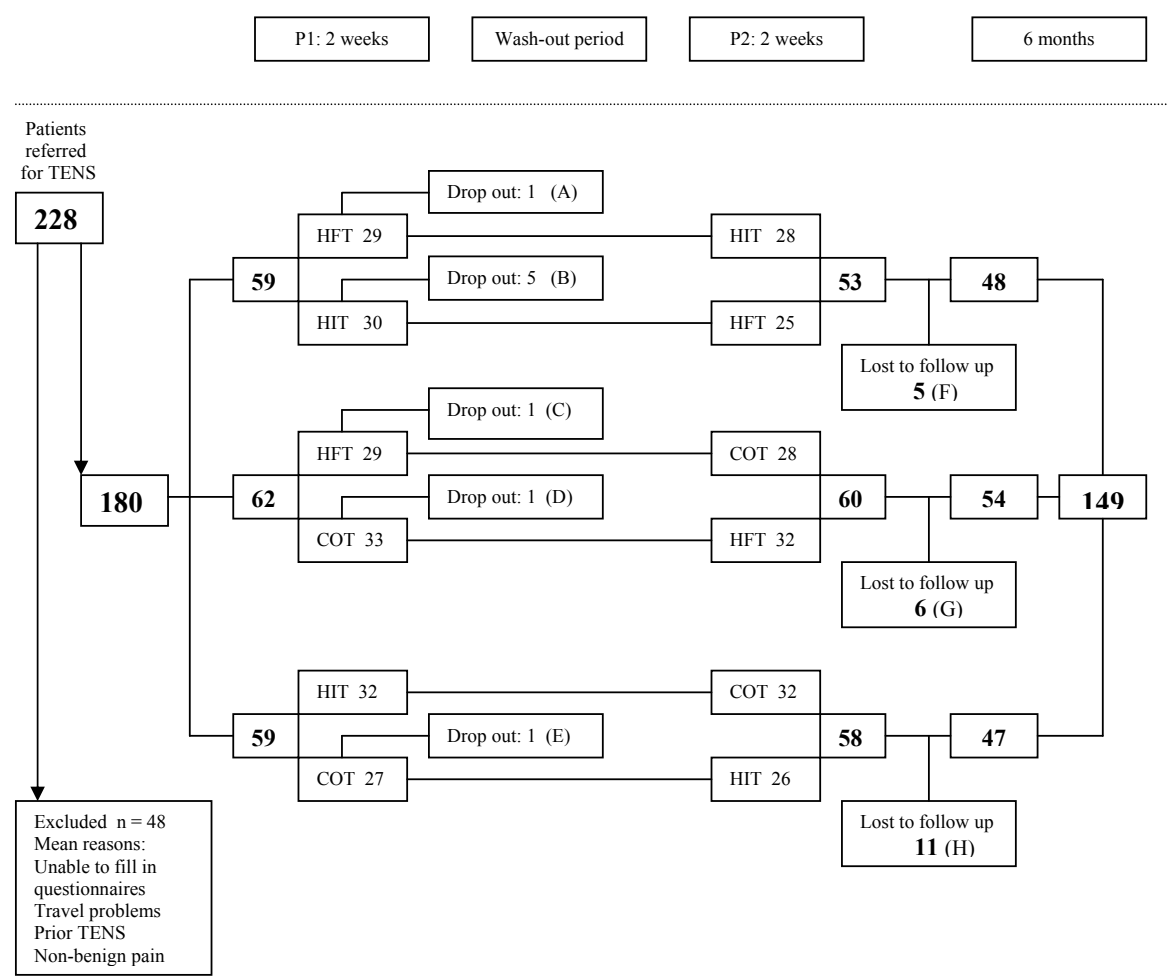

Figure 1. Flow diagram, summarizing the formation of the study group, the number of patients, group membership and dropouts or lost to follow up throughout the course of the study. Reasons for dropout: A: more pain $(1 \times)$; B: more pain $(1 \mathrm{x})$, skin irritation $(1 \mathrm{x})$, problems handling TENS $(2 \mathrm{x})$, positive effect $(1 \mathrm{x})$; C: more pain $(1 \mathrm{x})$, problems handling TENS $(1 \mathrm{x})$ and D: skin irritation $(1 \mathrm{x})$. Reasons lost to follow up: F: 1 patient died, unknown $(4 \mathrm{x})$ : G: unknown $(6 \mathrm{x})$ and $\mathrm{H}$ : 1 patient died, unknown $(10 x)$. 
Table 1. Prognostic variables and baseline values of outcome measure for three groups

\begin{tabular}{|c|c|c|c|c|}
\hline & $\begin{array}{c}\text { 1: HFT -HIT } \\
\mathrm{N}=59\end{array}$ & $\begin{array}{c}\text { 2: HFT- COT } \\
\quad \mathrm{N}=62\end{array}$ & $\begin{array}{c}\text { 3: HIT - COT } \\
\quad \mathrm{N}=59\end{array}$ & $\mathrm{p}$-value \\
\hline Age (mean, SD) & $52(14.7)$ & $50(13.7)$ & $49(12.8)$ & 0.683 \\
\hline Sex (\% male) & 34 & 42 & 31 & 0.286 \\
\hline \multicolumn{5}{|l|}{ Education (\%) } \\
\hline Low & 52.5 & 61 & 51 & 0.464 \\
\hline Middle & 44 & 31 & 37 & 0.314 \\
\hline High & 3.5 & 8 & 12 & 0.229 \\
\hline Duration pain (month, SD) & $81(92)$ & $66(96)$ & $78(89)$ & 0.231 \\
\hline Having a job (\%) & 34 & 32 & 34 & 0.165 \\
\hline Partner (\% yes) & 90 & 82 & 76 & 0.116 \\
\hline Pain (mm VAS, SD) & $65(17)$ & $64(20)$ & $63(21)$ & 0.961 \\
\hline \multicolumn{5}{|l|}{ Medical diagnosis (\%) } \\
\hline CLBP & 20.3 & 21 & 22 & 0.974 \\
\hline CPS & 13.6 & 9.7 & 10.2 & 0.765 \\
\hline CRPS II & 5.1 & 12.9 & 8.5 & 0.319 \\
\hline Failed back surgery & 11.9 & 6.5 & 11.9 & 0.518 \\
\hline Thoracic spinal pain & 8.5 & 8.1 & 3.4 & 0.469 \\
\hline Neuropathic pain & 15.3 & 14.5 & 11.9 & 0.855 \\
\hline Cervical Spinal pain & 11.9 & 12.9 & 10.2 & 0.895 \\
\hline IBS & 0 & 1.6 & 5.1 & 0.161 \\
\hline Cervicogenic headache & 6.8 & 8.1 & 6.8 & 0.951 \\
\hline Miscellaneous & 6.8 & 4.8 & 10.2 & 0.522 \\
\hline
\end{tabular}

CLBP Chronic Low Back Pain, CPS Chronic Pain Syndrome, CRPS II Complex regional Pain syndrome, IBS Irritable Bowel Syndrome

\section{Compliance}

Eighty-nine percent of the patients filled in their pain dairy adequately (at least 10 of 14 days). Only 12 patients (6\%) stopped during a treatment period due to lack of effect, worsening of pain or skin irritation. Reports of hours TENS per week for HFT 36.7 (SD 8.6) hours, for HIT 19 (SD 10) hours, and for COT 40.6 (SD 19.8) hours, were as expected according to instructions. No differences were found in and between groups.

\section{Electrode placement}

Most patients (97\%) reported electrode placement directly over the site of pain or in the area of pain as most favorable stimulus site. 


\section{Adverse effects}

During the first period, skin irritation occurred in 9.4\% (17/180) of all patients, adherence problems of electrodes in 12.2\% (22/180) and problems attaching electrodes in 2.2\% (4/180). In four patients, the adverse effects resulted in withdrawal from the study (skin-irritation $2 \times$, problems attaching electrodes $2 \times$ ). During the second period skin-irritation was reported by $5.8 \%(10 / 171)$, adherence problems of electrodes $4.7 \%$, (8/171) and problems attaching electrodes on body 2.9\% (5/171). No significant differences in adverse effects were found between groups. At 6-month follow up, six patients (3 in HFT-COT-group and 3 in HIT-COT group) reported skin irritation due tot TENS, but still could use TENS regularly.

\section{Patients' global assessment of effect}

No differences in proportion of patients reporting positive result of the 2-weeks treatment periods were found between types of TENS within each group (Table 2). Patients had to assess two treatment periods (TENS-types). In group 1 (HFT-HIT) 29 patients continued TENS after the initially treatment period. Thereby, 14 patients reported success in both types of TENS, 7 patients reported only success of HFT and 8 reported only success of HIT. In group 2 (HIT-COT), 36 patients continued TENS. A positive outcome in both types of TENS in this group occurred in 24 patients, as 6 patients rated only HIT and 6 only COT as positive. In group 3 (HFT-COT) 36 patients continued TENS. Of these 23 patients judged both TENS-types as positive, 6 reported only positive outcome by HFT and 5 had only a positive result by COT.

A large number of patients $(n=60)$ had positive outcome in treatment with both types of TENS. A total of 100 patients (56\%) reported a post treatment positive result and continued TENS in the future.

Table 2. Total patients'judgments for period 1 and 2 together (\% positive results)

\begin{tabular}{cccc}
\hline & Group I & Group II & Group III \\
\hline HFT & $21 / 5936 \%$ & $30 / 6248 \%$ & \\
HIT & $22 / 5937 \%$ & -- & $30 / 5951 \%$ \\
COT & -- & $30 / 6248 \%$ & $29 / 5949 \%$ \\
\hline
\end{tabular}

HFT = High Frequency Tens, HIT = High frequency, high Intensity Tens, COT = COntrol Tens

\section{Pain}

Pain severity decreased between baseline and post treatment within all groups and types of TENS. In group I, pain reduction (VAS) was on average $13.3 \mathrm{~mm}$, in group 2 the reduction was $12.6 \mathrm{~mm}$ and in group 3 the result was $14 \mathrm{~mm}$. No significant difference in size of effect was 
found between types of TENS within groups (Table 3). The results of the linear mixed model indicated also no statistical difference in pain reducing effect by type of TENS (HFT compared to HIT and COT ( $p=0.729)$, HIT compared to HFT and COT ( $p=0.503)$,

COT compared to HFT and HIT $(p=0.753))$. Use of pain medication after TENS treatment also didn't differ between three groups or type of TENS.

Table 3. Comparison of pain reduction in mm VAS per type of TENS

\begin{tabular}{|c|c|c|c|c|c|c|c|}
\hline \multirow[b]{2}{*}{ Group I } & \multicolumn{2}{|c|}{$\begin{array}{c}\text { Pain reduction; mm VAS } \\
\text { Mean (SD) }\end{array}$} & \multirow[t]{2}{*}{$\begin{array}{c}\text { Mean } \\
\text { difference }\end{array}$} & \multirow[t]{2}{*}{ S.E Mean } & \multicolumn{2}{|c|}{$95 \% \mathrm{Cl}$} & \multirow[t]{2}{*}{ P-value } \\
\hline & HFT & HIT & & & & & \\
\hline$N=53$ & $13.4(21.9)$ & 13.5 (21.9) & -0.1 & 3.5 & -7.09 & 7.02 & 0.991 \\
\hline Group II & HIT & СОT & & & & & \\
\hline$N=58$ & $12(21)$ & $13(19.3)$ & -1.0 & 3.1 & -7.21 & 5.18 & 0.744 \\
\hline Group III & HFT & СOT & & & & & \\
\hline$N=60$ & $13.3(19.7)$ & 15 (23.6) & -1.7 & 3.5 & -8.61 & 5.24 & 0.629 \\
\hline
\end{tabular}

$\mathrm{HFT}=$ High Frequency Tens, HIT = High frequency, high Intensity Tens, COT = Control Tens

\section{Results follow-up at 6 months}

In total 151 patients (84\%) of 180 (see figure 1) patients initially entered in the study responded to the postal questionnaire at 6 months. After the first treatment period 9 patients withdrew from the study. Another 21 patients did not return their questionnaire, despite reminders. As two patients died before follow up, the results of 149 patients were analyzed at 6 months.

\section{Continuing TENS}

At 6 months 75 patients of the 100 patients who continued using TENS after the treatment period still used TENS regularly and 18 had stopped. Nine patients, who continued TENS after the treatment period didn't return the postal questionnaire at 6 months, were counted as non-users. In total, 27 patients had stopped using TENS. Therefore 75 patients (42\%) of all 180 patients initially entered in this study still used TENS at 6 months. Reasons for discontinuing TENS in the group with short-term positive outcome were a) decrease of sufficient hypoalgesic effect (10 patients), b) development of other illness complaints (3 patients) c) pregnancy (2 patients) and unknown (9 patients). Three patients (one in each group) stopped because they were totally pain free. In the group of patients still using TENS, 10 patients (13\%) reported an increased hypoalgesic effect. In 51 patients (67\%) the effect was stable over time and in 14 patients (18\%) the hypoalgesic effect decreased.

We compared pain ratings of patients still using TENS versus patients who didn't continue TENS at the beginning or stopped during the past 6 month. At 6 month, pain ratings on VAS in the group of TENS-users dropped compared to baseline (62 mm (SD 20) vs. $45 \mathrm{~mm}$ (SD 23)). 
In the group of non-users the pain ratings on VAS at 6 months were also lesser compared to baseline (64 mm (SD 20) vs. $60 \mathrm{~mm}$ (SD 20). The mean pain reduction in group users was greater than in the non-users group. This difference was statistical significant (Table 4).

Table 4. Pain reductions from baseline at 6 months follow up in TENS-users versus non-users

\begin{tabular}{|c|c|c|c|c|c|c|}
\hline \multicolumn{2}{|c|}{$\begin{array}{c}\text { Pain reduction; mm VAS } \\
\text { Mean (SD) }\end{array}$} & \multirow[t]{2}{*}{$\begin{array}{c}\text { Mean } \\
\text { difference }\end{array}$} & \multirow[t]{2}{*}{$\begin{array}{c}\text { S.E } \\
\text { difference }\end{array}$} & \multicolumn{2}{|c|}{$95 \%$ Confidence Interval } & \multirow[t]{2}{*}{$\begin{array}{c}\text { Sig. } \\
\text { (2-tailed) }\end{array}$} \\
\hline $\begin{array}{l}\text { Users } \\
N=75\end{array}$ & $\begin{array}{c}\text { Non-users } \\
\mathrm{N}=74\end{array}$ & & & Lower & Upper & \\
\hline $17(20)$ & $4(20)$ & 13 & 3.3 & -19 & -6 & .0001 \\
\hline
\end{tabular}

\section{Discussion}

A total of 100 patients (56\%) judged results of TENS-treatment as positive and continued using TENS direct after the trial. Yet, no differences in success rate or reduction in severity of pain per type of TENS was found in this study. Patients reported an equal reduction of severity of pain in all type of TENS. Therefore, there is no evidence of superiority of one type of TENS in treatment of patients with chronic pain.

Compared to reported relative difference in percentage change in pain severity from baseline as outcome ranged from 11\%-38\% [16], our reduction in pain of 19\% for the total study group is on average. A minimal reduction between 30 to $50 \%$ in VAS score is considered as clinical relevant [4]. Using the 50\% reduction outcome parameter, only $20 \%$ of all test periods would have been positive in our study. Comparing this result to the proportion of patients judged TENS (56\%) as positive indicates that $36 \%$ had less than $50 \%$ reduction of pain. Apparently 50\% reduction is too high to serve as a clinical relevant outcome. Recommendation for pain relief of 30\% in VAS-scores are probably more appropriate as in our population patient with positive judgments had on average $33.5 \%$ (range 25-43) pain reduction on VAS.

The fact that all TENS types displayed equal effects questions the supposed different working mechanisms. In COT the frequency of $30 \mathrm{~Hz}$ was chosen as a frequency in between low $(1-10 \mathrm{~Hz})$ and high $(50-100 \mathrm{~Hz})$ range, to diminish optimal neurophysiologic mechanisms. The combination with used pulse duration $(250 \mu \mathrm{sec})$ was based on feelings of comfort. Patients were allowed to use the TENS as often and long as they thought would be effective. Patients also were free to choose the intensity they preferred. However we cannot rule out any physiological effects of this type of TENS, but based on mentioned theoretical assumptions it should be less effective neurophysiologically. The fact that COT is equally effective might indicate that personal preferences of patient might be important. Johnson et al. [11] already mentioned that patient's preference for specific pulse frequencies and patterns is more related to reasons of comfort than to cause and site of pain. Psychological mechanisms such as increasing locus of control and enhancing coping with pain by TENS should taken into 
consideration for explaining effects of TENS, as these factors influence pain severity in general [10]. But definite conclusions on evidence for effectiveness of TENS or proposed working mechanisms cannot be made in this study, because a placebo group was not included.

The inconclusive results of this study are in line with a recent systematic review on TENS treatment for a variety of chronic pain syndromes [2]. Definite conclusions in this review could not be drawn due to methodological flaws (randomization, blinding, and sample size) and missing data on factors as: compliance, site of application, treatment duration, optimal frequencies and stimulus intensities. We tried to overcome these flaws by our study design with an appropriate randomization and blinding as well as acceptable sample size. Because of heterogeneity of chronic pain population, in terms of type and localization of pain and medical diagnosis, a crossover design was chosen. Heterogeneity of study populations is considered a factor diminishing treatment effects in randomized clinical trials. In a crossover, trial each participant acts as his or her control, thereby reducing heterogeneity and increasing power.

Compliance was generally good. Patients reported sufficient use of TENS during the 2 weeks treatment periods. The total hours of TENS in our study were much higher than reported in other studies $[2 ; 16 ; 19]$. A period of two weeks of daily use of TENS seems appropriate for decision making on continuing TENS-treatment. Yet, duration of our treatment period to evaluate effectiveness of TENS might be inadequate. Osiri et al. [19] stated that TENS benefits are achieved with treatment periods of at least 6 weeks. However this conclusion was based on only one study. We agree with Osiri that a one single treatment period, as used in may TENS studies, is inadequate to test clinical effectiveness. TENS has, as suggested, a direct impact on the pain modulating systems; therefore pain reduction reasonably should appear within two weeks, as applied on daily basis.

Electrode placement is another important factor, which can influence effectiveness of TENS [24]. During the two weeks test period patient were allowed to test several electrode placements as recommended by the physical therapist. In general most patients choose local placements within painful region. We did not control for adequate try-out of electrode placements during treatment periods. It is possible that searching for optimal electrode placements was not sufficient in all patients.

Adverse effects are rarely presented in studies of TENS [2]. The reported adverse effects in our study are comparable with other reports $[13 ; 18]$ although other studies mentioned no adverse effect at all [17]. Adverse effects by TENS seem rare, indicating TENS to be a safe method.

A declining effect of TENS with time is suggested [12]. Most studies on TENS however did not measure long-term effect [2; 16; 19]. In our study about 26\% of 100 patients stopped using TENS during the 6 month follow up. A decline of pain reducing effect was most reported reason for discontinuing. A much larger group (74\%) however continued TENS were some even reported progression in pain reduction. This results in a positive success rate of $42 \%$ of all patients randomized in the study on long term. The severity of pain at 6 months was in general less compared to baseline levels. As initially pain ratings were high this might be due to regression to the mean. On the other hand pain ratings of patients 
still using TENS were lower than patients who did not use TENS at 6 months follow up. The reduction in pain (rating) might have contributed to the continuation of TENS on long term. This might be indicative for a pain reducing effect of TENS in this group of patients. However, other reasons might influence patient's decision for continuing TENS. Since other reasons for continuing TENS were asked to the patients at 6 months, definite explanations for long-term use of TENS are lacking.

\section{Conclusion}

No differences in positive assessment of TENS by chronic pain patients or hypoalgesic effects were found between three different types of TENS. A substantial proportion of patients with chronic pain reported reduction in pain ratings, even after 6 months. Further research to detect specific characteristic of this subgroup is needed. Definite conclusions on effectiveness of TENS in general cannot be made in this study, because a placebo intervention was not included. Considering psychological working mechanism in future TENS-research seems necessary.

\section{References}

[1] Bolton JE. Accuracy of recall of usual pain intensity in back pain patients. Pain 1999;83(3):533-539

[2] Caroll D, Moore RA, McQuay HJ, Fairman F, Tramer M, Leijon G. Transcutaneous electrical nerve stimulation (TENS) for chronic pain (Cochrane review). The Cochrane Library 2002(4)

[3] Chesterton LS, Barlas P, Foster NE, Lundeberg T, Wright CC, Baxter GD. Sensory stimulation (TENS): effects of parameter manipulation on mechanical pain thresholds in healthy human subjects. Pain 2002;99(1-2):253-262

[4] Farrar JT. What is clinically meaningful: outcome measures in pain clinical trials. Clin J Pain 2000;16(2 Suppl):S106-112

[5] Farrar JT, Portenoy RK, Berlin JA, Kinman JL, Strom BL. Defining the clinically important difference in pain outcome measures. Pain 2000;88(3):287-294

[6] Garrison DW, Foreman RD. Effects of transcutaneous electrical nerve stimulation (TENS) on spontaneous and noxiously evoked dorsal horn cell activity in cats with transected spinal cords. Neurosci Lett 1996;216(2):125-128

[7] Grimmer KA. A controlled double blind study comparing effects of strong burst mode TENS and high rate TENS on painful osteoarthritic knees. Australian Journal of Physiotherapy 1992;48:49-56

[8] Hseuh TC, Kuan P, Hong C. The immediate effectiveness of electrical nerve stimulation and electrical muscle stimulation on myofascial triggerpoints The American Journal of Physical Medicine and Rehabilitation 1997;76:471-476 
[9] Jensen H, Zesler R, Christensen T. Transcutaneous electrical nerve stimulation (TNS) for painful osteoarthrosis of the knee. Int J Rehabil Res 1991;14(4):356-358

[10] Jensen MP, Karoly P. Control beliefs, coping efforts, and adjustment to chronic pain. J Consult Clin Psychol 1991;59(3):431-438

[11] Johnson MI, Ashton CH, Thompson JW. The consistency of pulse frequencies and pulse patterns of transcutaneous electrical nerve stimulation (TENS) used by chronic pain patients. Pain 1991;44(3):231234

[12] Johnson MI, Ashton CH, Thompson JW. An in-depth study of long-term users of transcutaneous electrical nerve stimulation (TENS). Implications for clinical use of TENS. Pain 1991;44(3):221-229

[13] Kumar D, Marshall HJ. Diabetic peripheral neuropathy: amelioration of pain with transcutaneous electrostimulation. Diabetes Care 1997;20(11):1702-1705

[14] Lackner JM, Carosella AM. The relative influence of perceived pain control, anxiety, and functional self efficacy on spinal function among patients with chronic low back pain. Spine (Phila Pa 1976) 1999;24(21):2254-2260; discussion 2260-2251

[15] Mannheimer C, Carlsson CA. The analgesic effect of transcutaneous electrical nerve stimulation (TNS) in patients with rheumatoid arthritis. A comparative study of different pulse patterns. Pain 1979;6(3):329-334

[16] Milne S, Welch V, Brosseau L, Saginur M, Shea B, Tugwell P, Wells G. Transcutaneous electrical nerve stimulation (TENS) for chronic low back pain. Cochrane Database Syst Rev 2001(2):CD003008

[17] Moore SR, Shurman J. Combined neuromuscular electrical stimulation and transcutaneous electrical nerve stimulation for treatment of chronic back pain: a double-blind, repeated measures comparison. Arch Phys Med Rehabil 1997;78(1):55-60

[18] Nash TPW, D. M. TENS: does type of stimulus really matter? Pain Clinics 1990;3:161-168

[19] Osiri M, Welch V, Brosseau L, Shea B, McGowan J, Tugwell P, Wells G. Transcutaneous electrical nerve stimulation for knee osteoarthritis (Cochrane Review). The Cochrane Library 2002(4)

[20] Sjolund BH. Peripheral nerve stimulation suppression of C-fiber-evoked flexion reflex in rats. Part 1: Parameters of continuous stimulation. J Neurosurg 1985;63(4):612-616

[21] Sjolund BH. Peripheral nerve stimulation suppression of C-fiber-evoked flexion reflex in rats. Part 2: Parameters of low-rate train stimulation of skin and muscle afferent nerves. J Neurosurg 1988;68(2):279283

[22] Tulgar M, McGlone F, Bowsher D, Miles JB. Comparative effectiveness of different stimulation modes in relieving pain. Part I. A pilot study. Pain 1991;47(2):151-155

[23] Tulgar M, McGlone F, Bowsher D, Miles JB. Comparative effectiveness of different stimulation modes in relieving pain. Part II. A double-blind controlled long-term clinical trial. Pain 1991;47(2):157-162

[24] Walsh DM. Transcutaneous electrical nerve stimulation (TENS): a review of experimental studies. Eur J Phys Med Rehabilitation 1996;6:41-51

[25] Walsh DM. TENS: Clinical Applications and Related Theory. New York: Churchill Livingstone, 1997

[26] Walsh DM, Foster NE, Baxter GD, Allen JM. Transcutaneous electrical nerve stimulation. Relevance of stimulation parameters to neurophysiological and hypoalgesic effects. Am J Phys Med Rehabil 1995;74(3):199-206 
Pain reducing effect of three types of TENS

[27] Walsh DM, Lowe AS, McCormack K, Willer JC, Baxter GD, Allen JM. Transcutaneous electrical nerve stimulation: effect on peripheral nerve conduction, mechanical pain threshold, and tactile threshold in humans. Arch Phys Med Rehabil 1998;79(9):1051-1058

[28] Wang B, Tang J, White PF, Naruse R, Sloninsky A, Kariger R, Gold J, Wender RH. Effect of the intensity of transcutaneous acupoint electrical stimulation on the postoperative analgesic requirement. Anesth Analg 1997;85(2):406-413

[29] Woolf CJ. Transcutaneous electrical nerve stimulation and the reaction to experimental pain in human subjects. Pain 1979;7(2):115-127 


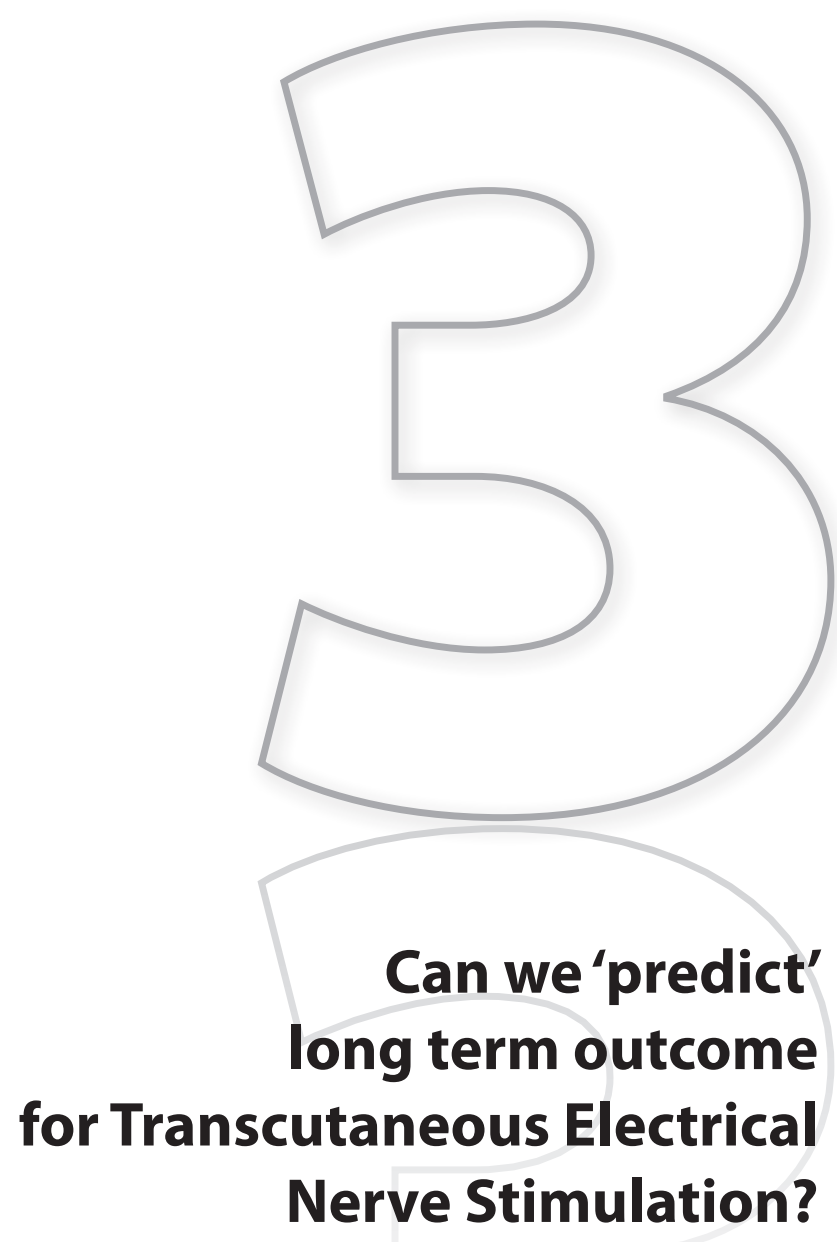

Albère J. Köke ${ }^{a, b, c}$, Rob Smeets ${ }^{b, c}$, Roberto.S. Perez $^{d}$, Alphons Kessels ${ }^{a}$, Bjorn Winkens ${ }^{\mathrm{e}}$, Maarten Kleef van ${ }^{\mathrm{a}}$, Jacob Patijn ${ }^{\mathrm{a}}$

a Pain Management and Research Center, University Medical Center Maastricht

${ }^{b}$ Adelante Centre of Expertise in Rehabilitation, Hoensbroek

c Department of Rehabilitation Medicine, Research School CAPHRI, Maastricht University

d Department of Anaesthesiology, VU University Medical Center and The Institute for Research in Extramural Medicine, Amsterdam

e Department of Methodology and statistics, Research School CAPHRI, Maastricht University 


\section{Abstract}

Evidence for effectiveness of transcutaneous electrical nerve stimulation (TENS) is still inconclusive. As heterogeneity of chronic pain patients might be an important factor for this lack of efficacy, identifying factors for successful long term outcome is of great importance. A prospective study was performed to identify variables with potential predictive value for two outcome measures on long term (6 months); 1) continuation of TENS and 2) a minimally clinical important pain reduction of $\geq 33 \%$. At baseline a set of risk factors including pain related variables and psychological factors was measured in 180 patients. In a multiple logistic regression analysis, higher patient's expectations, neuropathic pain, no severe pain (<80 mm VAS) were independently related to long term continuation of TENS.

For the outcome 'minimally clinical important pain reduction,' the multiple logistic regression analysis indicated that no multi sited pain ( $>2$ pain locations), and intermittent pain were positively and independently associated with a minimally clinical important pain reduction of $\geq 33 \%$. The results showed also that factors associated with successful outcome on long term are dependent on definition of successful outcome. 


\section{Introduction}

Transcutaneous electrical nerve stimulation (TENS) is a frequently used treatment for patients with chronic pain. Despite a large number of studies the effectiveness of TENS is still inconclusive $[6 ; 18-19 ; 30]$. A reason might be the heterogeneity of chronic pain patients. Due to differences in aetiology of pain and/or psychosocial factors, one cannot expect that each individual patient with chronic pain responds equally to TENS. Follow up studies report percentages of patients continuing TENS on long term [9; 26; 43], suggesting effectiveness of TENS in subgroups. Reasons for the continuation of TENS on long term are unknown. Studies aimed at identifying predictive factors, or subgroups of patients who benefit most from TENS treatment, are rarely conducted, despite recognition of their importance [44]. We identified 6 studies [16-17; 23; 29; 31; 45] examining factors associated with short term outcome following TENS treatment. Pain related variables such as intractable pain, intermittent pain and multi sited pain seems to predict TENS a positive outcome at short term [23; 31], however a diagnosis of neuropathic pain has been reported to predict both favourable [17] and unfavourable outcome [31]. Psychosocial factors such as personality disorders, mental illness (depressive state, distress and anxiety) [16; 29; 45], social isolation and analgesic abuse [23] have also been associated with short term outcome of TENS. However, lack of consistency regarding the chosen outcomes and predictors studied means that no firm conclusions can be drawn.

To improve future therapeutic strategies in chronic pain it is important to identify factors with predictive value, especially for long term outcome of pain treatment. The ability to identify patients with greater likelihood of a favourable outcome will allow appropriate selection and reduce the costs and disappointment of non-success. As far as we know, no study has examined factors associated with long term outcome in TENS treatment. Therefore, the purpose of this study is to identify factors that predict successful long term outcome after TENS in treatment in patients with chronic pain. We defined successful outcome of TENS as: 1) the continuation of TENS over a period of 6 months or 2) a minimally clinical important change in pain severity of at least $33 \%$ from baseline to 6 months follow-up.

\section{Methods}

Data from patients enrolled in a cross-over randomized controlled trial assessing the effectiveness of TENS, were used. In the study patients tested effectiveness of two different types of TENS, detailed description of types of treatment protocols is reported elsewhere [20]. Patients were recruited from the outpatient pain clinic of the University Hospital Maastricht, the Netherlands. A limited set of inclusion criteria ( $>6$ months pain duration, age above 18) were applied to include a spectrum of patient characteristics and complaints representative of daily practice. Patients with neurological sensibility deficits due to neurological pathology such as stroke, the use of a cardiac pacemaker, pregnancy, severe psychiatric disorders 
(screened by psychiatrist), pain due to cancer and previous TENS-treatment were excluded. Patients were randomized for type of TENS and used TENS, after instructions (4-6 times a day, stimulus period of $0.5-1 \mathrm{hr}$.), at home for two weeks. At the end of a test period the results of TENS of that test period were evaluated. After a wash out period of 2 weeks, the second TENStype was used for another two weeks period. At the end of the second period the patient had to decide whether or not to continue the TENS treatment at home. When patients decided to continue TENS, they were asked what type of TENS they preferred. Most patients had no preferences as both types were equally effective in the majority (62\%) of the patients. Since no differences in effectiveness were found between different types of TENS in our study [20], and most patients continued using both TENS after test periods, separate analyses of predictive factors were not performed for the different types of TENS.

At baseline (TO) prior to randomization, potential predictive factors were assessed (see subsection 2.3), at 6 months follow up (T1) data were collected on continuation of TENS and pain severity for analysis of predictors. A chart flow of study design is depicted in figure 1.

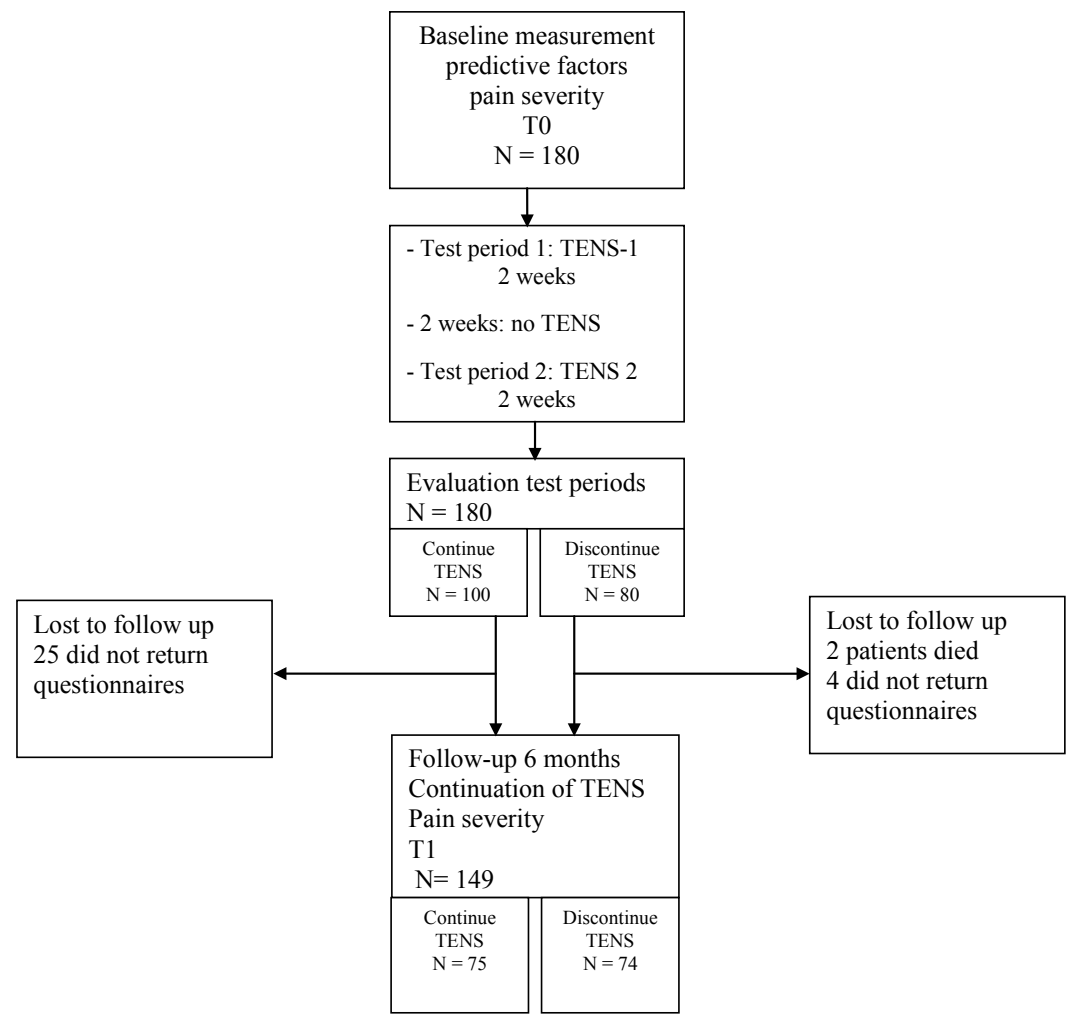

Figure 1. Flowchart study design 


\section{Outcome measures}

Successful outcome was defined in two ways.

1) Continuation of TENS

At follow-up measurement (T1), 6 months after baseline, patients were asked: "Do you still use TENS on regularly basis?" (yes or no). Patients who answered 'yes' to the question were classified as having a successful outcome, those that answered 'no' were classified as unsuccessful.

2) Clinically important pain reduction.

A pain reduction of $33 \%$ has been recommended as a minimally clinical important change in chronic pain to estimate successful treatment. [8; 15] Severity of pain was measured by $100 \mathrm{~mm}$ visual analogue scale (VAS) at baseline (T0) and at 6 months follow-up (T1). Patients were asked to score there average pain during the past 7 days $(0=$ 'no pain', $100=$ 'pain as bad it could be'). After subtracting the post-treatment pain score (T1) from pre-treatment pain (T0) score a percentage change score (raw change/baseline* 100 ) was calculated. Patients reporting pain reduction of 33\% or more at 6 months were classified having a successful outcome and those who did not were classified as unsuccessful.

\section{Potential variables with predictive value}

As chronic pain is a multidimensional phenomenon, patients suffer not only from pain, but also experience problems in psychological and physical functioning. We therefore chose a set of potential predictive factors from a biopsychosocial perspective. Potential predictors were pain-related variables, psychological factors and a measure of physical functioning, which can easily be obtained at first visit in daily practice.

\section{Pain related variables}

Pain-related variables were selected based on a previous study [23], they included: a) average pain intensity over the last week (VAS 0-100 mm), b) severe pain (pain intensity VAS score dichotomised; $<$ and $\geq 80 \mathrm{~mm}$ VAS), c) quality of pain (motivational affective domain) measured by Pain Rating Index subscale of McGill Pain Questionnaire (MPQ), intermittent pain (yes/ no), d) neuropathic pain (yes/no) and e) multi sited pain (pain at $>2$ locations; yes/no). Both VAS and MPQ are valid, reliable and responsive methods for measuring pain in chronic pain patients [39]. 


\section{Psychological factors}

Psychological factors are previously identified predictors of response to pain treatment in general [5; 12; 21-22; 25; 34], they included: a) locus of control, b) self-efficacy, c) catastrophizing, d) psychological distress and e) treatment expectations. Psychological factors were measured with self-reporting questionnaires. The Pain Coping and Cognition List (PCCL) was used to measure catastrophizing and locus of control (internal and external)[38]

Self efficacy was measured with the Chronic Pain Self-Efficacy Scale (CPSS) which assesses self-efficacy beliefs about control over pain and disability [2].The mental health subscale of the Dutch SF-36 [1] was used to measure psychological distress. Patient's expectancies about pain relieving effect of TENS were scored on a $100 \mathrm{~mm}$ VAS. Patients were asked: 'Do you expect that your pain will be reduced by TENS?' Not at all was scored as ' 0 ' and very much was rated as ' 100 '.

\section{Physical functioning}

To measure restrictions in daily physical activities the physical functioning subscale of the Dutch SF-36 [1] was used.

\section{Statistical analysis}

Differences in continuous variables were evaluated by independent-samples t-test or MannWhitney U-test if the data were clearly not-normally distributed (based on visual inspection of histograms). Differences in categorical variables were tested using Chi-square test or Fisher's exact test, where appropriate. The total number of variables entered into the final multiple regression models was restricted to comply with the rule that one needs at least 10 events per variable while performing a regression analysis [32].

First, univariate logistic regression analyses were performed for all potential factors with both outcome measures; continuation of TENS at 6 months (users /non-users) and minimally clinical important pain reduction ( $<33 \%$ VAS $/ \geq 33 \%$ VAS).

Second, those variables whose association met the threshold $p$-value $(p \leq 0.20)$ with outcome were entered into the initial multivariate model. Finally, multiple logistic analyses were performed with backward elimination method, using the likelihood ratio test ( $p \leq 0.05)$. Associations were expressed as odds ratios (OR) with corresponding 95\% confidence intervals. Multicollinearity was checked by correlation analysis, the variance inflating factor (VIF) and Condition Index (Cl). The fit of the final model was assessed with Hosmer-Lemeshow goodness-of-fit statistics and percentages of correctly-classified patients. Analyses were performed with SPSS version 16 . P-value $\leq 0.05$ was considered as statistically significant. 


\section{Results}

There was complete baseline data from 149 patients (83\%) of 180 patients randomized in the cross-over study. After the test periods of TENS, $56 \%(n=100)$ of the patients rated the test period as positive and continued TENS. Seventy-five patients of this group still used TENS at 6 months follow up. Sixteen patients stopped during the follow up period. Therefore at 6 months we had data of 74 who did not use TENS. Patients that did not return the questionnaire scored higher for expectancies about effectiveness of TENS but were not different on any of the other measures at baseline (Table 1).

Table 1. Summary baseline characteristics (mean and SD or percentages) of study population

\begin{tabular}{|c|c|c|}
\hline & $\begin{array}{l}\text { Patients returning } \\
\text { questionnaires } \\
\text { at } 6 \text { months } \\
\mathrm{N}=149 \\
\end{array}$ & $\begin{array}{l}\text { Patient not returning } \\
\text { questionnaire } \\
\text { at } 6 \text { months } \\
\mathrm{N}=31\end{array}$ \\
\hline Age(sd) & $50(13)$ & $50(16)$ \\
\hline Male sex (\%) & $34 \%$ & $42 \%$ \\
\hline Paid job (\% yes) & $35 \%$ & $26 \%$ \\
\hline $\begin{array}{l}\text { Education: } \\
\text { - low / middle / high }\end{array}$ & $53 \% / 38 \% / 9 \%$ & $64 \% / 34 \% / 2 \%$ \\
\hline $\begin{array}{l}\text { Average pain intensity past week } \\
\text { (VAS 0-100)(SD) }\end{array}$ & $63(20)$ & $68(18)$ \\
\hline $\begin{array}{l}\text { Quality of pain: } \\
\text { - PRI motivational affective (0-12) (SD) }\end{array}$ & $4.3(3.2)$ & $4.6(3.4)$ \\
\hline Severe pain ( $\geq 80 \mathrm{~mm}$ VAS) & $47 \%$ & $48 \%$ \\
\hline Intermittent pain (no) & $73 \%$ & $84 \%$ \\
\hline Neuropathic pain ( yes) & $15 \%$ & $8 \%$ \\
\hline $\begin{array}{l}\text { Duration of pain (mo), median/range } \\
\text { Multi sited pain ( }>2 \text { locations) }\end{array}$ & $\begin{array}{l}36 / 480 \\
27 \%\end{array}$ & $\begin{array}{c}36 / 252 \\
23 \%\end{array}$ \\
\hline Expectancies (VAS 0-100)* & $55(20)$ & $64(21)$ \\
\hline $\begin{array}{l}\text { Short Form-36: } \\
\text { - Mental Health Scale (0-100) (SD) } \\
\text { - Physical Functioning Scale (0-100) (SD) }\end{array}$ & $\begin{array}{l}50(20) \\
35(20)\end{array}$ & $\begin{array}{l}47(22) \\
31(20)\end{array}$ \\
\hline Chronic Pain Self-efficacy Scale (SD) & $957(338)$ & $860(414)$ \\
\hline $\begin{array}{l}\text { Pain Coping Cognition List } \\
\text { - Catastrophizing (0-6)(SD) } \\
\text { - Internal locus of control (0-6)(SD) } \\
\text { - External locus of control (0-6)(SD) }\end{array}$ & $\begin{array}{l}3.5(1) \\
2.9(1) \\
3.4(1)\end{array}$ & $\begin{array}{l}3.7(1.2) \\
2.7(1.1) \\
3.2(1.2)\end{array}$ \\
\hline
\end{tabular}




\section{Continuation of TENS}

At 6 months follow up, 75 patients still used TENS (users) compared to 74 patients not using TENS (non-users). The patients in the users-group had a statistically significant higher mean pain reduction of 28\% (SD 35\%) at 6 months, compared to $0 \%$ (SD 41\%) for patients in nonusers group $(p<0.001)$.

Univariate analyses showed that higher scores on patients' expectancies for pain relief, a diagnosis of neuropathic pain, lower levels of mental health and no severe pain $(<80 \mathrm{~mm}$ VAS) at baseline were associated $(p \leq 0.20)$ with a higher probability of using TENS at 6 months (table 2). In the multiple logistic regression analyses, expectancies for pain relief by TENS, neuropathic pain and no severe pain remained in the final model as independently factors associated with the continuation of TENS (Table 2). 
Table 2. Results of logistic regression analysis for outcome continuation of TENS

\begin{tabular}{|c|c|c|c|c|c|c|c|c|}
\hline & \multicolumn{4}{|c|}{ Univariate analysis } & \multicolumn{4}{|c|}{ Multiple analysis } \\
\hline & \multirow[t]{2}{*}{ OR } & \multicolumn{2}{|c|}{$95 \% \mathrm{Cl}$} & \multirow[t]{2}{*}{ Sig } & \multirow[t]{2}{*}{ OR } & \multicolumn{2}{|c|}{$95 \% \mathrm{Cl}$} & \multirow[t]{2}{*}{ Sig } \\
\hline & & lower & upper & & & lower & upper & \\
\hline \multicolumn{9}{|l|}{ Pain related variables: } \\
\hline Neuropathic pain & 3.322 & 1.229 & 8,980 & 0.018 & 3.314 & 1.177 & 9.329 & 0.023 \\
\hline Average pain past week (VAS) & 0.993 & 0.977 & 1.010 & 0.433 & & & & \\
\hline PRI-affective domain & 1.030 & 0.932 & 1.140 & 0.562 & & & & \\
\hline No severe pain $>80 \mathrm{~mm}$ VAS & 1.917 & 1.026 & 3.785 & 0.042 & 2.437 & 1.201 & 4.945 & 0.014 \\
\hline Multi sited pain & 0.973 & 0.512 & 1.850 & 0.933 & & & & \\
\hline No intermittent pain & 1.578 & 0.763 & 3.265 & 0.219 & & & & \\
\hline \multicolumn{9}{|l|}{ Psychological variables: } \\
\hline Expectancies (VAS) & 1.027 & 1.009 & 1.045 & 0.003 & 1.030 & 1.011 & 1.049 & 0.002 \\
\hline Mental health (SF36) & 1.016 & 1.000 & 1.033 & 0.057 & & & & \\
\hline Physical functioning (SF36) & 1.002 & 0.986 & 1.018 & 0.822 & & & & \\
\hline Catastrophizing (PCCL) & 1.103 & 0.799 & 1,522 & 0.553 & & & & \\
\hline Internal locus of control (PCCL) & 0.982 & 0.702 & 1.375 & 0.918 & & & & \\
\hline $\begin{array}{l}\text { External locus of control } \\
(\mathrm{PCCL})\end{array}$ & 1.085 & 0.792 & 1.486 & 0.611 & & & & \\
\hline Self-efficacy (CPSS) & 1.000 & 0.999 & 1.001 & 0.822 & & & & \\
\hline
\end{tabular}

$\mathrm{OR}=$ odds ratio $\mathrm{PRI}=$ Pain Rating Index, $\mathrm{VAS}=$ visual analogue scale, $\mathrm{SF} 36=$ short form $36, \mathrm{PCCL}=$ pain coping cognition list, CPSS=chronic pain self efficacy scale. Correctly Classified 64\%, Holmer Lemeshow: chi 9.413, df 8, p-value 0.309. VIF: no severe pain 1.012, neuropathic pain 1.005, expectancies 1.017. Condition Index range: 1.000-6.735 VIF 1.005-1.017 


\section{Minimally clinical important pain reduction ( $\geq 33 \%$ VAS)}

The $\geq 33 \%$ VAS group had an average pain reduction of 55\% (SD 20\%) compared to a pain reduction of $0.2 \%$ (SD 21\%) in group $<33 \%$ VAS. Forty-six of 149 patients who returned follow questionnaires at 6 months had a pain reduction $\geq 33 \%$. In the users group more patients had a pain reduction $\geq 33 \%$ (38 out of 75) compared to non-users group ( 8 out of 74).

In the univariate analyses, intermittent pain, no multi sited pain, were positively associated with a pain reduction of $\geq 33 \%$ (all $p \leq 0.20$ ). In the multiple logistic regression analysis both intermittent pain and no multi sited pain were independently associated with a pain reduction $\geq 33 \%$ (table 3 ).

Table 3. Results of logistic regression analysis for outcome minimally clinical important pain reduction $(\geq 33 \%$ VAS)

\begin{tabular}{cccccc}
\multicolumn{3}{c}{ Univariate analysis } & \multicolumn{3}{c}{ Multiple analysis } \\
\hline OR & $95 \% \mathrm{Cl}$ & $\mathrm{Sig}$ & OR & $95 \% \mathrm{Cl}$ & $\mathrm{Sig}$ \\
\hline \multicolumn{3}{c}{ lower upper } & & \multicolumn{3}{c}{ lower } & upper
\end{tabular}

Pain related variables

\begin{tabular}{lllllllll} 
Neuropathic pain & 0.518 & 0.180 & 1.489 & 0.222 & & & & \\
Average pain past week (VAS) & 0.996 & 0.972 & 1.020 & 0.752 & & & & \\
PRI-affective domain & 0.966 & 0.843 & 1.107 & 0.617 & & & & \\
No severe pain (> 80 mm VAS) & 0.933 & 0.368 & 2.365 & 0.884 & & & & \\
Multi sited pain & 0.355 & 0.139 & 0.905 & 0.030 & 0.430 & 0.208 & 0.891 & 0.023 \\
No intermittent pain & 0.288 & 0.102 & 0.817 & 0.019 & 0.351 & 0.162 & 0.757 & 0.008 \\
Psychological variables & & & & & & & & \\
Expectancies (VAS) & 0.992 & 0.968 & 1.018 & 0.557 & & & & \\
Mental health (SF36) & 1.002 & 0.979 & 1.026 & 0.863 & & & & \\
Physical functioning (SF36) & 1.008 & 0.985 & 1.031 & 0.494 & & & & \\
Catastrophizing (PCCL) & 0.949 & 0.607 & 1.482 & 0.817 & & & & \\
Internal locus of control(PCCL) & 1.034 & 0.672 & 1.591 & 0.879 & & & & \\
External locus of control(PCCL) & 1.288 & 0.797 & 8.083 & 0.302 & & & & \\
Self-efficacy (CPSS) & 1.000 & 0.998 & 1.001 & 0.519 & & & \\
\hline OR & & & & & & & \\
\hline
\end{tabular}

$\mathrm{OR}=$ odds ratio VAS = visual analogue scale, $\mathrm{PRI}=$ Pain Rating Index, SF36 = short form 36, PCCL = pain coping cognition list, CPSS = chronic pain self efficacy scale. Correctly Classified 70.5\%, Hosmer Lemeshow pvalue 0.891, AUC $0.712(95 \% \mathrm{Cl} 0.630-0.795)$ VIF no intermittent pain $=1.003$, VIF multi sited pain $=1.003$. Condition Index range: 1.000-4.336 


\section{Discussion}

This is the first study that examined factors associated with TENS outcome on long term.

These data show that there are different factors associated with TENS outcome dependent on the definition of successful outcome, as previous reported for short term outcome of TENS [31].

\section{Predicting continuation of TENS}

\section{Severe pain}

Severe pain ( $\geq 80 \mathrm{~mm}$ VAS) was found to be a negatively associated factor with continuation of TENS at 6 months, this is in agreement with other studies with TENS [31] and long term outcome in other treatments for pain $[13 ; 33]$.

Severe pain may be associated with impaired spinal GABAergic inhibitory function due to continuous nociceptive input [14]. As pain relief by TENS is produced by effective release of GABA within the dorsal horn [36] this might explain why patients with severe pain have perceived no effect of TENS.

\section{Neuropathic pain}

Our finding of neuropathic pain as a predictor is in contrast with results of a study on short term[31]. In their study Oosterhof et al. [31] classified patients as having neuropathic pain using Quantitative Sensory Testing (QST). Our diagnosis of neuropathic pain was based on a detailed medical history and a physical examination of the doctors at our pain clinic. No additional tests, such as disease specific questionnaires or QST, were part of the examination. This might have resulted in different classification of (neuropathic) pain problems in the studies explaining the different findings. 


\section{Expectancies}

Higher pre treatment expectancies predict pain reduction in several types of treatment for back and neck pain, osteoarthritis and headache [24; 33; 42] or functional recovery [27]. Our data confirm the importance of pre-treatment expectancies in predicting outcome. The fact that the group of patients who didn't return the follow-up questionnaires had higher treatment expectations overall, could bias these findings. Nine patients in this group continued TENS after the first treatment period. If all these patients stopped using TENS during the follow up period, due to diminished analgesic effect, this would result in a reduced predictive value of expectancies. However, since we have no compelling reason to think that this is the case, we still believe that expectancies are of predictive value for long term continuation of TENS. It is important though that these results are confirmed in future studies.

\section{Predicting minimally clinical important pain reduction}

\section{Intermittent pain}

The positive predictive value of intermittent pain on pain relief by TENS has been demonstrated in previous studies on short term outcome in TENS [16; 22] and is associated with better treatment response of medication [11] and chiropractic treatment [33]. Variability in pain intensity throughout a day or week is normal, although fluctuations can vary greatly between patients [46]. Pain problems with less variability in intensity might reflect less availability of inhibitory control [31], and are therefore more resistant to treatment in general. This may explain why more patients with intermittent pain achieve a clinically relevant reduction following TENS.

\section{Multi sited pain}

The finding of multi sited pain, as a negative predictor for a minimally clinical pain reduction is in line with other studies [13; 35]. For example, Anderson et al (1996) [3] showed that patients with multi sited pain had worse prognosis for being pain free within a period of 2 years, compared to patients with only neck-shoulder pain. This may be due to the pathophysiology of multi sited pain, which remains uncertain or due to peripheral and central sensitization [47]. The spreading of pain is associated with increased synaptic activity in central neurons and changes in descending control from supraspinal centers [10]. Alterations in endogenous pain modulation in patients with multi sited pain [28], could explain why patients with multi sited pain do not respond well to TENS, or indeed to other treatments. 


\section{Limitations of the study}

Although our study population was relatively large and contained a broad representation of pain disorders seen in pain clinics, generalisation of the results is restricted to the care setting in which these associations were found. The fact that our study population was heterogeneous however might have deflated some associations found.

The response rate at follow-up of the patients who continued TENS directly after the test period was lower than for patients who didn't continue TENS. This is surprising as we expected higher response rates at follow-up measurement in patients with positive treatment results. We don't have a proper explanation for this difference in response rate. Maybe the effectiveness of TENS decreased during the follow-up period after first promising results during the test period. This may lead to more disappointment and therefore less willingness to respond.

Unfortunately, we could not perform analysis based on type of TENS. In animal studies differences in effectiveness of different types of TENS have been reported [37], whether these differences translate into differences in hypoalgesia in humans however is unclear [7]. As mentioned in the methods section patients evaluated both types of TENS tested during the testing period and were allowed to use both types on long term. About 70\% evaluated both TENS types as positive and continued both types. At follow-up measurement we asked again what type of TENS patients preferred or used during the previous 6 months. Most patients reported the use of both types of TENS. Therefore, no specific analysis for predictive factors on type of TENS was possible. This remains an issue for further research. Also we did not assess precisely how many days or hours patients used TENS during the 6 months. Therefore no specific comments can be made on adherence to the instructions given during test periods. But we believe that patients use TENS in a way that is effective for them. So differences in frequency and duration of TENS use by patients during the 6 months do not affect the results in our view.

\section{Implications for daily practice and future research}

Pain-related factors such as; severe pain, neuropathic pain (for continuation of TENS) and intermittent pain and multi sited pain (for pain reduction) were associated with outcome as opposed to psychological factors (only expectations for continuation of TENS). These painrelated factors may be manifestations of changes in the endogenous pain-modulating system due to central sensitisation [47]. The question is whether these specific manifestations reflect different pathophysiology mechanisms. Research investigating the temporal aspects of pain and variability over time, related to effectiveness of TENS, may be valuable to indentify for which type of pain TENS is most effective. 
We found no psychological factors (except expectancies) associated with 'continuation of TENS' or a "minimally clinical pain reduction $\geq 33 \%$ '. This is surprising as many studies on outcome in chronic pain treatment have consistently found psychological factors to predict poor outcome [22; 25; 34; 40; 42]. Recently, van der Windt et al.[41] found differences between the importance of psychological predictors in (sub) acute shoulder pain compared to (sub) acute low back pain in primary care. The influence of psychological factors on outcome may vary across patients with different types of pain. As our study population consisted of different types of pain problems this might have reduced associations between psychological factors and outcomes. Future research is needed to examine the relationships between type of pain problems and type of psychological factors that could affect outcome of TENS.

Furthermore our results on expectancies might be biased due to differences in response rate, as already discussed. However enhancing expectancies about amount of pain relief (by TENS) seems worthwhile in daily clinical practice as in a study on drug efficacy the analgesic effect was almost doubled by stimulating positive expectancies [4]. Therefore, when TENS is considered as treatment, expectancies should be assessed and be facilitated before treatment starts.

\section{Conclusion}

Patients with neuropathic pain, no severe pain and high expectancies for pain relief by TENS are more likely to continue the use of TENS at 6 months. Patients who have intermittent, and/ or multi-site pain are more likely to achieve a minimally clinical important reduction of pain by application of TENS on long term. No specific recommendation can be made for type of TENS. Further studies in other populations are needed to confirm the predictive values of the findings for TENS in general and/or for different types of TENS specifically. 


\section{References}

[1] Aaronson NK, Muller M, Cohen PD, Essink-Bot ML, Fekkes M, Sanderman R, Sprangers MA, te Velde A, Verrips E. Translation, validation, and norming of the Dutch language version of the SF-36 Health Survey in community and chronic disease populations. J Clin Epidemiol 1998;51(11):1055-1068

[2] Anderson KO, Dowds BN, Pelletz RE, Edwards WT, Peeters-Asdourian C. Development and initial validation of a scale to measure self-efficacy beliefs in patients with chronic pain. Pain 1995;63(1):77-84

[3] Andersson HI, Ejlertsson G, Leden I, Rosenberg C. Characteristics of subjects with chronic pain, in relation to local and widespread pain report. A prospective study of symptoms, clinical findings and blood tests in subgroups of a geographically defined population. Scand J Rheumatol 1996;25(3):146-154

[4] Bingel U, Wanigasekera V, Wiech K, Ni Mhuircheartaigh R, Lee MC, Ploner M, Tracey I. The effect of treatment expectation on drug efficacy: imaging the analgesic benefit of the opioid remifentanil. Sci Transl Med 2011;3(70):70ra14

[5] Bot SD, van der Waal JM, Terwee CB, van der Windt DA, Scholten RJ, Bouter LM, Dekker J. Predictors of outcome in neck and shoulder symptoms: a cohort study in general practice. Spine (Phila Pa 1976) 2005;30(16):E459-470

[6] Carroll D, Moore RA, McQuay HJ, Fairman F, Tramer M, Leijon G. Transcutaneous electrical nerve stimulation (TENS) for chronic pain. Cochrane Database Syst Rev 2001(3):CD003222

[7] Claydon LS, Chesterton LS, Barlas P, Sim J. Effects of simultaneous dual-site TENS stimulation on experimental pain. Eur J Pain 2008;12(6):696-704

[8] Farrar JT, Portenoy RK, Berlin JA, Kinman JL, Strom BL. Defining the clinically important difference in pain outcome measures. Pain 2000;88(3):287-294

[9] Fishbain DA, Chabal C, Abbott A, Heine LW, Cutler R. Transcutaneous electrical nerve stimulation (TENS) treatment outcome in long-term users. Clin J Pain 1996;12(3):201-214

[10] Graven-Nielsen T, Arendt-Nielsen L. Assessment of mechanisms in localized and widespread musculoskeletal pain. Nat Rev Rheumatol 2010;6(10):599-606

[11] Harris RE, Williams DA, McLean SA, Sen A, Hufford M, Gendreau RM, Gracely RH, Clauw DJ. Characterization and consequences of pain variability in individuals with fibromyalgia. Arthritis Rheum 2005;52(11):3670-3674

[12] Hasenbring M. Predictors of efficacy in treatment of chronic low back pain. Curr Opin Anaesthesiol 1998;11(5):553-558

[13] Hill JC, Lewis M, Sim J, Hay EM, Dziedzic K. Predictors of poor outcome in patients with neck pain treated by physical therapy. Clin J Pain 2007;23(8):683-690

[14] Janssen SP, Truin M, Van Kleef M, Joosten EA. Differential GABAergic disinhibition during the development of painful peripheral neuropathy. Neuroscience 2011;184:183-194

[15] Jensen MP, Chen C, Brugger AM. Interpretation of visual analog scale ratings and change scores: a reanalysis of two clinical trials of postoperative pain. J Pain 2003;4(7):407-414

[16] Johansson F, Almay BG, von Knorring L. Personality factors related to the outcome of treatment with transcutaneous nerve stimulation. Psychiatr Clin (Basel) 1981;14(2):96-104 
[17] Johansson F, Almay BG, Von Knorring L, Terenius L. Predictors for the outcome of treatment with high frequency transcutaneous electrical nerve stimulation in patients with chronic pain. Pain 1980;9(1):55-61

[18] Johnson M, Martinson M. Efficacy of electrical nerve stimulation for chronic musculoskeletal pain: a meta-analysis of randomized controlled trials. Pain 2007;130(1-2):157-165

[19] Khadilkar A, Milne S, Brosseau L, Robinson V, Saginur M, Shea B, Tugwell P, Wells G. Transcutaneous electrical nerve stimulation (TENS) for chronic low-back pain. Cochrane Database Syst Rev 2005(3):CD003008

[20] Koke AJ, Schouten JS, Lamerichs-Geelen MJ, Lipsch JS, Waltje EM, van Kleef M, Patijn J. Pain reducing effect of three types of transcutaneous electrical nerve stimulation in patients with chronic pain: a randomized crossover trial. Pain 2004;108(1-2):36-42

[21] Korres RC, Murphy WD, Rosenthal TL, Elias DB, North WC. Predicting outcome of chronic pain management via modified self-efficacy scale. Behav Res Ther 1990;28(2):165-169

[22] Lame IE, Peters ML, Patijn J, Kessels AG, Geurts J, van Kleef M. Can the outcome of spinal cord stimulation in chronic complex regional pain syndrome type I patients be predicted by catastrophizing thoughts? Anesth Analg 2009;109(2):592-599

[23] Lampl C, Kreczi T, Klingler D. Transcutaneous electrical nerve stimulation in the treatment of chronic pain: predictive factors and evaluation of the method. Clin J Pain 1998;14(2):134-142

[24] Linde K, Witt CM, Streng A, Weidenhammer W, Wagenpfeil S, Brinkhaus B, Willich SN, Melchart D. The impact of patient expectations on outcomes in four randomized controlled trials of acupuncture in patients with chronic pain. Pain 2007;128(3):264-271

[25] McCracken LM, Turk DC. Behavioral and cognitive-behavioral treatment for chronic pain: outcome, predictors of outcome, and treatment process. Spine (Phila Pa 1976) 2002;27(22):2564-2573

[26] Meyler WJ, de Jongste MJ, Rolf CA. Clinical evaluation of pain treatment with electrostimulation: a study on TENS in patients with different pain syndromes. Clin J Pain 1994;10(1):22-27

[27] Myers SS, Phillips RS, Davis RB, Cherkin DC, Legedza A, Kaptchuk TJ, Hrbek A, Buring JE, Post D, Connelly MT, Eisenberg DM. Patient expectations as predictors of outcome in patients with acute low back pain. J Gen Intern Med 2008;23(2):148-153

[28] Nielsen LA, Henriksson KG. Pathophysiological mechanisms in chronic musculoskeletal pain (fibromyalgia): the role of central and peripheral sensitization and pain disinhibition. Best Pract Res Clin Rheumatol 2007;21(3):465-480

[29] Nielzen S, Sjolund BH, Eriksson MB. Psychiatric factors influencing the treatment of pain with peripheral conditioning stimulation. Pain 1982;13(4):365-371

[30] Nnoaham KE, Kumbang J. Transcutaneous electrical nerve stimulation (TENS) for chronic pain. Cochrane Database Syst Rev 2008(3):CD003222

[31] Oosterhof J, Samwel HJ, de Boo TM, Wilder-Smith OH, Oostendorp RA, Crul BJ. Predicting outcome of TENS in chronic pain: a prospective, randomized, placebo controlled trial. Pain 2008;136(1-2):11-20

[32] Peduzzi P, Concato J, Kemper E, Holford TR, Feinstein AR. A simulation study of the number of events per variable in logistic regression analysis. J Clin Epidemiol 1996:49(12):1373-1379 
[33] Rubinstein SM, Knol DL, Leboeuf-Yde C, de Koekkoek TE, Pfeifle CE, van Tulder MW. Predictors of a favorable outcome in patients treated by chiropractors for neck pain. Spine (Phila Pa 1976) 2008;33(13):1451-1458

[34] Samwel H, Slappendel R, Crul BJ, Voerman VF. Psychological predictors of the effectiveness of radiofrequency lesioning of the cervical spinal dorsal ganglion (RF-DRG). Eur J Pain 2000;4(2):149-155

[35] Schellingerhout JM, Verhagen AP, Heymans MW, Pool JJ, Vonk F, Koes BW, Wilhelmina de Vet HC. Which subgroups of patients with non-specific neck pain are more likely to benefit from spinal manipulation therapy, physiotherapy, or usual care? Pain 2008;139(3):670-680

[36] Sluka KA. Mechanism and management of pain for the physical therapist. Seattle: IASP Press, 2009

[37] Sluka KA, Vance CG, Lisi TL. High-frequency, but not low-frequency, transcutaneous electrical nerve stimulation reduces aspartate and glutamate release in the spinal cord dorsal horn. J Neurochem 2005;95(6):1794-1801

[38] Stomp GM, Vlaeyen JW, Kuile ter MM, Spinhoven P, Breukelen van G, Kole-Snijders AM. Pijn Coping en Cognitie Lijst (PCCL). Maastricht: Pijn Kennis Centrum, 2001

[39] Turk DC, Melzack R. Handbook of pain assesment. New York: The Guilford Press, 2001

[40] Turner JA, Holtzman S, Mancl L. Mediators, moderators, and predictors of therapeutic change in cognitive-behavioral therapy for chronic pain. Pain 2007;127(3):276-286

[41] van der Windt DA, Kuijpers T, Jellema P, van der Heijden GJ, Bouter LM. Do psychological factors predict outcome in both low-back pain and shoulder pain? Ann Rheum Dis 2007;66(3):313-319

[42] van Wijk RM, Geurts JW, Lousberg R, Wynne HJ, Hammink E, Knape JT, Groen GJ. Psychological predictors of substantial pain reduction after minimally invasive radiofrequency and injection treatments for chronic low back pain. Pain Med 2008;9(2):212-221

[43] Verdouw BC, Zuurmond WWA, deLange JJ, Metz GCH, Wagemans MFM. Long-term use and effectiveness of transcutaneous electrical nerve stimulation in treatment of chronic pain patients. Pain Clinic 1996;8(4):341-346

[44] Vlaeyen JW, Morley S. Cognitive-behavioral treatments for chronic pain: what works for whom? Clin J Pain 2005;21(1):1-8

[45] Widerstrom-Noga E, Dyrehag LE, Borglum-Jensen L, Aslund PG, Wenneberg B, Andersson SA. Pain threshold responses to two different modes of sensory stimulation in patients with orofacial muscular pain: psychologic considerations. J Orofac Pain 1998;12(1):27-34

[46] Williams DA, Gendreau M, Hufford MR, Groner K, Gracely RH, Clauw DJ. Pain assessment in patients with fibromyalgia syndrome: a consideration of methods for clinical trials. Clin J Pain 2004;20(5):348-356

[47] Woolf CJ. Central sensitization: implications for the diagnosis and treatment of pain. Pain 2011;152(3 Suppl):S2-15 



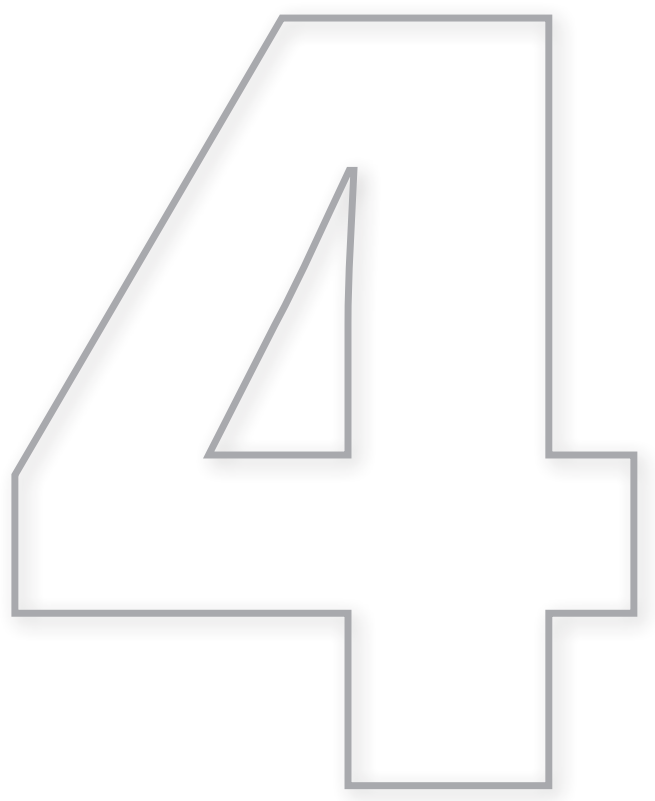

\title{
Why chronic pain patients use transcutaneous electrical nerve stimulation (TENS) on long term?
}

\author{
Köke Albère J.A. ${ }^{a, b, c}$, Smeets Rob E.M ${ }^{b, c}$, Perez. Roberto S.G.M. ${ }^{d}$, \\ Kessels Alphons ${ }^{\mathrm{a}}$, Winkens Bjorn. ${ }^{\mathrm{e}}$, Kleef van Maarten ${ }^{\mathrm{a}}$, Patijn Jacob ${ }^{\mathrm{a}}$
}

aPain Management and Research Center, University Medical Center Maastricht

${ }^{\text {b} A d e l a n t e ~ C e n t r e ~ o f ~ E x p e r t i s e ~ i n ~ R e h a b i l i t a t i o n, ~ H o e n s b r o e k ~}$ 'Department of rehabilitation medicine, Research School of CAPHRI, Maastricht University

dDepartment of Anaesthesiology, VU University Medical Center and The Institute for Research in Extramural Medicine, Amsterdam eDepartment of Methodology and Statistics, Research School of CAPHRI, Maastricht University 


\section{Abstract}

Background. The evidence for the effectiveness of TENS is still inconclusive. An important question in TENS treatment of chronic pain is why some patients respond well and others don't. Due to the heterogeneity of chronic pain patients, where psychosocial factors may influence pain, one cannot expect that all patients will respond equally to treatment.

Methods. Data of a randomized trial on effectiveness of TENS were used to analyse whether pain severity, catastrophizing, and locus of control, self-efficacy, mental functioning, physical functioning and health care utilisation were associated with the continuous use of TENS at 6 months.

Results. Out of 180 patients started with TENS treatment 75 (42\%) still used TENS after 6 months. These 75 users had significantly better improvements on all above mentioned factors compared to non-users, except for mental functioning. Effect sizes varied from 0.10 to 0.85 in the user group versus 0.00 to 0.21 in the non-user group. Improvements from baseline to 6 months in pain severity, internal locus of control, self efficacy beliefs and physical functioning were positively associated with long term use of TENS. Factors such as no current treatment and less analgesic consumption were also significantly associated with long term use of TENS. In a multiple regression analysis only pain reduction and less catastrophizing beliefs were both independently factors associated with long term use of TENS.

Conclusion. TENS has effects on several domains which might explain why some patients still use TENS, even as pain relief is minimal. Besides pain reduction a decrease of catastrophizing is associated with long term use of TENS. 


\section{Introduction}

The effectiveness of TENS to reduce pain, particularly at long-term, is still controversial $[7 ; 21 ; 31]$. In general the effectiveness on long term is considered to diminish due to a fading of current sensation [15; 23]. On the other hand, a subsample of patients seems to continue to use TENS successfully on long term $[15 ; 20 ; 25 ; 28 ; 42]$. Why some patients respond successful to TENS and others don't, has never been studied in detail. One can assume that pain relief is the most important factor for long term use of TENS, but Johnson et al. [19] reported that $14 \%$ of a study population continued using TENS despite experiencing none or only minor pain relief.

Pain is nowadays viewed as a complex and dynamic interaction between biological, psychological and social factors [17]. It is therefore reasonable to assume that multiple factors contribute to treatment adherence besides effective change in pain severity. In chronic pain treatment in general, improvements in pain related cognitions, increase in self-efficacy beliefs, adapting an active coping style have shown to mediate treatment success [27; 37; 41].

Besides pain relief, less pain medication taken, use of health care and medical costs and improvement of activity levels and work capacity are also reported as positive effects of TENS[8; 15-16; 38]. The question is whether these effects as well as other outcome measures contribute to long term use of TENS.

We hypothesize that the hypoalgesic effects of TENS are also due to enhanced feelings of control over pain by using TENS. Furthermore patients could use TENS as a substitute for other pain treatments, which are often accompanied with more side effects such as pain medication. More insight in mechanisms associated with responders and non-responders is valuable for developing treatment programs for patients with therapy resistant chronic pain. Therefore, we examined whether changes in severity from baseline to 6 month follow up of pain related and psychological variables are associated with the long term use of TENS. We hypothesized that use of TENS on long term is due to pain reduction and increased feelings of control and self-efficacy and better physical functioning. Furthermore we hypothesized that less health care utilization and medication use is associated with long term use of TENS.

\section{Methods}

To analyze factors associated with the continuation of TENS at long term data collection was incorporated in a randomized cross-over trial to study effectiveness of three types of TENS. Patients with chronic pain received (based on randomization) two out of three types of TENS (type 1: frequency $80 \mathrm{~Hz}$, pulse duration 80 microseconds, intensity threshold, type 2: frequency $80 \mathrm{~Hz}$, pulse duration 250 microseconds intensity high, type 3: frequency $30 \mathrm{~Hz}$, pulse duration 250 microseconds, intensity based on preference patient). Each type of TENS was used for 2 weeks on daily basis at home, after instructions by a physical therapist. After both test periods patients decided to continue using TENS or not. All patients were contacted again at 6 month follow up. For more detailed 
description of the study design see elsewhere [22]. The results of the effectiveness study showed that pain relief and continuation of TENS on long term did not differ between the three types of TENS. Also most patients rated both types of TENS as equally effective (pain relief) and used both types on long term [22]. Therefore no separate analysis on type of TENS could be performed. We therefore decided to analyze the data for the use of TENS in general, regardless of type of TENS.

\section{Primary outcome}

Primary outcome at 6 months after baseline measurement, patients were asked: "Do you still use TENS on regularly basis?" (yes or no). Also patients were asked why they stopped using TENS. Patient who used TENS at 6 months were classified as 'users'. Patients who stopped using TENS during the period from baseline until 6 months were classified as 'non-users'.

\section{Measurements}

At baseline (T0) and at 6 months follow-up (T1) we measured a) pain severity, b) physical functioning and psychological factors; c) catastrophizing, d) internal locus of control, e) external locus of control, f) mental functioning and g) self-efficacy.

Severity of pain was assessed by a $100 \mathrm{~mm}$ Visual Analogue Scale (average pain past week) [4]. The Dutch version of the Chronic Pain Self Efficacy Scale (CPSS-DLV) was used to assess self-efficacy beliefs about pain and disability. The CPSS is a valid and reliable questionnaire, and the total score ranges from 230-2300 [2]. The Pain Coping and Cognition List (PCCL) [39] is a valid and reliable screening questionnaire containing the subscales: catastrophizing, internal locus of control, external locus of control (score range 0-6). Higher scores indicate higher levels of catastrophizing and more internal or external locus of control. Mental functioning was measured as with mental health subscale of the Dutch SF-36 [1]. A higher score indicates a better mental functioning. Physical functioning was measured as: 1) patient's work status at 6 months (working/ sick leave) and 2) physical functioning was measured by the Dutch SF-36, with higher scores indicating better levels of physical functioning. For analysis mean change scores were calculated by subtracting scores at 6 months follow-up from baseline scores.

Furthermore, to measure health care utilization, patients were asked whether they still were treated for their'original' pain by a physician or therapist (no/yes) at follow up (6 months), and whether they still used medication for their pain ('no never,',yes').

\section{Statistical analysis}

Continuous variables were presented by mean (SD) and categorical variables by percentage. The differences in continuous variables were evaluated by independent-samples t-test or MannWhitney U-test if the data were clearly not-normally distributed (histograms). Differences in categorical variables were tested using Chi-square test or Fisher's exact test, where appropriate. 
To give insight in the importance of change of pain related factors and psychological variables over the follow-up period, effect size (ES) and standardized response mean (SRM) were calculated for each measure [32]. The effect size (ES) is equal to the mean change in score divided by the standard deviation of the baseline scores. The ES thus relates the change to the initial variation in scores. The SRM is equal to the mean change in score divided by the standard deviation of the change in scores. According to Cohen, [10] an ES of 0.2, 0.5 and 0.8 or above is considered, a small, medium and large effect, respectively

To examine which change (t6 minus t0) in pain related and psychological factors contribute to the long term use of TENS, a series of univariate logistic regression analysis was conducted first. Associations were expressed as odds ratios (OR) with corresponding 95\% confidence interval. Only those variables associated with outcome with a $p$ value $\leq 0.20$ were included in the multiple logistic analyses with backward method, using the likelihood ratio test $(p \leq 0.05)$. Multicollinearity was checked by correlation analysis, the variance inflation factor (VIF) and condition index (CI).

As $\geq 33 \%$ pain reduction is considered as a clinically relevant change in chronic pain [14] [18] also a subgroup analysis was performed to analyse factors associated with continuation of TENS without clinically relevant pain reduction. Data of TENS-users with pain reduction at 6 months $<33 \%$ and $\geq 33 \%$ and the group of non-users were used in this analysis. This analysis was performed to specify other factors, than pain reduction, that might be related to the use of TENS at 6 months. P-value $\leq 0.05$ is considered as statistically significant. Analyses were performed with SPSS version 16.0 for Windows.

\section{Results}

After the test periods (4 weeks in total), 100 patients of the 180 initially randomized continued to use TENS. The main reason for discontinuation of TENS at 4 weeks, according to the patient, was lack of sufficient pain reduction.

At 6 months follow up all 180 patients were send postal questionnaires. In total 151 patients returned the questionnaire of which 149 were useful for analysis. Of the 100 patients who continued to use TENS after the 4 week test period 91 returned their questionnaires. In total 75 patients still used TENS regularly and 16 patients stopped to use it. Reasons for discontinuing TENS were a) decrease of analgesic effect (10 patients (11\%)), b) development of other diseases (4 patients (3\%)) and c) pregnancy (2 patients (2\%)). Therefore data of 75 patients were analyzed as users.

Of all patients $(n=80)$ who discontinued their TENS after the four week test period, 58 returned their questionnaires at 6 months. The non-user group of total 74 subjects included 16 patients who stopped between the end of the 4 week test period and the six month follow up, together with 58 patients who discontinued their TENS after the 4 week test period. 


\section{Baseline comparison users versus non-users}

At baseline, no significant differences were found between users and non-users regarding sociodemographic variables, severity of pain, levels of control, catastrophizing, self-efficacy beliefs, mental health and physical functioning (Tables 1 and 2).

Table 1. Baseline comparison users vs. non-users for sociodemographic variables

\begin{tabular}{lccc}
\hline \multicolumn{1}{c}{ Baseline } & $\begin{array}{c}\text { Users } \\
\mathbf{n}=\mathbf{7 5}\end{array}$ & $\begin{array}{c}\text { Non-users } \\
\mathbf{n}=\mathbf{7 4}\end{array}$ & Sig \\
\hline Age, mean (SD) & $50.6(12.5)$ & $50.3(14)$ & 0.885 \\
Gender (female) & $67 \%$ & $65 \%$ & 0.817 \\
Married (yes) (\%) & $85 \%$ & $77 \%$ & 0.194 \\
Pain job (n=52) (\%) & $38 \%$ & $31 \%$ & 0.331 \\
Using pain medication (\%) & $81 \%$ & $83 \%$ & 0.606 \\
Duration complaints (months) mean (SD) & $75(95)$ & $80(100)$ & 0.771 \\
\hline
\end{tabular}


Table 2. Comparison of outcome measures at baseline and change scores at 6 months between users

\begin{tabular}{|c|c|c|c|c|c|c|c|}
\hline & $\mathbf{N}$ & $\begin{array}{c}\text { Mean } \\
\text { baseline } \\
\text { score (SD) }\end{array}$ & sig $^{\&}$ & $\begin{array}{c}\text { Mean } \\
\text { change } \\
\text { score (SD) } \\
\text { (t6-t0) }\end{array}$ & sig $^{\#}$ & ES & SRM \\
\hline \multicolumn{8}{|c|}{ Pain (100 mm VAS) } \\
\hline Users & 75 & $62(19)$ & \multirow[t]{2}{*}{0.435} & $-17(20)$ & \multirow[t]{2}{*}{$<0.001$} & 0.85 & 0.85 \\
\hline Non-users & 74 & $64(21)$ & & $-4(20)$ & & 0.20 & 0.20 \\
\hline \multicolumn{8}{|c|}{ Catastrophizing (PCCL) } \\
\hline Users & 75 & $3.5(1.0)$ & \multirow[t]{2}{*}{0.555} & $-0.5(0.9)$ & \multirow[t]{2}{*}{0.002} & 0.50 & 0.55 \\
\hline Non-users & 74 & $3.4(1.0)$ & & $-0.02(0.9)$ & & 0.02 & 0.02 \\
\hline \multicolumn{8}{|c|}{ Internal control (PCCL) } \\
\hline Users & 75 & $2.9(1.0)$ & \multirow[t]{2}{*}{0.919} & $0.5(0.8)$ & \multirow[t]{2}{*}{0.017} & 0.53 & 0.66 \\
\hline Non-users & 74 & $2.9(0.9)$ & & $0.2(0.7)$ & & 0.21 & 0.26 \\
\hline \multicolumn{8}{|c|}{ External control (PCCL) } \\
\hline Users & 75 & $3.4(1.0)$ & \multirow[t]{2}{*}{0.613} & $-0.2(0.9)$ & \multirow[t]{2}{*}{0.891} & 0.19 & 0.22 \\
\hline Non-users & 72 & $3.3(1.1)$ & & $-0.2(0.9)$ & & 0.19 & 0.22 \\
\hline \multicolumn{8}{|c|}{ Self efficacy (CPSS) } \\
\hline Users & 75 & 965 (333) & \multirow[t]{2}{*}{0.760} & $136(255)$ & \multirow[t]{2}{*}{0.004} & 0.40 & 0.51 \\
\hline Non-users & 73 & $948(345)$ & & $8(266)$ & & 0.02 & 0.03 \\
\hline \multicolumn{8}{|c|}{ Mental Health (SF-36) } \\
\hline Users & 75 & $54(19)$ & \multirow[t]{2}{*}{0.056} & $2(18)$ & \multirow[t]{2}{*}{0.558} & 0,10 & 0,11 \\
\hline Non-users & 74 & $47(20)$ & & $0(17)$ & & 0,00 & 0,00 \\
\hline \multicolumn{8}{|c|}{ Physical Functioning (SF-36) } \\
\hline Users & 75 & $34(20)$ & \multirow[t]{2}{*}{0.824} & $12(23)$ & \multirow[t]{2}{*}{0.005} & 0.60 & 0.61 \\
\hline Non-users & 74 & $35(20)$ & & $2(16)$ & & 0.10 & 0,10 \\
\hline
\end{tabular}

\&sig mean baseline comparison, " sig mean change comparison

VAS = visual analogue scale, PCCL = pain coping cognition list, CPSS=chronic pain self-efficacy scale, SF-36= short form 36. ES = effect size, SRM= standardized Response mean. Negative change scores for pain, and catastrophizing, reflects positive improvements. Negative change score for external control reflects a negative change. Positive change score on internal control, self-efficacy and physical functioning are positive improvements 


\section{Treatment effects at 6 months}

The user group had statistically significant better outcome for pain, catastrophizing beliefs, internal locus of control, self efficacy and daily physical functioning compared to non-users (Table 2). On average, the user group had a mean pain reduction of $17 \mathrm{~mm}$ (SD 20) on the VAS compared to $4 \mathrm{~mm}$ (SD 20) for the non-users (Table 2), and the ES and SRM were both large for users. Catastrophizing beliefs decreased, and feeling of internal control and self efficacy beliefs increased in user group, but the ES and SRM were small to medium for users compared to no to small effects in the non-users. Improvement in daily physical functioning was also statistically significant better in users (with medium ES and SRM) compared to non-users.

Initially, at baseline only a small portion of the patients had a paid job. In both groups patients returned to work, but more patients (statistically significant) in non-users group did. The utilization of health care was statistically significantly less for users (Table 3 ).

Table 3. Health care utilization and work status at 6 months

\begin{tabular}{lccc}
\hline & $\begin{array}{c}\text { Responders } \\
(\mathbf{n}=\mathbf{7 5})\end{array}$ & $\begin{array}{c}\text { Non-responders } \\
(\mathbf{n}=\mathbf{7 4})\end{array}$ & p-value \\
\hline Under treatment ${ }^{\text {\$ }}$ yes & 37 & 58 & \\
no & 36 & 16 & \\
Medication use yes & 33 & 55 & 0.001 \\
$\quad$ no & 42 & 19 & \\
Work status at 6 months* & $\mathrm{n}=23$ & $\mathrm{n}=17$ & 0.03 \\
yes & 8 & 14 & \\
no & 15 & 3 & \\
\hline
\end{tabular}

$\$ 2$ data missing in responders group

*at baseline 52 patients had work, at 6 months 40 patients returned questionnaires.

\section{Factors associated with long term use of TENS}

Change scores in reduction of average pain (of past 7 days), better physical functioning, decreased catastrophizing beliefs, increased feelings of internal control and self efficacy were all found to be significantly associated with long term use of TENS.

In the multiple analyses only the change in pain severity and decreased catastrophizing beliefs were independently related to use of TENS at 6 months (Table 4).

Although not measured as change factors both variables 'not currently under treatment' and 'taking less pain medication' at 6 months were also significantly associated with the use or TENS at 6 months. Significantly fewer users were currently under treatment (OR 3.5 $(95 \% \mathrm{Cl}, 1.7-7.2) \mathrm{p}<0.001)$ and took less pain medication (OR $2.3(95 \% \mathrm{Cl}, 1.1-4.5) \mathrm{p}=0.020)$ than non-users. 
Table 4. Results of univariate and multiple logistic regression analyses for long term use of TENS as outcome

\begin{tabular}{|c|c|c|c|c|c|c|c|c|}
\hline \multirow[b]{3}{*}{ Improvement pain severity (VAS) } & \multicolumn{4}{|c|}{$\begin{array}{l}\text { Univariate } \\
\text { Regression }\end{array}$} & \multicolumn{4}{|c|}{$\begin{array}{c}\text { Multiple } \\
\text { Regression }\end{array}$} \\
\hline & \multirow{2}{*}{$\begin{array}{l}\operatorname{Exp}(\mathrm{B}) \\
1.032\end{array}$} & \multicolumn{2}{|c|}{$\begin{array}{c}95 \% \mathrm{Cl} \\
\text { lower upper }\end{array}$} & \multirow{2}{*}{$\begin{aligned} & \text { Sig } \\
&<0.001\end{aligned}$} & \multirow{2}{*}{$\begin{array}{l}\operatorname{Exp}(B) \\
1.027\end{array}$} & \multicolumn{2}{|c|}{$\begin{array}{c}95 \% \mathrm{Cl} \\
\text { lower upper }\end{array}$} & \multirow{2}{*}{$\begin{array}{c}\text { Sig } \\
0.004\end{array}$} \\
\hline & & 1.014 & 1.051 & & & 1.008 & 1.045 & \\
\hline Less catastrophizing (PCCL) & 1.824 & 1.213 & 2.473 & 0.004 & 1.540 & 1.008 & 2.352 & 0.046 \\
\hline $\begin{array}{l}\text { Higher internal locus } \\
\text { of control }(\mathrm{PCCL})\end{array}$ & 1.730 & 1.088 & 2.750 & 0.021 & & & & \\
\hline $\begin{array}{l}\text { Lower external locus } \\
\text { of control (PCCL) }\end{array}$ & 0.976 & 0.694 & 1.373 & 0.890 & & & & \\
\hline Higher self efficacy beliefs (CPSS) & 1.002 & 1.001 & 1.003 & 0.006 & & & & \\
\hline $\begin{array}{l}\text { Improvement physical } \\
\text { functioning (SF36) }\end{array}$ & 1.024 & 1.006 & 1.042 & 0.008 & & & & \\
\hline Improvement mental health (SF36) & 1.006 & 0.987 & 1.024 & 0.555 & & & & \\
\hline
\end{tabular}

$\mathrm{VAS}=$ visual analogue scale (average pain /week), $\mathrm{PCCL}=$ pain coping cognition list, CPSS=chronic pain self efficacy scale, SF-36=short form 36.

\section{Subgroup analysis: users with pain reduction $\geq 33 \%$ vs. users $<33 \%$ pain reduction vs. non-users}

Of all 75 users at 6 months, 38 patients (51\%) had a pain reduction $\geq 33 \%$. The users with $\geq 33 \%$ pain reduction had significantly better outcome for catastrophizing beliefs, internal locus of control, self efficacy and mental health, compared to users with $<33 \%$ pain reduction and non-users (Table 5). Only change in daily physical functioning and external locus of control was not significantly changed between the three groups (table 5). Although most change scores were in favor of users $<33 \%$, no statistical significant different change scores on all measurements were found between non-users and users $<33 \%$. Also fewer patients still received treatment (69\% vs. $78 \% ; p=0.268$ ) and used pain medication ( $67 \%$ vs. $74 \% ; p=0.454$ ) at 6 months in users $<33 \%$ compared to non-users, but these differences were not statistically different. 
Table 5. Comparison mean change scores (t6-t0) between users $\geq 33 \%$ pain reduction, users with pain reduction $<33 \%$ and non-users

\begin{tabular}{|c|c|c|c|c|c|c|}
\hline Change score t6-t0 & $\begin{array}{c}\text { p- value } \\
\text { group1 } \\
\text { vs. } \\
\text { group } 3\end{array}$ & $\begin{array}{c}\text { Group } 1 \\
\text { ( } \geq 33 \%) \\
\text { Mean } \\
\text { change } \\
\text { (SD) } \\
n=38\end{array}$ & $\begin{array}{c}\text { p-value } \\
\text { group } 1 \\
\text { vs. } \\
\text { group } 2\end{array}$ & $\begin{array}{c}\text { Group } 2 \\
(<33 \%) \\
\text { Mean } \\
\text { change } \\
(\mathrm{SD}) \\
\mathrm{n}=37\end{array}$ & $\begin{array}{c}\text { p-value } \\
\text { group } 2 \\
\text { vs. } \\
\text { group3 }\end{array}$ & $\begin{array}{c}\text { Group } 3 \\
\text { non-users } \\
\text { Mean } \\
\text { change } \\
\text { (SD) } \\
\mathrm{n}=74\end{array}$ \\
\hline Pain (100 mm VAS) & $<0.001$ & $-32(14)$ & $<0.001$ & $-1.5(11)$ & 0.445 & $-4.3(20)$ \\
\hline Catastrophizing\& & $<0.001$ & $-0.72(0.8)$ & 0.039 & $-0.21(0.8)$ & 0.284 & $-0.01(0.9)$ \\
\hline Internal locus of control\& & 0.001 & $0.66(0.8)$ & 0.040 & $0.24(0.7)$ & 0.572 & $0.16(0.7)$ \\
\hline External locus of control ${ }^{\&}$ & 0.182 & $-0.48(1.1)$ & 0.078 & $0.00(0.8)$ & 0.202 & $-0.02(0.9)$ \\
\hline Self-efficacy (CPSS) & $<0.001$ & $217(276)$ & 0.020 & $53(204)$ & 0.378 & $8(266)$ \\
\hline $\begin{array}{l}\text { SF-36- physical functio- } \\
\text { ning }\end{array}$ & 0.002 & $16.9(29)$ & 0.148 & $7(15)$ & 0.141 & $2.3(16)$ \\
\hline SF36-mental health & 0.030 & 7.7 (19) & 0.008 & $4(16)$ & 0.181 & $0(17)$ \\
\hline
\end{tabular}

VAS = visual analogue scale Negative change scores for pain, and catastrophizing, reflects positive improvements. Negative change score for external control reflects a negative change. Positive change score on internal control, self-efficacy and physical functioning are positive improvements. Pain 100mm VAS $=$ (average pain /week, \&= measured with PCCL= pain coping cognition list, CPSS=chronic pain self efficacy scale, SF-36 = short form 36.

\section{Discussion}

This is the first prospective study that explored what factors are associated with the continuation of TENS at 6 months in chronic pain patients. In this study, we found that a decrease in catastrophizing thoughts is an independent factor related to using TENS at 6 months ('users'), together with reduction in pain severity. The continuation of TENS on long term was also associated with higher levels of self-efficacy, higher levels of internal locus of control, better daily functioning and less health care utilization (no current treatment and less analgesic intake). TENS therefore seems to have clinically relevant effects in other domains besides pain reduction.

\section{Pain relief}

As expected, pain relief was significantly and independently associated with the continuation of TENS after 6 months. The reduction in severity of pain was on average $28 \%$ in the user group The ES and SRM of average pain were both large indicating also a relevant clinical effect. The results of the pain reduction indicates also that nearly half the patients had levels 
of pain reduction $<33 \%$, but still used TENS. In this group, about $23 \%$ of the patients had a change score between baseline and 6 months follow-up that indicated no pain reduction at all. Similar, Johnson et al. [19] reported that 14\% of their patients also continued TENS without pain reduction at 3 months follow up. Reasons for continuation of TENS despite minor pain relief remain unclear. Maybe some patients find less than 33\% pain reduction still clinically relevant or at least sufficient for themselves to continue TENS. Another reason for continuation of TENS could be the reduction of analgesic consumption in users. Additionally, users $<33 \%$ in our study had a positive effect on the consumption of analgesics (although not statistically significant). Apparently, patients who use TENS on long term need less pain medication or other treatments to control their pain. It seems that TENS can be seen or is used by patients as a substitute for other analgesics. This is confirmed by a result from a meta-analysis [3] in which was found that TENS significantly reduced analgesic consumption for postoperative pain. Our assessment and evaluation of pain medication and treatment was, however, very general. No evaluation on type and dosage of medication/treatment was done. As fewer patients in the users group were under treatment, this might also reflect sufficient pain relief by TENS. At last, patient satisfaction with treatment does not always correlates with sufficient pain relief. Patients tend to be satisfied with treatment even when pain is not relieved [26].

\section{Reduced pain catastrophizing}

This is the first study showing that pain catastrophizing decreased with TENS use on long term. The effect sizes found in this study are comparable to other reports of change in pain catastrophizing due to physical training or psychological treatment [29; 37]. Pain catastrophizing is conceptualized as a negative cognitive-affective response to anticipated or actual pain [34]. Pain catastrophizing is characterized by the tendency to magnify the threat value of pain stimulus and to feel helpless in the context of pain. Whether this decrease in pain catastrophizing is caused directly by TENS is unknown. We therefore can only discus some possible speculative explanations. A first explanation might be a reduction of feelings of helplessness. Reducing feelings of helplessness are associated with successful pain management $[11 ; 34]$. The fact that TENS is a self-administered treatment and patients can use their TENS devices throughout the day in different circumstances might contribute to lesser feelings of helplessness. The decreased health care utilization in users could also the result of less helplessness due to reduction in pain catastrophizing. More pain catastrophizing is associated with more visits to health care professionals $[12 ; 40]$.

Reductions in pain catastrophizing by treatment are also associated with improvements in pain related activity interference and disability [6; 34] Therefore a second explanation could be that the improvement of physical functioning could lead to increased confidence in one's body which lead to a change in pain catastrophizing beliefs. 


\section{Physical functioning}

An important finding was the increased level of physical functioning in the users group. This effect might be mediated through pain reduction, as severity of pain is associated with experienced disability [24]. However, also changes in pain catastrophizing have been found as mediator for improvements in physical functioning [6; 34; 37]. Additionally, higher perceived control and self efficacy beliefs are associated with functional disability [40]. Therefore, improvement in physical functioning can be due to a combination of pain reduction, less catastrophizing and higher levels of control and self efficacy. However, in the multiple analyses, increased physical functioning did not remain in the model as an independent factor. According to meta-analysis, there is limited evidence to support effectiveness of TENS in improving physical function in patients with knee pain [33; 35]. A randomized trial also reported improvement of physical functioning by TENS in patients with chronic neck pain [9].

Return to work rate in responders was lower than in nonusers, which appears contradictory to increased level of physical activities in general. Return to work, however, depends on different non-medical variables, such as social security law, work satisfaction and support, which are unlikely to be influenced directly by TENS.

\section{Comparison with other studies on secondary outcomes}

The results of our study are comparable to other studies that addressed the long term effect of TENS on other outcome variables besides pain reduction $[5 ; 8 ; 13 ; 15-16 ; 30 ; 38 ; 43]$

Seven out of 8 studies reported a reduction in pain medication intake. An increase in physical activity was reported in 3 studies. However, most of these studies collected data retrospectively, didn't select patients at random patient, used no control group and/or the control group was not comparable at baseline, which seriously limits generalization of the results of these studies.

\section{Limitations of the study}

In our study we used data form a randomized observer-blinded trial. The analyses, however, were not based on originally randomized groups, because no differences in pain reducing effect were found in a previous study between three types of TENS [22]. No analysis based on type of TENS were not performed, as patients reported equal benefits of all types of TENS they used during the four week test-period and continued to use these types during the follow up period. Since baseline comparisons showed no significant differences between the groups (users vs. non-users), data were collected prospective, and researchers were blinded in outcome evaluation, it is unlikely that this has led to biased results. 


\section{Clinical implications}

The pain reducing effect of TENS in this study (average 28\%) might not be higher as other pain treatments, but it seems that some patients prefer TENS over other forms of treatment. The results implicate that TENS can be used as a substitute for pain medication, especially in patients with adverse effects due to medication. On the other hand, TENS might be combined with other pain treatment which can result in higher effectiveness overall. In animal studies, the effectiveness of combined TENS- morphine treatment resulted in better results [36]. As TENS has effects in the field of pain related cognitions and pain related disability, it can also be considered as an adjunct treatment to cognitive-behavioral approaches to teach patients to cope with pain.

\section{Conclusion}

The most important finding is that catastrophizing beliefs decreased in patients using TENS on long term. This was independently associated with continuation of TENS, together with pain relief. We further conclude that continued use of TENS had a large effect on pain relief, medium effects on physical functioning, catastrophizing and self-efficacy beliefs and small effects on internal feelings of control. TENS also reduces healthcare utilization and medication use, but doesn't significantly influence the proportion of patients resuming work. The effect on several domains might explain why some patients still use TENS, even as pain relief is minimal or absent. Further research is warranted to explain these finding in more detail. 


\section{References}

[1] Aaronson NK, Muller M, Cohen PD, Essink-Bot ML, Fekkes M, Sanderman R, Sprangers MA, te Velde A, Verrips E. Translation, validation, and norming of the Dutch language version of the SF-36 Health Survey in community and chronic disease populations. J Clin Epidemiol 1998;51(11):1055-1068

[2] Anderson KO, Dowds BN, Pelletz RE, Edwards WT, Peeters-Asdourian C. Development and initial validation of a scale to measure self-efficacy beliefs in patients with chronic pain. Pain 1995;63(1):77-84

[3] Bjordal JM, Johnson MI, Ljunggreen AE. Transcutaneous electrical nerve stimulation (TENS) can reduce postoperative analgesic consumption. A meta-analysis with assessment of optimal treatment parameters for postoperative pain. Eur J Pain 2003;7(2):181-188

[4] Bolton JE. Accuracy of recall of usual pain intensity in back pain patients. Pain 1999;83(3):533-539

[5] Bremerich A, Gellrich NC, Krischek-Bremerich P. [TENS in the face and neck areas. Transcutaneous electric nerve stimulation (TENS) in the therapy of chronic pain in the face and neck areas]. Schweiz Monatsschr Zahnmed 1995;105(9):1174-1179

[6] Burns JW, Kubilus A, Bruehl S, Harden RN, Lofland K. Do changes in cognitive factors influence outcome following multidisciplinary treatment for chronic pain? A cross-lagged panel analysis. J Consult Clin Psychol 2003;71(1):81-91

[7] Caroll D, Moore RA, McQuay HJ, Fairman F, Tramer M, Leijon G. Transcutaneous electrical nerve stimulation (TENS) for chronic pain (Cochrane review). The Cochrane Library 2002(4)

[8] Chabal C, Fishbain DA, Weaver M, Heine LW. Long-term transcutaneous electrical nerve stimulation (TENS) use: impact on medication utilization and physical therapy costs. Clin J Pain 1998;14(1):66-73

[9] Chiu TTW, Hui-Chan CWY, Cheing G. A randomized trial of TENS and exercise for patients with chronic neck pain. Clinical Rehabilitation 2005;19:850-860

[10] Cohen J. Statistical power analysis for the behavorial sciences (2nd ed.). Hillsdale: Lawrence Earkbaum Associates, 1988

[11] Coughlin AM, Badura AS, Fleischer TD, Guck TP. Multidisciplinary treatment of chronic pain patients: its efficacy in changing patient locus of control. Arch Phys Med Rehabil 2000;81(6):739-740

[12] Edwards RR, Bingham CO, 3rd, Bathon J, Haythornthwaite JA. Catastrophizing and pain in arthritis, fibromyalgia, and other rheumatic diseases. Arthritis Rheum 2006;55(2):325-332

[13] Eriksson MB, Sjolund BH, Nielzen S. Long term results of peripheral conditioning stimulation as an analgesic measure in chronic pain. Pain 1979;6(3):335-347

[14] Farrar JT, Young JP, Jr., LaMoreaux L, Werth JL, Poole RM. Clinical importance of changes in chronic pain intensity measured on an 11-point numerical pain rating scale. Pain 2001;94(2):149-158

[15] Fishbain DA, Chabal C, Abbott A, Heine LW, Cutler R. Transcutaneous electrical nerve stimulation (TENS) treatment outcome in long-term users. Clin J Pain 1996;12(3):201-214

[16] Fried T, Johnson R, McCracken W. Transcutaneous electrical nerve stimulation: its role in the control of chronic pain. Arch Phys Med Rehabil 1984;65(5):228-231

[17] Gatchel RJ, Peng YB, Peters ML, Fuchs PN, Turk DC. The biopsychosocial approach to chronic pain: scientific advances and future directions. Psychol Bull 2007;133(4):581-624 
[18] Jensen MP, Chen C, Brugger AM. Interpretation of visual analog scale ratings and change scores: a reanalysis of two clinical trials of postoperative pain. J Pain 2003:4(7):407-414

[19] Johnson MI, Ashton CH, Thompson JW. An in-depth study of long-term users of transcutaneous electrical nerve stimulation (TENS). Implications for clinical use of TENS. Pain 1991;44(3):221-229

[20] Johnson MI, Ashton CH, Thompson JW. Long term use of transcutaneous electrical nerve stimulation at Newcastle Pain Relief Clinic. J R Soc Med 1992;85(5):267-268

[21] Khadilkar A, Milne S, Brosseau L, Robinson V, Saginur M, Shea B, Tugwell P, Wells G. Transcutaneous electrical nerev stimulation (TENS) for chronic low back pain ( Cohrane review). Cochrane Database Syst Rev 2006;3

[22] Koke AJ, Schouten JS, Lamerichs-Geelen MJ, Lipsch JS, Waltje EM, van Kleef M, Patijn J. Pain reducing effect of three types of transcutaneous electrical nerve stimulation in patients with chronic pain: a randomized crossover trial. Pain 2004;108(1-2):36-42

[23] Lampl C, Kreczi T, Klingler D. Transcutaneous electrical nerve stimulation in the treatment of chronic pain: predictive factors and evaluation of the method. Clin J Pain 1998;14(2):134-142

[24] Leeuw M, Goossens ME, Linton SJ, Crombez G, Boersma K, Vlaeyen JW. The fear-avoidance model of musculoskeletal pain: current state of scientific evidence. J Behav Med 2007;30(1):77-94

[25] Long DM. The current status of electrical stimulation of the nervous system for the relief of chronic pain. Surg Neurol 1998;49(2):142-144

[26] Marnie, Morabia A, Bernstein M, Klopfenstein CE, Forster A. Treatment efficacy is not an index of pain intensity. Can J Anaest 2000;47(12):1166-1170

[27] McCracken LM, Turk DC. Behavioral and cognitive-behavioral treatment for chronic pain: outcome, predictors of outcome, and treatment process. Spine (Phila Pa 1976) 2002;27(22):2564-2573

[28] Meyler WJ, de Jongste MJ, Rolf CA. Clinical evaluation of pain treatment with electrostimulation: a study on TENS in patients with different pain syndromes. Clin J Pain 1994;10(1):22-27

[29] Morley S, Eccleston C, Williams A. Systematic review and meta-analysis of randomized controlled trials of cognitive behaviour therapy and behaviour therapy for chronic pain in adults, excluding headache. Pain 1999;80(1-2):1-13

[30] Nathan PW, Wall PD. Treatment of post-herpetic neuralgia by prolonged electric stimulation. Br Med J 1974;3(5932):645-647

[31] Nnoaham KE, Kumbang J. Transcutaneous electrical nerve stimulation (TENS) for chronic pain. Cochrane Database Syst Rev 2008(3):CD003222

[32] Norman GR, Wyrwich KW, Patrick DL. The mathematical relationship among different forms of responsiveness coefficients. Qual Life Res 2007;16(5):815-822

[33] Philadelphia Panel. Evidence-based clinical practice guidelines on selected rehabilitation interventions for knee pain. Phys Ther 2001;81:1675-1700

[34] Quartana PJ, Campbell CM, Edwards RR. Pain catastrophizing: a critical review. Expert Rev Neurother 2009;9(5):745-758

[35] Rutjes AW, Nuesch E, Sterchi R, Kalichman L, Hendriks E, Osiri M, Brosseau L, Reichenbach S, Juni P. Transcutaneous electrostimulation for osteoarthritis of the knee. Cochrane Database Syst Rev 2009(4):CD002823 
[36] Sluka KA. Systemic morphine in combination with TENS produces an increased antihyperalgesia in rats with acute inflammation. J Pain 2000;1(3):204-211

[37] Smeets RJ, Vlaeyen JW, Kester AD, Knottnerus JA. Reduction of pain catastrophizing mediates the outcome of both physical and cognitive-behavioral treatment in chronic low back pain. J Pain 2006;7(4):261-271

[38] Sternbach RA, Ignelzi RJ, Deems LM, Timmermans G. Transcutaneous electrical analgesia: a follow-up analysis. Pain 1976;2(1):35-41

[39] Stomp GM, Vlaeyen JW, Kuile ter MM, Spinhoven P, Breukelen van G, Kole-Snijders AM. Pijn Coping en Cognitie Lijst (PCCL). Maastricht: Pijn Kennis Centrum, 2001

[40] Sullivan MJ, Thorn B, Haythornthwaite JA, Keefe F, Martin M, Bradley LA, Lefebvre JC. Theoretical perspectives on the relation between catastrophizing and pain. Clin J Pain 2001;17(1):52-64

[41] Turner JA, Holtzman S, Mancl L. Mediators, moderators, and predictors of therapeutic change in cognitive-behavioral therapy for chronic pain. Pain 2007;127(3):276-286

[42] Verdouw BC, Zuurmond WWA, deLange JJ, Metz GCH, Wagemans MFM. Long-term use and effectiveness of transcutaneous electrical nerve stimulation in treatment of chronic pain patients. Pain Clinic 1996;8(4):341-346

[43] Vielvoye-Kerkmeer APE, Ruigrok NJF, van der Kaaden MN. Transcutaneous electrical nerve stimulation (TENS). Pain 1987:S369 


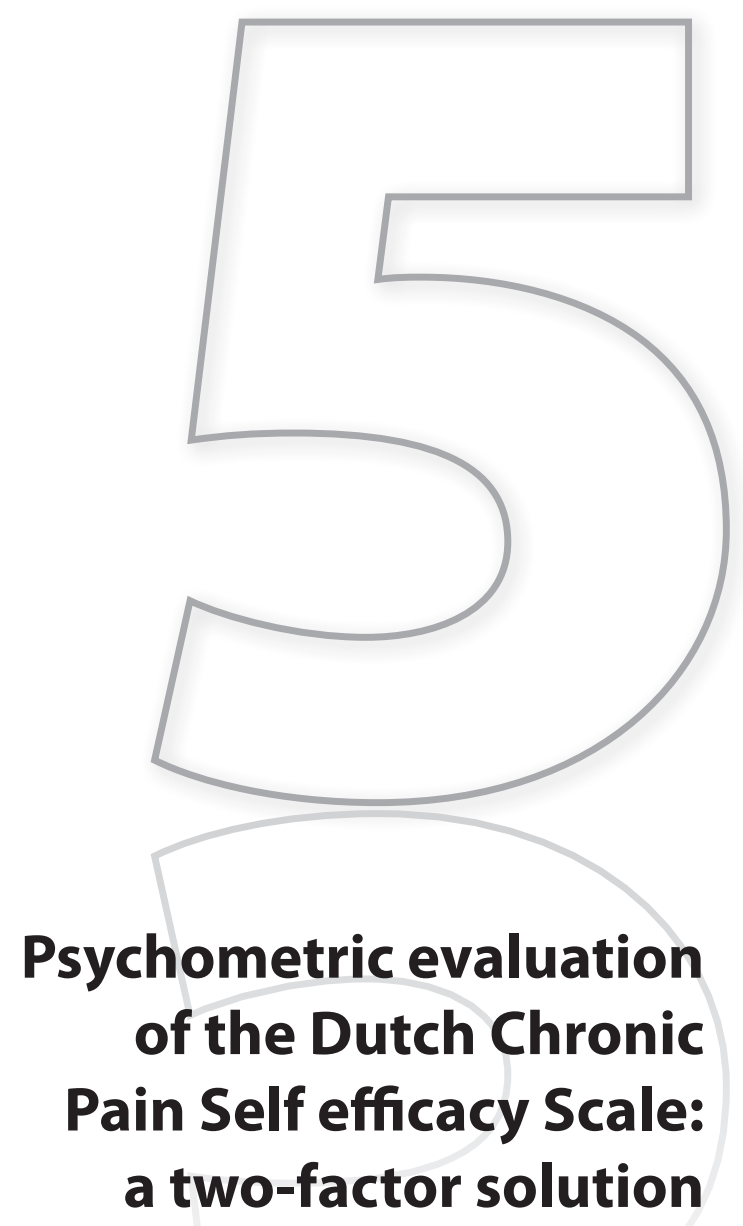

Albère J. Köke ${ }^{a, b, d,}$, Jeffrey Roelofs ${ }^{c}$, Rob E.M. Smeets ${ }^{b, d}$,
Roberto.S. Perez ${ }^{\mathrm{e}}$, Maarten Kleef van ${ }^{a}$, Jacob Patijn

aPain Management and Research Centre, University Medical Centre Maastricht

${ }^{\text {b} A d e l a n t e ~ C e n t r e ~ o f ~ E x p e r t i s e ~ i n ~ R e h a b i l i t a t i o n, ~ H o e n s b r o e k ~}$

${ }^{\circ}$ Clinical Psychological Science, Maastricht University

dDepartment of rehabilitation medicine, Research School of CAPHRI, Maastricht University

e Department of Anaesthesiology, VU University Medical Centre and the Institute for Research in Extramural Medicine, Amsterdam, the Netherlands 


\section{Abstract}

Background. The Chronic Pain Self Efficacy Scale (CPSS) has been developed to measure self-efficacy beliefs in patients with chronic pain. This paper reports the results of a study evaluating various psychometric properties of the Dutchlanguage version of the CPSS (CPSS-DLV).

Methods. The original CPSS was first translated into a Dutch language version. Then factor structure, test-retest stability and concurrent validity of the CPSS-DLV were tested in a sample of 231 patients with mixed chronic pain conditions.

Results. The result was a two-factor model of the CPSS-DLV, consisting of a pain self-efficacy subscale (PSE-DLV) and a functional self-efficacy subscale (FSE-DLV). Two of 22 items from the original CPSS were removed from the scale as a result of marked cross loadings. Good test-retest stability for FSE-DLV (ICC = .88 (95\% Cl, .84-.92) and for PSE-DLV (ICC = .87 $(95 \% \mathrm{Cl}, .82-.90)$ and Cronbach's alpha were found (.91 for FSEDLV and .88 for PSE-DLV). For evaluative purposes, the Smallest Detectable Change (SDC) was calculated, with the SDC for FSE-DLV being 20 points and for PSE-DLV 17 points.

Conclusion. The CPSS-DLV consists of two scales which have been shown to be reliable and valid indices of specific selfefficacy beliefs in patients with multiple pain conditions. 


\section{Introduction}

Self-efficacy is considered to be one of the most important variables in understanding how patients adjust to pain [21]. Self-efficacy refers to the belief that required behaviours can be successfully performed in given situations or domains [6].People with stronger self efficacy beliefs are thought to be more determined and persistent in performing certain behaviours. General trait-like self-efficacy beliefs and domain-specific self-efficacy beliefs have been studied [9; 32]. Two specific domains of self-efficacy have been examined in patients with chronic pain: beliefs related to the (self) management of pain $[8 ; 26-30 ; 35]$ and beliefs related to daily physical functioning or performing tasks [3-5; 12; 16-18; 24-25].

Self-efficacy enhancing interventions are promising for reducing chronic disability and pain [33-34]. However, reducing pain does not always result in improvement of daily physical functioning. Therefore, psychometrically-sound instruments of self-efficacy beliefs are warranted for dealing separately with pain complaints and daily physical functioning, since most psychological and/or rehabilitation treatments of chronic pain are aimed at improving daily functioning without specific emphasis on reducing pain.

Several self-efficacy scales have been proposed in the literature. Some of these have been developed for specific pain diagnoses [25; 31] or have combined self-efficacy beliefs on pain with disability [36]. The Chronic Pain Self-efficacy Scale (CPSS) [2] was developed to measure domain-specific self-efficacy beliefs in a heterogeneous group of chronic pain patients. The CPSS was originally based on the Arthritis Self Efficacy Scale (ASE) [31] and consists of 22 items that assess self-efficacy beliefs on control over pain and disability, and which were originally subdivided in three domains: pain management self-efficacy (PSE: five items), coping with symptoms self-efficacy (CSE: eight items), and physical function self-efficacy (FSE: nine items). Respondents are asked to indicate how certain they are that they are able to carry out a specific activity or to achieve a specific outcome on a ten-point scale, ranging from very uncertain (10) to very certain (100). Anderson [2] found adequate internal consistency for the three subscales, as well as sufficient support for the concurrent and construct validity.

The purpose of the current study was to examine the psychometric properties of a Dutch version of the CPSS. More specifically, the three-factor model of the CPSS was tested by means of confirmatory factor analysis, reliability in terms of internal consistency, and testretest stability. The Smallest Detectable Change (SDC) was examined, and, finally, concurrent criterion validity was assessed.

\section{Methods}

A total of 231 patients (147 females and 84 males, mean age 49 years (SD \pm 11$)$ ) were included in the present study. All patients were recruited from the pain clinic of the University Hospital of Maastricht. Data were used from 165 patients (107 females and 58 males, mean 
age 50 years (SD \pm 13$)$ ) who participated in a study on the effectiveness of TENS treatment between April 2000 and March 2001 (details study design see [23]). In order to obtain a sufficiently large sample size for the purposes of factor analysis, a further 66 patients ( 40 females and 24 males, mean age 48 years $(S D \pm 12)$ ) referred to the pain clinic were also included (using the same inclusion criteria as those for the TENS study), who completed the CPSSDLV during their first visit between October 2006 and January 2007. For the analysis of testretest stability and concurrent validity only data of 165 patients participating in the TENS-trial were used. No statistical differences according to sex, age, pain diagnosis and pain duration were found between sample $(n=165)$ from the TENS-study and second sample $(n=66)$. The total sample comprised a mixed group of chronic pain patients suffering from chronic low back pain $(n=53)$, chronic widespread pain $(n=29)$, CRPS type $1(n=18)$, headache $(n=18)$, failed back surgery syndrome $(n=21)$, neuropathic pain $(n=29)$, thoracic $(n=22)$ and cervical pain $(n=24)$, and miscellaneous complaints of pain $(n=17)$. Median duration of pain was 36 months in all patients (inter-quartile range; IQR: $25 \rightarrow 18$ months, IQR: $75 \rightarrow 96$ months).

\section{Procedure}

The original CPSS was translated into Dutch by two independent Dutch native speakers. A translation back into English was carried out by an English native speaker, and checked against the original for inconsistencies (AJK). The psychometric properties of the CPSSDLV, other than the factor structure, were examined in patients participating in a study that examined the effectiveness of TENS [23]. In that study, the CPSS-DLV was measured before and after a two-week test treatment period with TENS. The research protocol was approved by a local IRB.

\section{Statistical analysis}

The distribution of individual items was checked prior to conducting any further analysis. Skewness and kurtosis of all items were within the acceptable range of -1 to +1 . Confirmatory factor analysis was conducted by means of LISREL (version 8.30). The fit of the previouslyreported three-factor model of the CPSS was examined, as well as that of a one-factor model, since total scores are often reported on the CPSS. The maximum-likelihood algorithm was used to assess the fit of the models. The models were estimated while allowing the latent variables to be intercorrelated (only applicable to the three-factor model). Each item was forced to load on their corresponding factor only, and residuals for each item were assumed to be uncorrelated. The goodness-of-fit of the models was evaluated by means of several descriptive criteria, as follows: (a) the Root Mean-Square Error of Approximation (RMSEA); (b) the Non-Normed Fit Index (NNFI); (c) the Comparative Fit Index (CFI); (d) the Goodness of Fit Index (GFI); and (e) the Expected Cross-Validation Index (ECVI). The RMSEA quantifies the divergence between the data and a proposed model per degree of freedom. Values below 
.05 indicate a close fit, whereas values of up to .08 represent reasonable errors of approximation. A 90\% confidence interval for the RMSEA point estimate is also provided. The NNFI, CFI, and GFI indices measure how much better the model fits compared to a baseline model, in which the observed variables (items) are assumed to be uncorrelated (i.e., the independence model). Values above .90 are considered to be indicative of an adequate fit, whereas values above .95 are indicative of a very good fit [22]. The ECVI is a relative measure used to compare competing models: the model with the lowest value has the best fit. As the one-factor model and three-factor models are nested, the fit of both models can be compared by means of a likelihood ratio test. In the case that the confirmatory factor analysis does not provide support for a three-factor model, an explanatory factor analysis will be conducted to examine the underlying factor structure.

With respect to the reliability of the obtained CPSS-DLV scales, at the end of the two-week test period with TENS, patients evaluated the effects of treatment on a six-point scale (global perceive effect) from 1 (completely improved) to 6 (a lot worse). For analysis of test-retest stability of the CPSS patients who scored 'a little improved', unchanged' and 'a little worse' on the global perceived effect scale were categorised as 'stable' $(n=51)$. Test-retest analysis was only applied to the stable group, for which IntraClass Correlation Coefficients (ICC) were computed. Since the CPSS-DLV is used for evaluation purposes, the smallest detectable change (SDC) was calculated. The SDC expresses measurement error in the same units as those of the original measurement. More specifically, the SDC was calculated as $1.96 * \sqrt{2} *$ standard error of measurements (SEM). The SEM was calculated as $\sqrt{ }\left(\sigma^{2}+\sigma^{2}\right.$ residual) which is based on variance between measures to account for systematic error between measurement, and residual variance corresponding with the interaction between subjects and measurements [15]. Finally, Cronbach's alpha was calculated in order to obtain the internal consistency of the obtained scales of the CPSS-DLV. A Cronbach's alpha $>0.70$ is considered to be acceptable [20].

Concurrent criterion validity was only analysed in patients who participated in the TENSstudy ( $n=165$ ). We hypothesised that higher levels of self-efficacy beliefs are associated with:

- lower scores on severity of pain, catastrophizing, external locus of control

— higher scores on internal locus of control and physical functioning.

To investigate the concurrent criterion validity of the CPSS-DLV we measured at baseline:

Severity of pain (during the preceding week) was measured on a 100-mm visual analogue scale [7]. Pain catastrophizing, health related external and internal control was measured by the Pain Coping and Cognition List (PCCL) [40]. Catastrophizing contains negative thoughts about the catastrophic consequences of pain, as well as thoughts about helplessness. High catastrophizing is associated with higher disability and pain intensity [38-39; 41]. Health related locus of control reflects a person's belief about being responsible for his own health in general. Internal locus of control reflects positive expectancies about personal control of pain, while external locus of control reflects expectancies about control of pain by change or 
by powerful others ( for example a medical specialist) [13]. Physical Functioning was measures using the physical functioning subscale of the Dutch SF36 [1]. Differences in associations between the CPSS-DLV subscales and the above-mentioned questionnaires will be reported in case they should prove to be statistically significant (as tested by means of z-tests) [10]. Only correlations of .40 and above were considered relevant for supporting criterion validity [36].

\section{Results}

\section{Confirmatory factor analysis}

Table 1 presents the goodness-of-fit indices for the one-factor and three-factor models of the CPSS-DLV. As can be seen, the fit indices (i.e., RMSEA, NNFI, CFI, and GFI) showed that both models fitted poorly with the data. Although the ECVI indicated that the three-factor model had the best fit of the two models, which was supported by the likelihood ratio test $\left(\Delta \mathrm{x}_{(3)}^{2}=234, \mathrm{p}<.001\right)$, it can be concluded that the results of the confirmatory factor analysis do not support a three-factor model of the CPSS-DLV.

Table 1. Goodness-of-fit indices for the one-factor and three-factor model of the CPSS-DLV as obtained by means of confirmatory factor analysis $(n=231)$

\begin{tabular}{lccccc}
\hline & RMSEA (90\% Cl) & NNFI & CFI & GFI & ECVI \\
\hline CPSS one-factor model & $.15(.14-.16)$ & .74 & .76 & .67 & 5.81 \\
CPSS three-factor model & $.12(.11-.13)$ & .81 & .83 & .74 & 4.22 \\
\hline
\end{tabular}

RMSEA = Root Mean-Square Errors of Approximation; NNFI=Non-Normed Fit Index; CFI=Comparative Fit Index; GFI= Goodness of Fit Index; ECVI= Expected Cross-Validation Index.

\section{Exploratory factor analysis}

The next step in examining the factor structure of the CPSS-DLV was to conduct an exploratory factor analysis. CPSS-DLV data were subjected to principal components analysis with oblimin rotation (i.e., allowing the factors obtained to be intercorrelated). By applying the criteria of Comrey and Lee [11] factor loadings of .32 and above can be interpreted. Parallel analysis was used to determine the number of factors to be retained [44]. O'Connor's parallel analysis programme [37] was used for this purpose. Parallel analysis generates eigenvalues from a random dataset. These random eigenvalues are then compared to the eigenvalues obtained with the factor analysis. The number of factors to be retained is equal to the number of eigenvalues derived from principal components analysis that are larger than the random eigenvalues ( $95^{\text {th }}$ percentile). 
The first three randomly generated eigenvalues ( $95^{\text {th }}$ percentile) produced by parallel analysis were 1.70, 1.56, and 1.48. The first three eigenvalues of the factor analysis were 10.64, 1.70, and 1.25 , indicating that two factors should be retained. Table 2 presents the factor loadings of each item on the factors. Communalities ranged from .23 to .76. The factors accounted for 48.4 and $7.7 \%$ of the total variance. All items had meaningful loadings on their corresponding factor, except for items 15 and 16, which loaded substantially on both factors. Item 15 ("how certain are you that you can control your fatigue?") contains a question on a physical symptom (fatigue) which can also be related to disability, as does item 16 ("how certain are you that you can regulate your activity so as to be active without aggravating your physical symptoms?") (e.g., fatigue, pain). Based on the content of these items, it is logical that they would not be part of the two-factor structure. In summary, we found a two-factor solution for the CPSS-DLV, both consisting of ten items.

Table 2. Factor loadings of the CRSS as obtained by means of exploratory factor analysis $(n=231)$

\begin{tabular}{cccc}
\hline Item & Item description & Factor $\mathbf{1}$ & Factor $\mathbf{2}$ \\
\hline 9 & FSE & .89 & -.02 \\
10 & FSE & .88 & -.01 \\
7 & FSE & .85 & -.14 \\
2 & PSE & .72 & .15 \\
14 & FSE & .69 & -.13 \\
13 & FSE & .69 & .18 \\
8 & FSE & .69 & .10 \\
11 & FSE & .69 & .23 \\
12 & FSE & .68 & .16 \\
6 & FSE & .60 & .13 \\
15 & CSE & .37 & .35 \\
4 & PSE & -.19 & .80 \\
21 & CSE & -.01 & .77 \\
22 & CSE & -.01 & .72 \\
20 & CSE & .14 & .71 \\
17 & CSE & .19 & .68 \\
5 & PSE & -.04 & .65 \\
18 & CSE & .34 & .59 \\
19 & CSE & .22 & .59 \\
1 & PSE & .19 & .51 \\
16 & CSE & .41 & .45 \\
3 & PSE & .04 & .45 \\
\hline
\end{tabular}

FSE $=$ functional self efficacy, $P S E=$ pain self efficacy, CSE= complaints/symptoms self efficacy 
The first factor (FSE-DLV) consisted of items reflecting disability-related self-efficacy beliefs compared to FSE, as found by Anderson et al. [2], while the second factor (PSE-DLV) comprised items indicative of pain-related self-efficacy beliefs which contained items of both PSE/CSE of the original CPSS. Table 3 presents descriptive information on the CPSS-DLV scales and the other self-report instruments used in the current study. Two points should be made. Firstly, there were no sex differences in the scales. The correlation between the subscales of the CPSS-DLV was high (.70), which brings into question the usefulness of both subscales. We therefore calculated the correlation corrected for attenuation (i.e., unreliability), which yielded a correlation of .78. Since this correlation does not approach the value 1, it can be concluded that both CPSS-DLV subscales make use of different but related aspects of self-efficacy beliefs.

Table 3. General descriptive information on the CPSS-DLV scales and the other measurement instruments $(n=165)$

\begin{tabular}{|c|c|c|c|c|c|c|c|c|c|}
\hline \multirow[b]{2}{*}{ Measurement } & \multicolumn{3}{|c|}{ Total group } & \multicolumn{2}{|c|}{ Females } & \multicolumn{2}{|c|}{ Males } & \multirow[b]{2}{*}{$\mathrm{T}$} & \multirow[b]{2}{*}{$p$} \\
\hline & Mean & SD & $a$ & Mean & SD & Mean & SD & & \\
\hline $\begin{array}{l}\text { Pain self-efficacy } \\
\text { (PSE-DLV) }\end{array}$ & 51.7 & 18.5 & .88 & 52.6 & 18.1 & 49.8 & 19.2 & -.932 & .352 \\
\hline $\begin{array}{l}\text { Functional } \\
\text { self-efficacy (FSE-DLV) }\end{array}$ & 47.2 & 20.8 & .91 & 46.6 & 18.9 & 48.3 & 24.2 & .498 & .619 \\
\hline Pain severity (VAS) & 63.7 & 19.6 & & 64 & 19.1 & 63 & 20.5 & -.340 & .735 \\
\hline $\begin{array}{l}\text { Physical functioning } \\
\text { (RAND) }\end{array}$ & 41 & 24 & .88 & 41.5 & 23.6 & 39.7 & 25.8 & -.449 & .654 \\
\hline $\begin{array}{l}\text { Internal locus } \\
\text { of control (PCCL) }\end{array}$ & 2.9 & 1.0 & .84 & 2.9 & 1 & 2.7 & 0.94 & -1.086 & .279 \\
\hline $\begin{array}{l}\text { External locus } \\
\text { of control (PCCL) }\end{array}$ & 3.4 & 1.0 & .65 & 3.3 & 1 & 3.4 & 1 & .426 & .671 \\
\hline Catastrophizing (PCCL) & 3.6 & 1.0 & .85 & 3.5 & 1 & 3.6 & 1 & .763 & .446 \\
\hline
\end{tabular}

\section{Reliability}

Test-retest stability of the two-factor solution of the CPSS-DLV was examined in 51 individuals who remained stable during the two-week interval with respect to pain complaints. The mean scores for FSE-DLV and PSE-DLV in this group were 45.8 (SD \pm 20.7$)$ and 48.7 (SD \pm 18.2$)$ at baseline (T0) and $46.5(\mathrm{SD} \pm 20.3)$ and $47(\mathrm{SD} \pm 16.4)$ two weeks later (T1). The intraclass correlation coefficient shows good test-retest stability in the 'stable' group for FSE-DLV $($ ICC $=0.88(95 \% \mathrm{Cl}, 0.84-0.92))$ and for PSE-DLV $($ ICC $=0.87$ (95\% Cl, 0.82-0.90)). In the 'stable' group, Cronbach's alpha for FSE-DLV is 0.91 and for PSE-DLV 0.88 indicating good internal consistency of both scales. Finally, the smallest detectable change for FSE-DLV was 20 points and for PSE-DLV 17 points. 


\section{Concurrent criterion validity}

The concurrent validity was examined for FSE-DLV and PSE-DLV based on the two-factor model of the Dutch version of the CPSS using data from 165 patients. Table 4 presents a correlation matrix of the two CPSS-DLV scales and the questionnaire scores. In line with the prediction, both CPSS-DLV scales were significantly and negatively associated with pain severity scores (VAS). Furthermore, correlation coefficients between catastrophizing and FSE-DLV and PSE-DLV were substantial and negative, which is in line with our expectations. Higher levels of internal locus of control are associated with higher FSE-DLV and PSE-DLV self-efficacy scores, whereas higher levels of external locus of control are associated with lower levels of self-efficacy beliefs on FSE-DLV and PSE-DLV. Correlation coefficients were weaker for external control compared to internal control. Finally, a higher level of physical functioning was associated with higher levels of self efficacy beliefs on FSE-DLV and PSE-DLV. As expected, FSE-DLV correlation coefficients for FSE-DLV and physical functioning were significantly higher than for PSE-DLV, considering the domain specificity (Table 4). All correlation coefficients found were statistically significant $(p<0.01)$. Associations between PSE and pain severity, internal locus of control and catastrophizing were above the minimum level of .40. For FSE, associations with physical functioning and catastrophizing were above .40 (see Table 4). Taken together, these findings support the concurrent criterion validity of the PSE and FSE scales.

Table 4. Correlation matrix of self-report measures ( $n=165)$

\begin{tabular}{|c|c|c|c|c|}
\hline \multirow{2}{*}{ Measurement } & \multirow{2}{*}{$\begin{array}{l}\text { Pain self-effi- } \\
\text { cacy } \\
\text { (PSE-DLV) }\end{array}$} & \multirow{2}{*}{$\begin{array}{c}\text { Functional self- } \\
\text {-efficacy } \\
\text { (FSE-DLV) }\end{array}$} & \multicolumn{2}{|c|}{ Z-test } \\
\hline & & & Z & sig \\
\hline Pain severity (VAS) & -.40 & -.34 & -1.074 & .283 \\
\hline Physical functioning (SF-36) & .37 & .63 & -5.108 & $<.001$ \\
\hline Internal locus of control (PCCL) & .52 & .36 & 2.988 & .003 \\
\hline External locus of control (PCCL) & -.24 & -.17 & -1.179 & .238 \\
\hline Catastrophizing (PCCL) & -.60 & -.67 & 1.573 & .116 \\
\hline
\end{tabular}

VAS = visual analogue scale, PSE-DLV= pain self-efficacy Dutch language version,

FSE-DLV=functional self-efficacy Dutch language version, PCCL =Pain Coping and Cognition List, SF-36=Short Form 36 


\section{Discussion}

This study was aimed at investigating the psychometric properties of a Dutch-language version of the CPSS (CPSS-DLV). A sample of chronic pain patients with mixed chronic pain conditions was used to examine the factor structure, reliability, and validity of the CPSS-DLV. Results from the confirmatory factor analysis did not provide the previously proposed threefactor model of the CPSS with a good fit. An exploratory factor analysis was performed to further elucidate the factor structure, which yielded a two-factor model. These two factors were labelled 'pain-related self-efficacy' (PSE) and 'functional self-efficacy' (FSE).

The different findings regarding factor solution may be due to the method used to determine the number of factors to be retained. Anderson et al. [2] relied on a visual inspection of the Scree test, which is a subjective interpretation. The current study relied on parallel analysis, which is a highly recommended procedure for determining the number of factors to be retained in an exploratory factor analysis [44]. Interestingly, the randomly generated eigenvalues were 1.70, 1.56 and 1.48. Comparing these with the eigenvalues found in the original study [2] (10.59, 2.03 and 1.36) would also indicate that two factors should have been retained in that study. However determination of factor structure remains a largely interpretive activity. Therefore the proposed two factor solution should be confirmed in another new patient sample.

Another explanation could be the differences between the study populations. In other words, both populations had suffered from chronic pain complaints for many years. However, in Anderson's study, low back pain was the most prominent pain condition (63\%), whereas only $23 \%$ of our patients suffered from low back pain. Our study population included more patients with headache (7\% versus 1\%) and also a group of patients with neuropathic pain (20\% versus $0 \%$ ). Since these pain problems may differ in type, impact on daily functioning and effective pain management options this could have contributed to the differences in the results.

The two items that were deleted from the scale due to salient cross-loadings both contained ambiguous information. In other words, item CSE-1 ("how certain are you that you can control your fatigue") refers to patients' control of fatigue as a symptom. However, fatigue may be also associated with activity, which could explain the loading on both factors. Item CSE-2 ("how certain are you that you can regulate your activity so as to be active without aggravating your physical symptoms (e.g., fatigue, pain)") contains a question about remaining active and controlling (aggravating) physical symptoms. It might seem logical that patients could have interpreted these questions in two ways, thus explaining the salient loading on both factors.

Another difference in subscale items compared to the original CPSS concerned item 2 of the original PSE ("how certain are you that you can continue most of your daily activities"). In our opinion, this is indeed a question related to activity, and therefore more appropriate for the functional self-efficacy subscale. Based on the content of the items, in our opinion omitting items CSE-1 and CSE-2 and replacing item PSE-2 is correct. This results in a CPSS-DLV with two subscales (functional self-efficacy and pain self-efficacy) each containing ten items. 
The CPSS-DLV shows good test-retest stability in patients who remained stable for two weeks. No test-retest stability analyses have been performed with the original CPSS. For the test-retest analysis, we used a sample of the patient group who had had TENS treatment for a period of two weeks. The fact that the patients were undergoing treatment may have had an influence on the test-retest results. However, we only analysed test-retest stability in a subgroup of 'stable' patients. Stability was estimated using the global perceived effect scored by the patients which is a measurement commonly used to study psychometric quality of measurement tools [14]. Mean difference in pain severity (VAS 0-100) measured in this stable group after the treatment period was only $9 \mathrm{~mm}(\mathrm{SD} \pm 19$ ), which is not considered as a clinical relevant change [19]. Therefore, in our view this group of patients was 'stable' and suitable for test-retest analysis. Reliability in terms of internal consistency was good and in line with other measures of self-efficacy [36].

The concurrent validity of the CPSS-DLV was supported by a number of indices. More specifically, consistent relations ( $r \geqq 40$ ) were found between PSE-DLV and pain severity, pain related internal locus of control and pain catastrophizing, and between FSE-DLV and physical functioning and catastrophizing.

We found slightly higher correlation coefficients for FSE and daily physical functioning than in the original study. However, the original FSE (which contained nine items as opposed to ten) was compared with the activity scales of the Multidimensional Pain Inventory (MPI). The present study used the physical functioning subscale of the SF36. Both scales are regarded as being sufficiently reliable and valid for assessing disability.

As well as pain and daily functioning, we also studied the associations between self-efficacy and the constructs of health related 'locus of control'and 'pain catastrophizing thoughts'. Self-efficacy is behaviour-specific, whereas health related locus of control reflects a person's belief of being responsible for his own health in general [13]. The correlation with self-efficacy was found to be higher for internal locus of control than for external locus of control. This can, in our view, be explained by the fact that external control reflects beliefs in powerful others to control or manage pain, while internal control reflects beliefs about the respondent's own attitudes and/or capability.

Catastrophizing thoughts are defined as a negative orientation to pain itself or its possible consequences. High catastrophizing is associated with higher disability and pain intensity [38-39; 41; 43]. Both subscales of the CPPS-DLV correlated strongly (PSE -0.60 and FSE -0.67), since catastrophizing contains negative beliefs about worrying about pain itself as well as beliefs about helplessness (daily functioning as a consequence of pain) this might explain the observed correlations with both subscales.

Based on these results of the factor analysis and the construct validity analysis, and the fact that the calculated correlation corrected for attenuation (i.e., unreliability) was only slightly higher, we conclude that dividing self efficacy beliefs of patients with chronic pain into the two proposed subscales is appropriate. 
The results of the present study may have clinical implications. Since lasting pain relief is often not achieved with current pain treatment [42], improving pain self-management and daily functioning, despite pain, seem to be important targets for treatment. Self-efficacy enhancing interventions are promising for reducing chronic disability and pain [33-34]. In the Netherlands, all rehabilitation centres provide pain rehabilitation programmes that are aimed at enhancing self management for improving the quality of life of chronic pain patients. In order to regulate the content of treatment and to evaluate the effectiveness of these pain programmes, the self-efficacy beliefs of both pain management and daily functioning should be measured separately. The CPSS-DLV is an instrument that measures self-efficacy beliefs in both specific domains that are relevant to the heterogeneous group of patients with chronic pain.

Based on our data the CPSS-DLV can be considered to be a reliable and valid measurement instrument for assessing domain-specific self-efficacy beliefs in patients with a variety of chronic pain complaints in the Netherlands. Further analysis should confirm the proposed two factor solution and the clinical relevance of the distinction in of pain and functional self efficacy beliefs. 


\section{References}

[1] Aaronson NK, Muller M, Cohen PD, Essink-Bot ML, Fekkes M, Sanderman R, Sprangers MA, te Velde A, Verrips E. Translation, validation, and norming of the Dutch language version of the SF-36 Health Survey in community and chronic disease populations. J Clin Epidemiol 1998;51(11):1055-1068

[2] Anderson KO, Dowds BN, Pelletz RE, Edwards WT, Peeters-Asdourian C. Development and initial validation of a scale to measure self-efficacy beliefs in patients with chronic pain. Pain 1995;63(1):77-84

[3] Arnstein P. The mediation of disability by self efficacy in different samples of chronic pain patients. Disabil Rehabil 2000;22(17):794-801

[4] Arnstein P, Caudill M, Mandle CL, Norris A, Beasley R. Self efficacy as a mediator of the relationship between pain intensity, disability and depression in chronic pain patients. Pain 1999;80(3):483-491

[5] Asghari A, Nicholas MK. Pain self-efficacy beliefs and pain behaviour. A prospective study. Pain 2001;94(1):85-100

[6] Bandura A. Self-efficacy: toward a unifying theory of behavioral change. Psychol Rev 1977;84(2):191215

[7] Bolton JE. Accuracy of recall of usual pain intensity in back pain patients. Pain 1999;83(3):533-539

[8] Buckelew SP, Murray SE, Hewett JE, Johnson J, Huyser B. Self-efficacy, pain, and physical activity among fibromyalgia subjects. Arthritis Care Res 1995;8(1):43-50

[9] Chen G, Gully SM, Eden D. Validation of a new general self-efficacy scale. Organizational Research Methods 2001;4:62-83

[10] Cohen J, Cohen P. Applied multiple regression/correlation analysis for the behavioral sciences Hillsdal: Erlbaum, 1983

[11] Comrey AL, Lee HB. A first course in factor analysis. Hillsdale: Erlbaum, 1992

[12] Council JR, Ahern DK, Follick MJ, Kline CL. Expectancies and functional impairment in chronic low back pain. Pain 1988;33(3):323-331

[13] Cross MJ, March LM, Lapsley HM, Byrne E, Brooks PM. Patient self-efficacy and health locus of control: relationships with health status and arthritis-related expenditure. Rheumatology (Oxford) 2006;45(1):92-96

[14] de Vet HC, Ostelo RW, Terwee CB, van der Roer N, Knol DL, Beckerman H, Boers M, Bouter LM. Minimally important change determined by a visual method integrating an anchor-based and a distributionbased approach. Qual Life Res 2007;16(1):131-142

[15] de Vet HC, Terwee CB, Knol DL, Bouter LM. When to use agreement versus reliability measures. J Clin Epidemiol 2006;59(10):1033-1039

[16] Denison E, Asenlof P, Lindberg P. Self-efficacy, fear avoidance, and pain intensity as predictors of disability in subacute and chronic musculoskeletal pain patients in primary health care. Pain 2004;111(3):245-252

[17] Dolce JJ, Crocker MF, Doleys DM. Prediction of outcome among chronic pain patients. Behav Res Ther 1986;24(3):313-319 
[18] Estlander AM, Vanharanta H, Moneta GB, Kaivanto K. Anthropometric variables, self-efficacy beliefs, and pain and disability ratings on the isokinetic performance of low back pain patients. Spine (Phila Pa 1976) 1994;19(8):941-947

[19] Farrar JT, Portenoy RK, Berlin JA, Kinman JL, Strom BL. Defining the clinically important difference in pain outcome measures. Pain 2000;88(3):287-294

[20] Fleiss JL. The design and analysis of clinical experiments. New York: John Wiley \& Sons, 1986

[21] Keefe FJ, Ahles TA, Porter LS, Sutton LM, McBride CM, Pope MS, McKinstry ET, Furstenberg CP, Dalton J, Baucom DH. The self-efficacy of family caregivers for helping cancer patients manage pain at end-oflife. Pain 2003;103(1-2):157-162

[22] Kelloway EK. Using LISREL for structural equation modelling: a researchers guide. Newbury Park: CA:Sage, 1998

[23] Koke AJ, Schouten JS, Lamerichs-Geelen MJ, Lipsch JS, Waltje EM, van Kleef M, Patijn J. Pain reducing effect of three types of transcutaneous electrical nerve stimulation in patients with chronic pain: a randomized crossover trial. Pain 2004;108(1-2):36-42

[24] Kores RC, Murphy WD, Rosenthal TL, Elias DB, North WC. Predicting outcome of chronic pain treatment via a modified self-efficacy scale. Behav Res Ther 1990;28(2):165-169

[25] Lackner JM, Carosella AM. The relative influence of perceived pain control, anxiety, and functional self efficacy on spinal function among patients with chronic low back pain. Spine (Phila Pa 1976) 1999;24(21):2254-2260; discussion 2260-2251

[26] Lefebvre JC, Keefe FJ, Affleck G, Raezer LB, Starr K, Caldwell DS, Tennen H. The relationship of arthritis self-efficacy to daily pain, daily mood, and daily pain coping in rheumatoid arthritis patients. Pain 1999;80(1-2):425-435

[27] Levin JB, Lofland KR, Cassisi JE, Poreh AM, Blonsky ER. The relationship between self-efficacy and disability in chronic low bak pain patients. International Journal of Rehabilitation Health 1996;2(1):19-28

[28] Lin CC. Comparison of the effects of perceived self-efficacy on coping with chronic cancer pain and coping with chronic low back pain. Clin J Pain 1998;14(4):303-310

[29] Lin CC, Ward SE. Perceived self-efficacy and outcome expectancies in coping with chronic low back pain. Res Nurs Health 1996;19(4):299-310

[30] Litt MD. Self-efficacy and perceived control: cognitive mediators of pain tolerance. J Pers Soc Psychol 1988;54(1):149-160

[31] Lorig K, Chastain RL, Ung E, Shoor S, Holman HR. Development and evaluation of a scale to measure perceived self-efficacy in people with arthritis. Arthritis Rheum 1989;32(1):37-44

[32] Luszczynska A, Gutierrez DB, Schwarzer R. General self-efficacy in various domains of human functioning. Evidence from five countries. International Journal of Psychology 2005;40(80-89)

[33] Marks R, Allegrante JP, Lorig K. A review and synthesis of research evidence for self-efficacy-enhancing interventions for reducing chronic disability: implications for health education practice (part I). Health Promot Pract 2005;6(1):37-43

[34] Marks R, Allegrante JP, Lorig K. A review and synthesis of research evidence for self-efficacy-enhancing interventions for reducing chronic disability: implications for health education practice (part II). Health Promot Pract 2005;6(2):148-156 
[35] Meredith P, Strong J, Feeney JA. Adult attachment, anxiety, and pain self-efficacy as predictors of pain intensity and disability. Pain 2006;123(1-2):146-154

[36] Nicholas MK. The pain self-efficacy questionnaire: Taking pain into account. Eur J Pain 2007;11(2):153163

[37] O'Connor BP. SPSS and SAS programs for determing $y=$ the number of components using parallel analysis and Velicer's Map test Behavior Research Methods Instrumentation and Computers 2000;32:396-402

[38] Peters ML, Vlaeyen JW, Weber WE. The joint contribution of physical pathology, pain-related fear and catastrophizing to chronic back pain disability. Pain 2005;113(1-2):45-50

[39] Severeijns R, Vlaeyen JW, van den Hout MA, Weber WE. Pain catastrophizing predicts pain intensity, disability, and psychological distress independent of the level of physical impairment. Clin J Pain 2001;17(2):165-172

[40] Stomp-van den Berg SG, Vlaeyen JW, ter Kuile MM, Spinhoven P, van Breukelen G, Kole-Snijders AMJ. Maastricht: Pijn Kenniscentrum, 2001

[41] Sullivan MJ, Thorn B, Haythornthwaite JA, Keefe F, Martin M, Bradley LA, Lefebvre JC. Theoretical perspectives on the relation between catastrophizing and pain. Clin J Pain 2001;17(1):52-64

[42] Turk DC. Clinical effectiveness and cost-effectiveness of treatments for patients with chronic pain. Clin J Pain 2002;18(6):355-365

[43] Woby SR, Watson PJ, Roach NK, Urmston M. Adjustment to chronic low back pain--the relative influence of fear-avoidance beliefs, catastrophizing, and appraisals of control. Behav Res Ther 2004;42(7):761-774

[44] Zwick WR, Velicer WF. Comparison of five rules for determining the number of components to retain. Psychological Bulletin 1986;99:432-442 



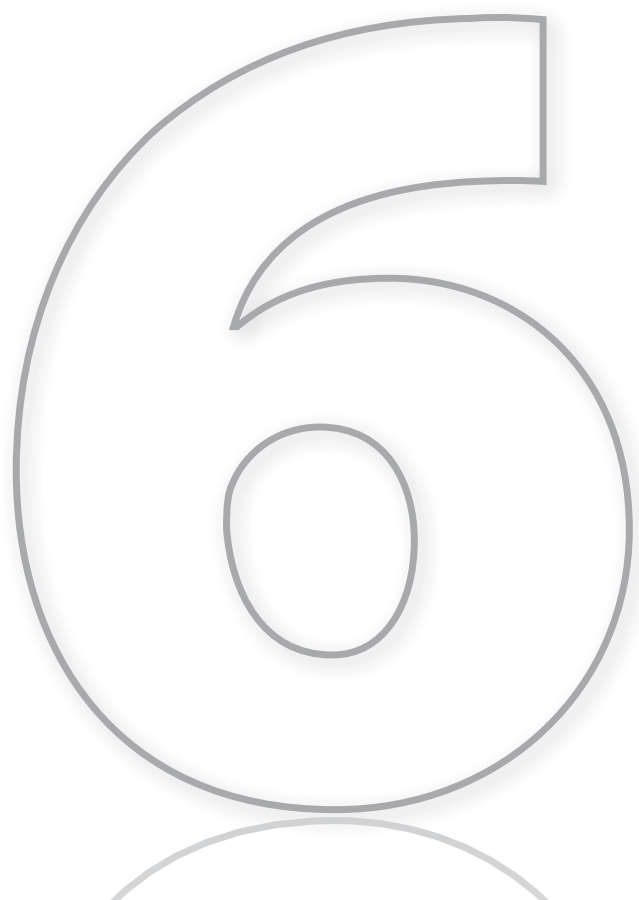

\title{
Minimal clinically important change and minimal detectable change of pain. Do clinicians and patients agree?
}

\author{
Albère Köke ${ }^{a, b, c}$, Raymond Ostelo ${ }^{d}$, Jacob Patijna ${ }^{a}$, \\ Maarten Kleef van ${ }^{a}$, Rob Smeets ${ }^{b, c}$
}

a Pain Management and Research Center, University Medical Center Maastricht

${ }^{b}$ Adelante Centre of Expertise in Rehabilitation, Hoensbroek

'Department of Rehabilitation Medicine, Research School CAPHRI, Maastricht University ${ }^{d}$ Institute for Research in Extramural Medicine (EMGO Institute), VU University Medical Center, 


\section{Abstract}

Background. A 30\% decrease in pain has been recommended as a minimally clinical important change (MCIC) for all acute and chronic pain complaints. This 30\% recommendation is based on a classification of improvement made by researchers/clinicians. However, possible side effects, costs or inconveniences of the treatment are not taken into account within this approach. Also no minimal detectable change (MDC) is presented by the $30 \%$ recommendation. We therefore compared a MCIC based on a researchers/clinicians perspective with a MCIC from a patient's perspective and the MDC was calculated.

Methods. Data of 180 patients with chronic pain recruited for a randomized trial for transcutaneous electrical nerve stimulation were used. At the start and the end of 2 weeks daily TENS treatment pain severity was measured by 3 visual analogue pain scales (average pain, worst pain, least pain). At the end of the treatment global perceived effect was measured from a researcher's/clinician's perspective and the patient's perspective.

Results. The results show that for all 3 pain scales MCIC from a patient's perspective was lower compared to a MCIC based on a researchers'/clinicians' perspective. Furthermore MDC was higher as MCIC for a pain scales used.

Conclusion. The recommendation of 30\% reduction in pain as a standard for success of treatment is not adequate for all patients with chronic pain, type of pain treatment and pain scales used. Although the advantages of a standard value for clinically relevant change are tempting, the methods for calculating such a standard are currently not sufficiently explicit and valid. 


\section{Introduction}

In the treatment of chronic pain the amount of pain reduction is one of the most important outcomes [21]. Although pain is common, measurement of the intensity of pain can be far from simple [18]. In general, a treatment is considered to be effective if in a clinical trial a statistical significant difference between treatments is found. But although a statistical significant difference is necessary, in itself it is not sufficient to prove that the observed change is also clinically important $[11 ; 14]$.

Therefore it is important to know whether the observed difference is also a clinically relevant difference or merely caused by measurement error.

The concept of a 'minimal clinically important difference' was first defined by Jaeschke [19] as the smallest difference in score in the domain of interest which patients perceive as beneficial and which mandates, in the absence of troublesome side effects and excessive cost, a change in the patient's management. It represents a certain minimal response (signal) to a given treatment stimulus. The term 'minimally clinically important difference' is used to indicate differences between patients, for a change in health status within patients the term 'minimally clinically important change' (MCIC) is used [10].

For evaluative purposes it is also important to measure agreement (absolute measurement error or noise) in the study population by defining the minimal detectable change[9]. The minimally detectable change (MDC) is the smallest change beyond measurement error that can be detected within a patient, by an instrument. If the MCIC is larger than the MDC (signal > noise), the instrument is considered responsive to assess a clinically important change for individual patients of that particular study population [24].

For pain research a 30\% decrease in pain for an individual patient has been recommended as a reasonable $\mathrm{MCIC}$ for all acute and chronic pain complaints irrespective of interventions provided [13-14], however a recommendation about MDC was not presented. The recommended $30 \%$ pain reduction is based on the relationships between changes in pain intensity and patient reports of overall improvement in efficacy studies on pregabalin in chronic pain in patients [13]. A global perceived effect measurement, in which a patient rate himself as "improved", "unchanged", or "worse," is mostly used in studies on MCIC as an external anchor [6]. However the validity of this global perceive effect, as a "transition scale', is questioned [6; 22; 25] as the ratings are likely to be influenced by the current status or 'recall bias', natural recovery, regression to the mean and placebo effects. The use of an invalid external criterion could bias MCIC scores.

Also the recommended 30\% pain reduction was based on a cut point chosen from the clinician's perspective and not from a patient's point of view. When assessing the MCIC however, it is (according to Jaeschke's definition) important that the patients perspective is used, thereby including whether or not the effect of an intervention is beneficial in relation to possible side effects and or unconviences. Furthermore, a MCIC is regarded as context-specific, which means that MCIC is specific for the intervention provided and the population under 
study $[2-3 ; 15]$. Therefore, the question arises whether this IMMPACT recommendation of $30 \%$ pain reduction, based on clinician's perspective, is the same as a MCIC based on patient's perspective. Furthermore it is important to find out if the recommended MCIC can be generalized to all type of treatments.

The first goal of the study is to compare MCIC for pain reducing effect of transcutaneous electrical nerve stimulation (TENS) from a clinician's perceptive and a patient's perspective. A second goal is to asses the validity (as a transition scale) of a global perceived effect transition scale for the estimation of MCIC. Finally a MDC for pain reduction was calculated to compare MCIC and MDC within the same population under treatment for both perspectives.

\section{Methods}

Data of patients with chronic pain recruited for randomized trial for TENS [23] were used for the current study. The eligibility criteria (described elsewhere [23]) were broad in order to recruit a representative group of patient with chronic pain as seen in daily practice. In the trial patients received a 2 weeks treatment with TENS. At baseline (TO) patients pain intensity was measured. At end of treatment (T1) pain intensity and global perceived effect of success of treatment was measured.

\section{Pain measurement}

At both assessments $(\mathrm{TO}, \mathrm{T} 1)$ the patients scored the intensity of their pain on three $100 \mathrm{~mm}$ VAS scales; average pain during the past week, the maximum (worst) pain during the past week, and the minimum (least) pain during the past week. A score of 0 indicated no pain; a score of 100 meant worst pain possible.

\section{Clinician's and patient's perspective}

At the end of treatment patient rated success of TENS treatment during the past 2 weeks, on a 6 point global perceived effect (GPE) scale; $1=$ completely improved, $2=$ much improved $3=$ little improved, $4=$ unchanged, $5=a$ little worse, and $6=a$ lot worse. Using a clinician's perspective (RP), "improvers" were classified by the scores "completely improved and much improved" $(1+2)$.

Patient's perspective (PP) of success at the end of treatment was measured by asking the patient whether he/she wanted to continue the TENS-treatment based on his/her experience during the past 2 weeks of using TENS while taking the level of pain relief, side effects and inconveniences into account (yes/no). Patients who wanted to continue TENS (category yes) after the 2 weeks treatment period were classified as "improvers". 


\section{Measurement properties}

To compare the influence of the two different perspectives two measurement properties were estimated; MCIC and MDC. For the MCIC mean change scores were calculated by subtracting the post treatment pain score (T1) from pre treatment pain (T0) score. Then, using the definitions of 'improvers' from both perspectives as described above as an external anchor, the area under the curve (AUC) of a receiver operator characteristics (ROC) curve is used to calculate the MCIC. For the MCIC, the optimal cut-off point was estimated by choosing that point that yields the lowest overall misclassification. That is the most optimal balance between sensitivity (true positives) and specificity (true negatives). Patients with higher T0 scores need larger change scores to estimate them as improved, and in order to control for the well known influence of pre treatment pain score [20; 29; 31], we also calculated MCIC as the percentage change score (raw change/baseline * 100).

For estimating the MDC we used the 'change' scores of patients who were 'stable'. We classified patients as 'stable' based on score 'unchanged' of the 6 point GEP scale.

Then, using ANOVA analyses (2.1) the standard error of measurement (SEM) was calculated as $\sqrt{ }\left(\sigma^{2}+\sigma^{2}\right.$ residual) which is based on variance between measures to account for systematic error between measurement, and residual variance corresponding with the interaction between subjects and measurements [10; 30]. We also calculated the SEM for the percentage change scores, by dividing the standard deviation (SD) of the mean differences $\left(\mathrm{SD}_{\text {diff }}\right)$ by $\sqrt{2}$. In this SEM the systematic error is not taken into account [10]. The MDC is calculated as $1.64 \times \sqrt{ } 2 \times$ SEM [10].

\section{Validity of global perceived effect (GPE)}

According to Guyatt et al. [16] a strong correlation (>0.5) between the change score and a GPE must exist. To test the validity of GPE as a transition scale correlations between GPE and pain change scores were calculated for all pain scales. According to Kamper et al. [22], preand post treatment pain scores should independently associated with GPE. Therefore, we performed (in analogy with Kamper et al. [22]) regression analysis with GPE as the dependent variable. In the first step of the analysis the post treatment pain score was entered into the model as independent variable. In the second step the pre treatment pain score was entered. To establish validity, the addition of the pre treatment pain score should significantly increase the explained variance $\left(R^{2}\right)$. For the measurement of patient's perspective we performed a logistic regression analysis. 


\section{Results}

In total 180 patients with chronic musculoskeletal pain completed all measurements after the two weeks test period (T1).The population comprised a mixed group of chronic pain patients suffering from chronic low back pain $(n=38)$, chronic widespread pain $(n=20)$, CRPS type $1(n=16)$, headache $(n=13)$, failed back surgery syndrome $(n=18)$, neuropathic pain $(n=25)$, thoracic $(n=12)$ and cervical pain $(n=21)$, irritable bowel syndrome $(n=4)$, and miscellaneous complaints of pain ( $n=13$ ). Mean age was 50 years (SD 13.7) ranging from 18 to 85 and $64 \%$ was women. The highest education level was low in 55\%, middle in $37 \%$ and high in $8 \%$. Of all patients, 33\% had a paid job, and 31\% received a disability payment. Median duration of pain was 36 months (inter-quartile range; IQR: 25\%; 18 months, IQR: 75\%; 96 months).

\section{MCIC and MDC from clinician's and patient's perspective}

Of all 180 patients, 50 patients (28\%) rated their improvements on 6 point GPE scale as completely relieved and/or much improved, 44 patients (24\%) had a little improvement, and 62 (34\%) rated their complaints as unchanged. Deterioration (a little worse and a much worse) was scored by 24 patients (13\%). The results show that the number of patients classified as "improvers" is higher for clinician's perspective compared to classification by patient's perspective (93 vs. 50). Table 1 shows the mean scores and standard deviations at baseline and change scores at end of treatment, in patients classified as improvers /non- improvers by clinician's and patient's perspective.

Table 1. Baseline pain scores (T0) and mean change in pain intensity at end of treatment ( $\mathrm{T} 1$ ) for improvers /non-improvers based on clinician's perspective (CP) and patient's perspective (PP)

\begin{tabular}{|c|c|c|c|c|c|c|}
\hline & \multicolumn{2}{|c|}{ Average pain } & \multicolumn{2}{|c|}{ Worst pain } & \multicolumn{2}{|c|}{ Least pain } \\
\hline & $\begin{array}{c}\text { Mean (SD) } \\
\text { T0 } \\
\end{array}$ & $\begin{array}{l}\text { Change } \\
\text { Score }\end{array}$ & T0 & $\begin{array}{l}\text { Change } \\
\text { score }\end{array}$ & T0 & $\begin{array}{l}\text { Change } \\
\text { score }\end{array}$ \\
\hline \multicolumn{7}{|l|}{$\mathrm{CP}$} \\
\hline Improvers $\mathrm{N}=50$ & $\begin{array}{l}60.8 \\
(18.6)\end{array}$ & $\begin{array}{l}-32.8 \\
(22.4)\end{array}$ & $\begin{array}{l}75.9 \\
(17.1)\end{array}$ & $\begin{array}{l}-30.6 \\
(24.4)\end{array}$ & $\begin{array}{l}40.6 \\
(20.4)\end{array}$ & $\begin{array}{l}-21.1 \\
(20.6)\end{array}$ \\
\hline Non-improvers $\mathrm{N}=130$ & $\begin{array}{c}65.2 \\
(19.8)\end{array}$ & $\begin{array}{c}-8.4 \\
(17.5)\end{array}$ & $\begin{array}{l}77.3 \\
(15.9)\end{array}$ & $\begin{array}{c}-6.6 \\
(16.3)\end{array}$ & $\begin{array}{l}47.9 \\
(26.6)\end{array}$ & $\begin{array}{c}-0.6 \\
(21.7)\end{array}$ \\
\hline \multicolumn{7}{|l|}{ PP } \\
\hline $\begin{array}{l}\text { Improvers } \\
\mathrm{N}=93\end{array}$ & $\begin{array}{c}60 \\
(19.8)\end{array}$ & $-27.3(20.9)$ & $\begin{array}{l}73.8 \\
(16.9)\end{array}$ & $\begin{array}{l}-21 \\
(24)\end{array}$ & $\begin{array}{c}32.8 \\
(18.3)\end{array}$ & $\begin{array}{r}-16.5 \\
(21)\end{array}$ \\
\hline $\begin{array}{l}\text { Non-improvers } \\
\mathrm{N}=87\end{array}$ & $68.2(18.5)$ & $-2.1(13.9)$ & $\begin{array}{l}80.2 \\
(14.7)\end{array}$ & $-5(16.1)$ & $\begin{array}{l}50.3 \\
(27.1)\end{array}$ & $-4.7(20.5)$ \\
\hline
\end{tabular}




\section{Measurement properties MCIC and MDC}

Cut point based on ROC to estimate MCIC are presented in table 2. MCIC for all three types of pain measurements, based on the clinician's perspective (CP), are higher compared to MCIC based on patient's perspective (PP). MDC, were larger as MCIC for three pain scales.

Table 2. Minimal Detectable Change and MCIC, based cut-off scores of the ROC Curve for average, worst and least pain, based on clinician's and patient perspective for absolute and percentage change scores

\begin{tabular}{lcccccccc}
\hline & \multicolumn{2}{c}{ SEM } & \multicolumn{2}{c}{ MDC } & MCIC & Se/Sp & MCIC & Se/Sp \\
\hline CP & abs.* & $\%$ & raw & $\%$ & abs. & abs. & $\%$ & $\%$ \\
Average pain & 10.1 & 17 & 23.4 & 39.4 & 20.5 & $72 / 79$ & 39.9 & $76 / 85$ \\
Worst pain & 12.5 & 17 & 29 & 39.4 & 12.5 & $76 / 69$ & 24.5 & $66 / 81$ \\
Least pain & 14.9 & 71.3 & 34.6 & 164 & 9.5 & $70 / 74$ & 26.5 & $74 / 77$ \\
PP & & & & & & & & \\
Average pain & 9.7 & 18.8 & 22.5 & 43.6 & 13.5 & $74 / 85$ & 20 & $76 / 82$ \\
Worst pain & 12 & 16.7 & 27.8 & 38.5 & 11.5 & $66 / 74$ & 17.3 & $65 / 78$ \\
Least pain & 14.6 & 68 & 33.6 & 157.7 & 6.5 & $62 / 77$ & 14 & $66 / 79$ \\
\hline
\end{tabular}

$\mathrm{CP}=$ clinician's perspective based on GPE, PP = patients perspective based on question about continuation TENS. SEM = standard error measurement, $\mathrm{Se}=$ sensitivity (true positives) $\mathrm{Sp}=$ specificity ( true negatives) abs. $=$ absolute

\section{Validation GPE}

The correlation of GPE with the change pain scores is $0.604,0.470$, and 0.538 for average pain, worst pain and least pain respectively. Correlation of PP with change pain scores is 0.603 , 0.384 , and 0.473 , respectively. The regression analysis showed that pre-treatment pain scores were independently associated with GPE and PP, except for the worst pain scale. However, the contribution of pre-treatment pains score to overall explained variance was small (range $2.7 \%$ (average pain) to 3.9\% least pain) (see Table 3). 
Table 3. Results from the two-step regression analysis association GPE and PP as dependent variable and multiple model (pre-treatment included after post-treatment pain scores)

\begin{tabular}{|c|c|c|c|c|}
\hline \multirow[b]{2}{*}{ GPE } & \multirow{2}{*}{$\begin{array}{c}\text { Standardized } \\
\text { regression } \\
\text { coefficient }\end{array}$} & \multirow[t]{2}{*}{ Sig } & \multicolumn{2}{|c|}{ Explained variance $\mathrm{R}^{2}$} \\
\hline & & & Post & post + pre \\
\hline \multicolumn{5}{|c|}{ Average } \\
\hline Post & -.773 & $<0.001$ & 43.5 & 46.2 \\
\hline Pre & .201 & 0.004 & & \\
\hline \multicolumn{5}{|l|}{ Worst } \\
\hline Post & -.463 & $<0.001$ & 22.4 & 22.5 \\
\hline Pre & -.022 & 0.771 & & \\
\hline \multicolumn{5}{|l|}{ Least } \\
\hline Pro & -.715 & $<0.001$ & 31.8 & 35.7 \\
\hline Pre & .249 & 0.002 & & \\
\hline \multicolumn{5}{|l|}{ PP } \\
\hline \multicolumn{5}{|c|}{ Average } \\
\hline Post & -.106 & $<0.001$ & 55.5 & 59.0 \\
\hline Pre & .040 & 0.008 & & \\
\hline \multicolumn{5}{|l|}{ Worst } \\
\hline Post & -.052 & $<0.001$ & 30.3 & 30.1 \\
\hline Pre & -.002 & 0.873 & & \\
\hline \multicolumn{5}{|l|}{ Least } \\
\hline Post & -.078 & $<0.001$ & 40.6 & 45.8 \\
\hline Pre & .032 & 0.004 & & \\
\hline
\end{tabular}

$\mathrm{GPE}=$ global perceived effect; on which clinician's perspective is based, $\mathrm{PP}=$ patients perspective

\section{Discussion}

In this study we aimed to explore the influence of different perspectives on measurement properties. The results showed that size of a MCIC is dependent on what perspective (patient or clinician) used. MCIC based on clinician's perspective was higher compared to ratings from a patient's point of view. The MCIC from a patient's perspective was lower as the recommended 30\% pain reduction [13]. Reasons for this difference could be due to differences in methods used.

\section{Patient's versus clinician's perspective}

The classification of improvement based on clinician's perspective, solely looks at change in one outcome domain and does not take secondary effects, side effects, unconviences and costs into consideration. The results therefore do not reflect perceived changed from a patient's perspective taking into account benefits as well as side effects and costs. We asked the 
patients whether they wanted to continue the TENS-treatment based on their experience during the past 2 weeks of using TENS while specifically taking into account the level of pain relief, side effects and inconveniences. Reasons for patients to discontinue TENS, despite pain relief, were sparse. Patient mentioned; a) skin irritation, difficulties sticking electrodes (especially on the back), b) detachment of electrode during activities, c) negative feelings about possible danger of electric current or d) the fact that electrodes were visible to other people as reasons to discontinue TENS. From a patient perspective, financial costs were no issue as insurance companies reimburse the costs of TENS in the Netherland.

\section{Differences in side effects}

The low occurrence of side effects our study [23] could be an explanation for finding a lower MCIC as the recommendation of 30\%. In the studies, were 30\% recommendation is based on, patients received pregabalin (or placebo) as treatment. Pregabalin treatment is associated with different side effects, of which dizziness and somnolence was the most common [12]. The side effects of TENS are rare, and commonly limited to skin irritation [23]. We don't know whether or not side effects occurred within patient participating in the studies of Farrar and how patients rated these side effects relative to effectiveness. We think that our results lend support the assumption that the MCIC is context-specific (i.e. treatment specific) and that side effect and inconveniences, in addition to clinical effects, must be taken into account in the patient's decision on continuing treatment [3].

\section{Different type of pain measurement}

Also a possible explanation for the differences could be type of pain scale and/or calculation of pain scores. In Farrar's studies [14] patients kept a daily diary in which the described their pain (on an 11 point NRS) over the preceding 24 hour. The pain score used for analysis was the mean of the last 7 diary entries. In our study we used a single item $100 \mathrm{~mm}$ VAS pain scale to measure average pain past 7 days. As single ratings of pain may show high measurement error due to high variability in pain intensity, using the mean score of 7 consecutive days could reduce this variability. This method is based on the fact that repeated measures reduce the variability and increase the reliability of a measurement [7; 26]. This could be an explanation for finding a lower MCIC, based on clinician's perspective, by Farrar. The MCIC, based on patient's perspective for raw change score of average pain, was 20.5, which is in line with previous findings of MCIC using VAS scales of approximately $20 \mathrm{~mm}$ in chronic pain $[4 ; 17 ; 27]$.

We also calculated MCIC percentage change scores because influence of baseline scores on MCIC is well known [20; 29; 31]. Patients with higher baseline scores need larger change scores to estimate them as improved. Percentage change scores incorporate baseline scores and thereby represent best estimate for $\mathrm{MCIC}$ [31]. MCIC for percentage change scores, 
based on patient's perspective, were all lower in our study as the recommended $30 \%$ reduction. The MCIC for average pain scale was slightly higher than for worst pain and least pain in both perspectives. No other studies, as far as we know, have studied MCIC for worst and least pain. For worst and least pain lower change scores as for average pain were 'sufficient' to rate treatment as successful by patients. We don't know what change patient prefer; less average pain, less worst pain or less least pain, and contributes to defining treatment as successful. But our results highlight that it is important to specifically relate the MCIC to the type of pain measurement used.

\section{$M C I C$ and $M D C$}

At the recommendation of 30\% pain reduction no value for MDC was added. But in order to be able to judge whether an instrument can detect a MCIC one needs information about the MDC. In our study we found MDC for absolute pain scores higher as MCIC absolute pain scores. As the level of pain varies greatly, even within a day [34], this larger variability is probably responsible for large MDC. The percentage MDC based on classification of unchanged of GPE, was slightly better, at least for average pain scale. However in the type of SEM estimation used to calculated percentage MDC no systematic error was included [10]. Therefore the real percentage MDC is probably somewhat higher. The MDC percentage change scores based on patient's perspective was much higher as MCIC. This is due to the inclusion of patients with pain reduction but who didn't continued TENS. Therefore this group cannot be considered as unchanged, compared to the classification with the GPE scores. The larger MDC compared to MCIC is in line with previous research. Van Grootel et al. [32-33] found a MDC of $49 \mathrm{~mm}$ for VAS pain (mean of scores measured with a pain diary) in patients with chronic temporomandibular disorder (TMD). They did not calculate a MCIC but reported that their MDC exceeded a 30\% reduction of pain. Only Hägg et al. [17] found, based on raw change scores, a MDC lower as the MCIC (15 mm VAS compared to 18-19 mm) in patients with low back pain. Hägg et al. [17] used a mean pain score of three $100 \mathrm{~mm}$ VAS pain scales (worse, least, current), but no percentages changes scores were calculated.

For 11 point NRS pain scales MCIC in combination of MDC is calculated for low back pain [31] and neck pain [28]. In chronic low back pain a MCIC of 2.5 points (based on ROC method) was found, whereas the MDC turned out to be 4.5 points. In a study on neck pain [28] found, a MDC of 4.3 were MCIC, based on ROC methods was 2.5.

A change in pain below MDC values does not mean the change was not important or relevant for a patient, but we cannot distinguish it from measurement error. This means that VAS pain scale average pain, worst pain and least pain during the last 7 days, at least in patients with chronic pain using TENS, have difficulty to detect a minimal clinically important change beyond measurement error. 


\section{Validity of global perceived effect scale}

The correlations between change pain scores and GPE and PP were he same as found in a study by Kamper et al. [22]. As part of the patients improve or remain stable this could influence correlation coefficients negatively [8]. Therefore also regression analyses were performed. Kamper et al. [22] also found that pre-treatment pain scores contributed only a small proportion of variance (1-5\%) to GPE over a two week treatment period. When they analysed longer treatment periods ( $>2$ weeks), the contribution of pre-treatment pain scores were no longer significant. They concluded that a GPE scale might be acceptable as a transition scale for short term evaluations, but not for long term evaluation. Our findings confirm Kamper's finding for short term evaluation

\section{How to measure treatment success?}

All these results reflect in our view that we don't fully understand the process of patient's evaluation of treatment effects. The somewhat arbitrarily chosen cut-off point of 30\% as recommended by the IMMPACT-group reflects the clinician's perspective, and not so much the patient's perspective. It represents therefore a clinically important change as viewed by clinicians. By doing so, the benefits of TENS (or other treatments) are not balanced to the efforts for a patient, costs, side effects and inconveniences while using TENS. Only patients can take all these issues into account. It is therefore highly important to measure success from a patient's perspective [1]. Based on GPE classification of improved a success rate of only 28\% (50 out of 180 patients) was found. However in total 50\% (91 out of 180) wanted to continue TENS. The amount of pain relief in these patients was not the same in all patients. Some patients who indicated that they would like to continue to use TENS reported only minor changes in pain. Therefore the amount of change in pain intensity seems not the only factor in a patient's decision to continue TENS. One explanation might be that patients experience other improvements or benefits that are related to TENS. An important effect could be that TENS is found to be a surrogate for other pain reducing treatment such as medication. Bjordal et al. [5] reviewed the effectiveness of TENS in post-operative pain. They found that TENS significantly reduced the use or need for analgesic medication. It is likely that many patients would be interested in a treatment that produces a only a small decrease in pain but has no or few significant side effects [20]. Another explanation could be the fact that patients with chronic pain have repeated experiences of treatment failures which results in lower expectations for the next treatment [35]. Our patients had long lasting pain complaints for many years and were treated extensively before referred to our pain clinic, resulting in lower expectations for pain reduction. On the other hand patients may have expectations or desires about a certain amount of pain relieve prior to the start of treatment that are not perceived after treat- 
ment is completed. In those cases a patient might not continue the treatment despite a relative large reduction in pain [35]. Therefore the relevance of a treatment effect can only be judged by patients. Of course policy makers need to consider if the effects of the intervention are large enough that resources should be allocated to provision of the intervention [15]. We agree with Ferreira and colleagues [15] that potential recipients of the intervention should have a key part of those considerations whether the effects of intervention are worthwhile.

\section{Future research}

The emphasis for future research should be on the patient's perception of change. Our assessment of success from a patients perspective was only a dichotomised scale based on the answer whether the patient wants to continue TENS, based on his/her experience during the past 2 weeks of using TENS while taking the level of pain relief, side effects and inconveniences into account. Although this type of global assessment is in line with the originally definition of $\mathrm{MCIC}$, it is probably also too simplistic or insufficiently sensitive for the evaluation of effects that are important or worthwhile for patients. More detailed answer categories (based on a comparison of benefits and harms) could be helpful to determine differences in relevant domains that contribute to patient's decisions $[1 ; 15 ; 35]$. As the level of potential harms increases, greater benefits are necessary to attain important differences for patients. A more thorough analysis of benefits and harms in the decision making process between patient and caregiver is therefore warranted to improve the assessment of clinically relevant changes scores [1-2]. It also seems worthwhile to ask, prior to treatment, what expectations about the amount of effect (in several domains) patients with chronic pain have and what a worthwhile effect means to them. Decisions about treatment choice and evaluation of effects are then based on these expectations [35]. Further research on how we measure pain and change in pain, a MDC are all larger than MCIC's, seems also warranted.

\section{Conclusion}

Finally we conclude that the recommendation of 30\% reduction in pain as a standard for success of treatment is therefore not adequate for all patients with chronic pain, type of pain treatment and pain scales used. Although the advantage of a standard value for clinically relevant change is tempting, the methods for calculating such a standard are currently not sufficiently explicit and valid. 


\section{References}

[1] Barrett B, Brown D, Mundt M, Brown R. Sufficiently important difference: expanding the framework of clinical significance. Med Decis Making 2005;25(3):250-261

[2] Barrett B, Brown R, Mundt M, Dye L, Alt J, Safdar N, Maberry R. Using benefit harm tradeoffs to estimate sufficiently important difference: the case of the common cold. Med Decis Making 2005;25(1):47-55

[3] Beaton DE, Boers M, Wells GA. Many faces of the minimal clinically important difference (MCID): a literature review and directions for future research. Curr Opin Rheumatol 2002;14(2):109-114

[4] Beurskens AJ, de Vet HC, Koke AJ. Responsiveness of functional status in low back pain: a comparison of different instruments. Pain 1996;65(1):71-76

[5] Bjordal JM, Johnson MI, Ljunggreen AE. Transcutaneous electrical nerve stimulation (TENS) can reduce postoperative analgesic consumption. A meta-analysis with assessment of optimal treatment parameters for postoperative pain. Eur J Pain 2003;7(2):181-188

[6] Copay AG, Subach BR, Glassman SD, Polly DW, Jr., Schuler TC. Understanding the minimum clinically important difference: a review of concepts and methods. Spine J 2007;7(5):541-546

[7] Cronbach LJ. Essentials of psychological testing (3rd ed.). New York: Harper \& Row, 1970

[8] de Vet HC, Ostelo RW, Terwee CB, van der Roer N, Knol DL, Beckerman H, Boers M, Bouter LM. Minimally important change determined by a visual method integrating an anchor-based and a distributionbased approach. Qual Life Res 2007;16(1):131-142

[9] de Vet HC, Terluin B, Knol DL, Roorda LD, Mokkink LB, Ostelo RW, Hendriks EJ, Bouter LM, Terwee CB. Three ways to quantify uncertainty in individually applied "minimally important change" values. J Clin Epidemiol 2010;63(1):37-45

[10] de Vet HC, Terwee CB, Knol DL, Bouter LM. When to use agreement versus reliability measures. J Clin Epidemiol 2006;59(10):1033-1039

[11] de Vet HC, Terwee CB, Ostelo RW, Beckerman H, Knol DL, Bouter LM. Minimal changes in health status questionnaires: distinction between minimally detectable change and minimally important change. Health Qual Life Outcomes 2006;4:54

[12] Dworkin RH, Corbin AE, Young JP, Jr., Sharma U, LaMoreaux L, Bockbrader H, Garofalo EA, Poole RM. Pregabalin for the treatment of postherpetic neuralgia: a randomized, placebo-controlled trial. Neurology 2003;60(8):1274-1283

[13] Dworkin RH, Turk DC, Farrar JT, Haythornthwaite JA, Jensen MP, Katz NP, Kerns RD, Stucki G, Allen RR, Bellamy N, Carr DB, Chandler J, Cowan P, Dionne R, Galer BS, Hertz S, Jadad AR, Kramer LD, Manning DC, Martin S, McCormick CG, McDermott MP, McGrath P, Quessy S, Rappaport BA, Robbins W, Robinson JP, Rothman M, Royal MA, Simon L, Stauffer JW, Stein W, Tollett J, Wernicke J, Witter J. Core outcome measures for chronic pain clinical trials: IMMPACT recommendations. Pain 2005;113(1-2):919

[14] Farrar JT, Young JP, Jr., LaMoreaux L, Werth JL, Poole RM. Clinical importance of changes in chronic pain intensity measured on an 11-point numerical pain rating scale. Pain 2001;94(2):149-158 
[15] Ferreira ML, Herbert RD, Ferreira PH, Latimer J, Ostelo RW, Nascimento DP, Smeets RJ. A critical review of methods used to determine the smallest wothwhile effect of interventions for low back pain. 2011:accepted for publication

[16] Guyatt GH, Norman GR, Juniper EF, Griffith LE. A critical look at transition ratings. J Clin Epidemiol 2002;55(9):900-908

[17] Hagg O, Fritzell P, Nordwall A. The clinical importance of changes in outcome scores after treatment for chronic low back pain. Eur Spine J 2003;12(1):12-20

[18] Ho K, Spence J, Murphy MF. Review of pain-measurement tools. Ann Emerg Med 1996;27(4):427-432

[19] Jaeschke R, Singer J, Guyatt GH. Measurement of health status. Ascertaining the minimal clinically important difference. Control Clin Trials 1989;10(4):407-415

[20] Jensen MP, Chen C, Brugger AM. Interpretation of visual analog scale ratings and change scores: a reanalysis of two clinical trials of postoperative pain. J Pain 2003;4(7):407-414

[21] Jensen MP, Smith DG, Ehde DM, Robinsin LR. Pain site and the effects of amputation pain: further clarification of the meaning of mild, moderate, and severe pain. Pain 2001;91(3):317-322

[22] Kamper SJ, Ostelo RW, Knol DL, Maher CG, de Vet HC, Hancock MJ. Global Perceived Effect scales provided reliable assessments of health transition in people with musculoskeletal disorders, but ratings are strongly influenced by current status. J Clin Epidemiol 2010;63(7):760-766 e761

[23] Koke AJ, Schouten JS, Lamerichs-Geelen MJ, Lipsch JS, Waltje EM, van Kleef M, Patijn J. Pain reducing effect of three types of transcutaneous electrical nerve stimulation in patients with chronic pain: a randomized crossover trial. Pain 2004;108(1-2):36-42

[24] Mokkink LB, Terwee CB, Patrick DL, Alonso J, Stratford PW, Knol DL, Bouter LM, de Vet HC. The COSMIN study reached international consensus on taxonomy, terminology, and definitions of measurement properties for health-related patient-reported outcomes. J Clin Epidemiol 2010;63(7):737-745

[25] Norman GR, Stratford P, Regehr G. Methodological problems in the retrospective computation of responsiveness to change: the lesson of Cronbach. J Clin Epidemiol 1997;50(8):869-879

[26] Nunally J. Psychometric Theory. New York: McGraw-Hill, 1978

[27] Ostelo RW, de Vet HC. Clinically important outcomes in low back pain. Best Pract Res Clin Rheumatol 2005;19(4):593-607

[28] Pool JJ, Ostelo RW, Hoving JL, Bouter LM, de Vet HC. Minimal clinically important change of the Neck Disability Index and the Numerical Rating Scale for patients with neck pain. Spine (Phila Pa 1976) 2007;32(26):3047-3051

[29] Stratford PW, Binkley JM, Riddle DL, Guyatt GH. Sensitivity to change of the Roland-Morris Back Pain Questionnaire: part 1. Phys Ther 1998;78(11):1186-1196

[30] Terwee CB, Bot SD, de Boer MR, van der Windt DA, Knol DL, Dekker J, Bouter LM, de Vet HC. Quality criteria were proposed for measurement properties of health status questionnaires. J Clin Epidemiol 2007;60(1):34-42

[31] van der Roer N, Ostelo RW, Bekkering GE, van Tulder MW, de Vet HC. Minimal clinically important change for pain intensity, functional status, and general health status in patients with nonspecific low back pain. Spine (Phila Pa 1976) 2006;31(5):578-582 
[32] van Grootel RJ, van der Bilt A, van der Glas HW. Long-term reliable change of pain scores in individual myogenous TMD patients. Eur J Pain 2007;11 (6):635-643

[33] van Grootel RJ, van der Glas HW. Statistically and clinically important change of pain scores in patients with myogenous temporomandibular disorders. Eur J Pain 2009;13(5):506-510

[34] Williams DA, Gendreau M, Hufford MR, Groner K, Gracely RH, Clauw DJ. Pain assessment in patients with fibromyalgia syndrome: a consideration of methods for clinical trials. Clin J Pain 2004;20(5):348356

[35] Yelland MJ, Schluter PJ. Defining worthwhile and desired responses to treatment of chronic low back pain. Pain Med 2006;7(1):38-45. 



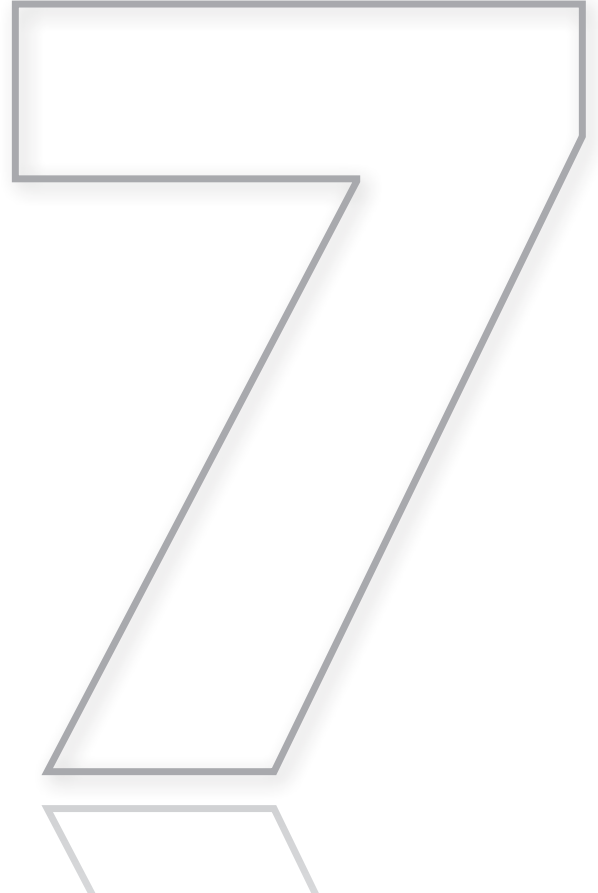

General discussion 



\section{Introduction}

Today, chronic pain affects approximately $19 \%$ of the Dutch population, leading to individual suffering and costs to society in terms of health care and lost productivity. Optimizing the treatment for patients with chronic pain, due to the modest effects of current treatment, poses a huge challenge to clinicians and researchers. In this thesis we focus on the effectiveness of Transcutaneous Electrical Nerve Stimulation (TENS). Despite many past randomized clinical trials (RCTs), the effectiveness of TENS remains unclear. In the introduction to this thesis, several explanatory factors for the lack of consistent findings during RCTs with regard to TENS were presented, and used as a framework for this thesis. Our first aim was to compare the effectiveness of different types of TENS in patients with chronic pain during a cross-over study. Our second aim was to examine what works for whom. Since there is no treatment that is effective for all chronic pain patients, we focused on identifying the characteristics and/or symptoms of responders and non-responders to TENS. Insight into those characteristics and/ or symptoms can be helpful in improving the selection of patients eligible for TENS treatment.

Although TENS is mainly used for pain relief, its secondary effects could be important in the evaluation of whether or not it is successful in a particular patient. Pain is a multifactorial phenomenon, and therefore TENS, as with other types of pain treatment, can be effective in several involved areas. Therefore, our third aim was to identify factors associated with a positive outcome (long-term continuation of TENS and pain reduction). Understanding why patients rate their treatment as successful, from a biopsychosocial perspective, can be useful in optimizing treatment. We hypothesized that TENS could have beneficial effects in the psychological domain, such as feelings of increased control or self-efficacy. Valid, reliable and responsive measurement tools are a basic condition for measuring these effects. No questionnaire was available in the Dutch language for measuring self-efficacy. We therefore translated and validated the Dutch version of the Chronic Pain Self-efficacy Scale (CPSS). Moreover, when measuring pain relief with visual analogue scales, questions arise about what exactly we are measuring, and how this is associated with treatment success. Therefore, the final aim of this thesis was to analyze the minimum important change scores (MCIC) for pain, and how best to determine these.

In this final chapter, we will discuss the results of the studies presented in this thesis. We conclude with additional recommendations for daily practice and future research. However, we first present the answers to our research questions.

\section{Main findings of this thesis}

- We found no difference in effectiveness between the three types of TENS: (1) high frequency $(80 \mathrm{~Hz})$, low intensity TENS (HFT); (2) high frequency $(80 \mathrm{~Hz})$, maximum tolerance intensity TENS (HIT); and (3) control TENS (COT) (high frequency $(30 \mathrm{~Hz})$, no specific instruction 
for intensity) (chapter 2). Patients reported that the severity of their pain was equally reduced with all three types of TENS, after a test period of two weeks. Approximately $62 \%$ of those patients, who rated the first test period as being positive, also gave a positive rating to the second test period with a different type of TENS. Therefore, there is no evidence of the superiority of a specific type of TENS in the treatment of patients with chronic pain. After the treatment periods, 100 (56\%) of the 180 patients included continued using TENS. At the six-month follow-up assessment, 75 (42\%) of the 180 patients initially entered in this study were still using TENS. A $28 \%$ versus $0 \%$ reduction in the intensity of pain was found in favor of the group of patients using TENS at six months.

- Several predictive factors, measured at baseline, were found for two defined outcome measures: (1) continuation of TENS in the long term; and (2) a 33\% reduction of pain in the long term (six months). Higher patient expectation, a diagnosis of neuropathic pain, and no severe pain ( $<80 \mathrm{~mm}$ VAS) were independently positively related to the continuation of TENS in the long term. For the outcome measure 'pain reduction $\geq 33 \%$ ', the factors of not having multi-sited pain and no constant pain were independently positively related. Therefore, factors associated with outcome measures in the long term are dependent on the type of outcome measure used.

— In order to explain why patients continue using TENS in the long term, we analyzed change scores between baseline and the six-month follow-up. Patients still using TENS in the long term (responders) reported a statistically significant improvement from baseline to the six-month follow-up in pain, catastrophizing beliefs, internal locus of control, self efficacy, and daily physical functioning compared to non-responders, with the exception of mental functioning. The effect varied from 0.10 to 0.85 in the responder group compared to 0.00 to 0.21 in the non-responder group. This shows that TENS also has effects in other areas than just pain relief. The most important factors contributing to the use of TENS in the long term were pain reduction and a decrease in pain catastrophizing, since both of these were the only independent factors associated with the long-term use of TENS. The availability of a device that patients can use themselves, whenever necessary, appears to be an important factor in the continuation of TENS. Moreover, responders were less often 'under treatment' and took less pain medication at six months, two factors also significantly associated with the long-term use of TENS.

— The Dutch Chronic Pain Self-efficacy Scale (CPSS) validation study uses a two-factor solution instead of the three-factor form of the original English version. The Dutch CPSS consists of two subscales; pain self-efficacy and functional self-efficacy. Both these subscales have been shown to be reliable and valid indices of specific self-efficacy beliefs in patients with multiple pain conditions. 
- Minimum clinical important change (MCIC) depends on whether the definition of the cutoff points is chosen from a clinician's/researcher's or a patient's point of view and on the treatment offered. An MCIC based on a clinician's/researcher's point of view was higher compared to that from a patient's point of view for pain relief after TENS treatment. The estimated MCIC for TENS treatment from a patient's point of view was lower than the recommended 30\% pain reduction for clinical trials into chronic pain. The recommended $30 \%$ reduction in pain was not applicable as a standard, clinically relevant change for all types of pain problems, pain measurements and pain treatments. Therefore, it is of the utmost importance to measure success from a patient's point of view.

\section{Discussion of the results}

In this section, we discuss the results of our studies and factors that could have influenced these results. Since no differences were found in our study between the types of TENS, the choices made regarding the design and execution of the effectiveness study are questionable.

\section{Study design}

Firstly, a cross-over design was used to test different types of TENS in the same patients. This type of design was chosen to increase the homogeneity of the study population since one patient is offered two treatments. We wanted to test whether a cross-over design is adequate, since the severity of the complaints must be equal prior to the start of both types of treatment. Any possible effects from the first treatment must have completely vanished before the second treatment is started. In our study, we used a two-week wash-out period after the first TENS treatment. Electrophysiological studies into experimental pain show that TENS has no long-lasting effects. The effects of TENS vanish within a few minutes to a maximum of one hour after treatment [9]. Therefore, the duration of the wash-out period (two weeks) seems adequate. This is further supported by the finding that there were no statistically significant differences in pain intensity scores at start of periods 1 and 2. An improvement in pain intensity at the start of period 2 compared to that of period 1 was reported by $9 \%$ of patients. In addition, $14 \%$ reported that pain intensity had worsened slightly at the start of period 2, compared to that of period 1. In our view, the limited changes in pain between baseline and the start of period 2, represent normal fluctuations in pain intensity and cannot be attributed to the long-term effect of the first two weeks of treatment with TENS. This result also indicates that TENS has no permanent long-term effect on pain reduction once it has been stopped. Therefore, the choice of a cross-over design seems to be appropriate for testing two types of TENS in one patient. 


\section{Study population}

Apart from the choice of a cross-over design to increase the homogeneity of the study population, we could also have used more strict inclusion criteria based on, for example, medical diagnosis. However, we chose not do this since the cause or location of chronic pain does not appear to be relevant to the effectiveness of TENS. TENS modulates nociceptive transmission throughout the nervous system, by closing the 'gate' in the dorsal horn and or the release of endogenous opioids [43]. Only type of pain was measured, as mechanisms involved in closing the gate may differ for nociceptive and neuropathic pain. We believe that our choice of inclusion criteria do not impede the finding of differences in effectiveness between types of TENS. Since our research was also aimed at determining the characteristics of responders and factors associated with the long-term use of TENS in patients normally seen in daily practice, a representative study population of patients with chronic pain was recruited.

\section{Adherence}

Another reason for the lack of effect could be adherence to the treatment protocol. Was TENS applied by patients in accordance with the instructions (daily use of TENS, three to six times a day for at least 30 minutes with HFT and HIT) provided by the therapist? Based on evaluations at the end of each treatment period, we noted that most patients (89\%) used TENS several times a day during the two weeks at the intensity levels instructed by the therapist. Only 6\% stopped during the treatment period, due to no effect, worsening of the pain or irritation of the skin. Reasons for drop-out (during the testing period) during high frequency low intensity TENS (HFT) were: increasing pain due to TENS (one patient); and during high frequency high intensity TENS (HIT): increasing pain due to TENS (one patient), problems handling TENS (attaching electrodes and/or using TENS; two patients), irritation of the skin (one patient), and two patients refused to stop for the two-week wash-out period because they had experienced positive effects from the first treatment period. We can, therefore, conclude that the majority of patients used TENS as instructed during the test period.

\section{Contrast between interventions}

It can also be queried whether the contrast between the chosen types of TENS was adequate. Different intensities of stimulus delivered by the type of TENS was the supposed critical factor for success. Longer pulse duration in combination with higher stimulus intensity was thought to be more effective, due to the stimulation of more afferent fibers [37]. Patients were instructed to use stimulus intensity just above threshold with HFT. In order to ensure that patients did not use stronger stimulations, which would diminish the contrast between HFT and HIT, we informed them that, with HFT, the less intense the stimulus, the better the results. During HIT, patients were instructed to use stimulus intensity at maximum tolerance, in order to produce 
a strong non-painful sensation. During COT, no specific instructions were given regarding stimulus intensity. At the end of each treatment period, patients evaluated TENS usage with their therapist. Based on these evaluations, and on the results of a pain diary kept during the treatment period, we can conclude that TENS treatment was used as intended. However, during the treatment with HFT, patients may have used an effective stimulus intensity, as patients were also instructed, during both HIT and HFT (but not during COT), to increase intensity as soon as the sensation of the current started to fade away during application. Increasing current amplitude (as stimulus perception fades away) in order to maintain the same intensity may lead to an effective dose, even when the sensation is only above sensory threshold [33]. Unfortunately, we did not collect exact data on the stimulus intensity used in our study and, therefore, we cannot rule out that there was insufficient contrast between the various types of TENS treatment. Recent research indicates a dose-specific effect of TENS on experimental pain in healthy humans [8-9; 11; 33]. However, the differences in success between strong painful stimulation and above-threshold stimulation were not statistically significant [33]. This is in line with our results. The finding that most patients responded equally to all types of TENS offered is striking. This could indicate that the personal preferences of patients are important [23]. It could be that patients choose a current intensity they assume to be comfortable and efficient for pain reduction, which appeals to their expectations. We found that pre-treatment expectations were predictive of the use of TENS in the long term. We also hypothesized that psychological factors (control, self-efficacy or catastrophizing) play a role in effectiveness in the long term. However, we did not measure changes in feelings of control or other psychological factors immediately after each test period. We assumed that these factors would be more important in the long term. This was confirmed by our findings of psychosocial factors associated with long-term outcome and of use of TENS. When looking at the results, this could even be an important factor in any evaluation immediately after the test period. Changes in beliefs about pain and control over pain are well known mediators in the successful treatment of patients suffering from chronic pain [2; 28; 44-45].

\section{Working mechanism}

The fact that all types of TENS showed equal effects calls into question the supposed separate working mechanisms per type. The equal effectiveness of our control TENS (COT), which was not based on the most ideal parameters when considering previous research, is particularly striking. According to the gate control theory, stimulation of large diameter afferents by high frequency TENS inhibits nociceptive fibre-evoked responses in the dorsal horn. The TENS parameters (HFT and HIT) in our study were primarily set up to stimulate large diameter afferent nerve afferents. According to the gate control theory, stimulation of large diameter afferents by high frequency TENS inhibits nociceptive fiber evoked responses in the dorsal horn. Inhibition, due to stimulation of large diameter afferents, can be the result of enhanced release of the inhibitory neurotransmitter $\gamma$-aminobutyric acid (GABA) [26]. As our control 
TENS was no shame treatment it is possible that all types of TENS in our study stimulated large diameter afferents sufficiently, to produce a pain relief by the release of GABA. However, Radhakrishnan and Sluka [37] found (in an animal study) that stimulation of large diameter afferent fibres from deep tissue are required and that activation of cutaneous afferents is not sufficient for TENS-induced pain reduction. Therefore higher pulse duration and higher pulse intensity were used in HIT, to stimulate more afferents from deep tissues. Again we found no better results for this type of TENS. A possible explanation is that working mechanism of type of TENS is not restricted to only one mechanism. In animal studies effects of high frequency TENS were also explained by other mechanisms than gate control theory [41]. For example, concentrations of b-endorphins in bloodstream and cerebrospinal fluid were increased by high frequency TENS and blockade of d-opioid receptors in the spinal cord reverses antihyperlagesia produced by high frequency TENS [41]. Also a decrease of glutamate and substance $P$ production in dorsal horn by high frequency TENS are reported [39; 42].

Therefore, a complicated neural circuitry seems to be activated in response to high frequency TENS that engages increased release of GABA, endogenous opioids, and decreased release of glutamate resulting in a reduction of nociception and consequently pain [41].

The effects of high frequency TENS on inhibition of nociceptive fibre-evoked response in the dorsal horn are all based on animal studies. Whether the effects found in these animal studies, translate into differences in hypoalgesic effects in humans is still a matter for debate, since psychological factors cannot be during animal studies.

All types of TENS used in our study probably stimulated large diameter afferent fibres. Therefore the effect of different types of TENS may be due to activations of various or a combination of, mechanisms involved in spinal inhibition of nociception. The finding of decreased catastrophizing associated with the use of TENS, and improvements in mental functioning in general might suggest that a supraspinal inhibitory effect, based on motivational-affective aspects of pain, is an important factor associated with effective pain relief by TENS. No definite conclusions regarding the evidence for effectiveness of TENS and proposed working mechanisms can be drawn on the basis of the results of this study. 


\section{Predicting long-term results}

Since the effectiveness of TENS for pain relief remains unclear, and there is only limited knowledge about the working mechanism of TENS in humans, it is important to discover which patients respond positively to TENS and which patients do not. The reason why TENS is effective in some patients and not in others is unclear. Knowledge of predictive factors can help in identifying those patients who should be referred to TENS and those who should not. Potential factors for predicting outcome were chosen from a biopsychosocial perspective, based on previous predictor studies in chronic pain in general. We analysed two outcome measures of success in order to discover which factors were associated with outcome:

- long-term continuation of TENS

- a minimum important pain reduction of 33\%

Traditionally, pain reduction is defined as the outcome measure for pain. However, as longterm follow-up studies report subgroups of patients continuing successfully with TENS, even for years at a time, we decided to define the continuation of TENS as an outcome measure as well. Patients may perceive benefits from TENS apart from pain reduction, which makes it a worthwhile intervention for them. Therefore, the continuation of TENS is not synonymous with pain reduction, but represents a different outcome in which several patient-perceived effects are incorporated.

For the long-term continuation of TENS, higher patient expectation, a diagnosis of neuropathic pain, and no severe pain (<80 mm VAS) were independently related. For the outcome'pain reduction $\geq 33 \%$, we found that not having multi-sited pain, intermittent pain, and a higher external locus of control were independently related to a supposed clinically-relevant pain reduction. The factors for predicting long-term use will be discussed first.

\section{Expectancies}

Higher expectancies were positively associated with the long-term use of TENS. These findings are in line with other studies $[25 ; 34 ; 40 ; 48]$. Expectations refer to the beliefs a patient has regarding the potential benefit of the treatment provided. The importance of expectations has been highlighted since higher pre-treatment expectations were predictive of improved outcome in several previous pain studies [18]. Patient expectations are an important issue since they can influence patient compliance. On the other hand, in our study, expectations were not associated with 30\% pain reduction. In other studies, positive treatment expectancy substantially enhanced (doubled) the pain-reducing effect of treatment, and negative treatment expectancy eliminated analgesia [6]. Why we did not find an association with 33\% or more pain reduction remains unclear. Perhaps the amount of pain reduction with TENS was in line with pre-treatment expectations, which were below a 33\% cut-off point. In our study, 
we measured expectancies, whether or not TENS was effective for pain relief in general. We did not inquire about the expected amount of pain relief. Efforts are needed to develop reliable and valid, yet simple tools for measuring aspects of expectations during clinical trials. It would be interesting to study more in detail, for example, by means of qualitative studies, what types of expectancies are important and how to measure these.

\section{Neuropathic pain}

Patients with neuropathic pain, or pain associated with disease or injury to the peripheral or central nervous system, were more likely to continue with TENS in the long term. Since TENS aims to reduce the transmission of nociceptive information throughout the nervous system, it seems logical that it can influence neuropathic pain. Seventy percent of patients with neuropathic pain continued with TENS in the long term. However, pain reduction in those patients was lower compared to patients with other pain diagnoses. During evaluation of the two TENS treatment periods, patients reported that, on average, TENS reduced the frequency and/or intensity of short spontaneous attacks of pain (characteristic for neuropathic pain) more than their more or less constant pain. This might explain long-term use, despite the lower average pain reduction. Our diagnosis of neuropathic pain was based on a detailed medical history and physical examination of the doctors at our pain clinic. No additional tests to quantify sensory characteristics were used as part of the examination. Adding a disease-specific questionnaire, such as the LANSS pain scale [5] or DN4 [7], based on descriptors that specifically define the most common qualities of neuropathic pain, would have provided more insight into the nature of pain relief in this group of patients. In neuropathic pain, evaluating the success of treatment by means of average pain reduction is probably not the best method of choice.

\section{Severity of pain}

Severe pain (> $80 \mathrm{~mm}$ VAS) was found to be negatively associated with the long-term use of TENS. Severe pain is recognised as a highly treatment-resistant type of pain, since it is associated with more interference during daily activities as well as psychosocial distress [30]. Moreover, severe pain may also be associated with impaired spinal GABAergic inhibitory function due to continuous nociceptive input [21]. Since pain relief with TENS is produced by the effective release of GABA within the dorsal horn, this could explain why patients with severe pain experience perceived no effect. 
We will now discuss the predictive factors for the outcome 'pain reduction $\geq 30 \%$ ', multi-sited pain, intermittent pain, and higher external locus of control.

\section{Multi-sited pain}

The finding of multi-sited pain as a negative predictive factor for pain reduction of $30 \%$ is in line with other research. The outcome of treatment has been found to be negatively influenced by other co-existing pain complaints $[20 ; 22 ; 35]$. It has been determined in a number of studies that there is a strong relationship between multi-sited pain and psychosocial distress [30]. Andersson et al. [1] found that a group of subjects with three or more injured body parts had a significantly worse prognosis of being pain free at the 24-month followup. Compared to patients with localised pain, multi-sited pain patients report greater pain intensity, longer pain duration, and greater disability [30]. In fibromyalgia patients, the number of local areas of pain has been found to be an independent predictor of pain intensity [46]. Estimates of multi-sited or widespread pain vary from $4.1-13.5 \%$ [27; 30]. In the small number of studies dealing with multi-sited pain within a clinical population, prevalence ranged from 15-21\% [30]. In our study, a larger percentage of the study population (49\%) suffered from multi-sited pain. This might have affected our overall results since multi-sited pain can be seen as a more complex and treatment-resistant pain problem. Therefore, it could be argued that multi-sited pain is an important measure in the clinical setting, even more so than pain intensity or site-specific pain [14].

\section{Intermittent pain}

In a single day, an individual with chronic pain may note that his or her level of pain varies greatly. It is not uncommon for pain scores on a 10-cm visual analogue scale (VAS) to range from 2 to 10 [50]. This variation in the intensity of chronic pain is thought to be due to systematic trends in pain levels that may be attributable to the pathogenesis of the condition, or fluctuations around a mean pain level that lacks any underlying trend [19]. It is thought that pain variability is a predictor of drug responsiveness. For example, Harris et al. [19] showed that individuals with greater pain variability at baseline were more likely to be responders. This is in line with our findings, and shows that intermittent pain was associated with a better response to TENS. However, it should be noted that we did not specifically measure fluctuation patterns over time. Specific explanations for this finding remain speculative; less fluctuation in pain severity may represent a less sufficiently working endogenous pain inhibitory system [17]. The properties of fluctuations in ongoing pain most likely reflect the interaction between peripheral and central processes, prompting the pain and coping mechanisms that patients develop to deal with the condition best. Less fluctuation is as- 
sociated with less ability to cope with the condition [17]. One obvious candidate system that can control this parameter is the integrity of descending modulatory pathways, which provides supraspinal feedback control on spinal cord nociceptive neurons and limits nociceptive cephalic information transmission [16; 38]. Therefore, the temporal properties of pain can reveal new information with potential mechanistic and clinical significance [17]. However, too few studies focus on pain variability within individuals over time to make it possible to comment on the importance and/or meaning of pain variability. This specific result of our study shows that future research on pain variability over time could be an important factor in determining the effect of treatment. 


\section{Why patients use TENS in the long term}

Another aim of our study was to explore why patients use TENS or rate TENS as successful in the long term. Since pain is a multidimensional phenomenon, we hypothesised that patients, besides for pain relief, continue to use TENS due to its effects in the areas of physical and mental functioning, self-efficacy, pain catastrophizing, and feelings of control. Indeed, responders (users) had relatively high positive and statistically significant effects for catastrophizing beliefs, feelings of control, self-efficacy, and daily physical functioning compared to non-responders. Therefore, we can conclude that TENS might be effective in other areas than just pain relief. Whether these effects are the indirect consequence of a reduction in pain or are due to other mechanism, remains unclear. In the multiple regression analysis, both pain relief and a decrease in catastrophizing beliefs were independently associated with the continuation of TENS in the long term. Pain catastrophizing is characterized by the tendency to magnify the threat value of pain stimulus, to increase worry about pain and its consequences, and to feel helpless in the context of pain [36]. Possible explanations for a decrease in catastrophizing by TENS could be: (1) attention diverted from the pain sensation due to increased awareness of the electric sensation, resulting in less magnification; (2) reduced feelings of helplessness (since TENS is a self-administered treatment); and (3) improvements in other areas, such as improved physical functioning, resulting in less worry as the patient becomes more active (also diverting the patient's attention away from his pain). This finding confirms our hypothesis that TENS might work by enhancing feelings of control, since it is a self-administered treatment which the patient can decide when and how to use. Unfortunately, the Pain Coping and Cognition List does not measure these sub-domains of catastrophizing specifically, so we cannot explain in more detail how TENS influences catastrophizing. Other studies [28; 44] also showed that a biomedical approach has potential effects in psychosocial areas.

The results of our study underscore the need to address psychological aspects in the management of patients with musculoskeletal pain, and may open the path for a bettertailored treatment approach in this group of patient [49].

The variability of pain relief in patients continuing to use TENS was great. Some patients even reported no or only a small amount of pain reduction, but still continued to use TENS. It is well known that patient satisfaction with treatment does not always correlate with sufficient pain relief. Patients tend to be satisfied with treatment even when they do not experience pain relief [29]. This could be due to (a combination of) reported improvements in daily functioning and psychological factors. Another explanation is that TENS is used by patients as a replacement for other pain treatments. As TENS is a low-cost, easy-to-use treatment with only minor side effects, patients may prefer to use it over other treatments even when they do not experience better results.

Nevertheless, we only found two factors independently associated with the use of TENS. Moreover, the explained variance for the continuation of TENS in the long term by pain relief and deceased pain catastrophizing was also unclear and needs further research. 


\section{Chronic pain self-efficacy scale}

We hypothesized that TENS can be helpful in increasing feelings of self-control and self-efficacy. Self-efficacy is considered to be one of the most important variables in understanding how patients adjust to pain $[24 ; 31]$. There is evidence that higher self efficacy about managing pain is associated with more positive treatment outcomes, higher return to work rates, better adherence and more effective control of pain [31].

Since no measurement for self-efficacy was available in the Dutch language, we translated and validated a Dutch version of the Chronic Pain Self efficacy Scale (CPSS-DLV). The results showed that the CPSS-DLV is a reliable and valid measurement instrument for assessing area-specific, self-efficacy beliefs in Dutch patients with a variety of chronic pain complaints. However, our confirmatory factor analysis could not establish the existence of the three proposed sub-scales in the original CPSS. Our exploratory factor analysis only distinguished two subscales; pain self-efficacy and functional self-efficacy.

As a tailored treatment approach targets other goals than just pain relief, especially that of improving daily functioning despite the presence of pain, we think it is necessary to measure important beliefs more specifically. However, since both sub-scales were highly correlated, the importance of measuring pain self-efficacy and functional self-efficacy separately remains a matter of discussion, and hopefully further analysis will confirm the clinical relevance of the distinction between pain and functional self-efficacy beliefs.

\section{Minimally clinical important change}

Finally, we analyzed whether treatment success can be defined by using the concept of minimum clinical important change (MCIC). The recommended MCIC of 30\% pain reduction is based on an arbitrary cut-off point on a globally-perceived effect scale (GPE), derived from the perspective of a researcher or clinician [13]. In our study, we estimated an MCIC from the clinician's and the patient's perspective for three VAS pain scales (average pain, worst pain and least pain during the past 7 days). This resulted in different MCIC's, with a lower MCIC for the method using the patient's perspective for all three pain scales. Our results clearly showed that defining a minimum important change by a researcher or clinician is not the same as asking patients to define the amount of change that is important to them. The perspective of a researcher or clinician does not take into account the potential harm or inconvenience of the treatment, or the effects of treatment other than pain relief. Therefore, the tempting idea of one universal MCIC cannot be applied to the field of pain. There is a need for new methods the evaluate success of treatment in chronic pain form a patients point of view [3-4; 15; 52]. In order to establish new methods for evaluating treatment outcome relating to pain, further studies, including qualitative ones, are needed to examine how patients rate a treatment as being successful. We also estimated the minimal detectable change (MDC) forVAS pain scales (average pain, worst pain and least pain) to compare with MCIC. In all pain scales MDC for 
absolute pain scores were higher as MCIC absolute pain scores. The percentage MDC based on classification of unchanged of GPE, was slightly better, at least for average pain scale. However in the type of SEM estimation used to calculated percentage MDC no systematic error was included[12]. Therefore the real percentage MDC is probably somewhat higher. These findings indicate that measuring clinical relevant change in pain severity with VAS pain scales is difficult due to large measurement error. 


\section{Implications for clinical practice}

Our study on the effectiveness of different types of TENS did not result in direct recommendations for the use of a particular type of TENS in daily practice. Neither can we conclude that TENS in general is an effective treatment, since we had no control group receiving no treatment or a placebo. However, based on the results of our study, we recommend the following for daily practice, if TENS is opted for:

- Based on the factors found to be associated with the continuation of TENS and/or minimum clinical pain reduction, we do not recommend the use of TENS for all patients with chronic pain. Factors found to be associated with the outcome of TENS should be assessed during a routine clinical examination and/or by routine questionnaires.

— In particular in patients with multi-sited pain, for example, fibromyalgia patients, we do not recommend the use of TENS. In patients with severe pain, we believe it is necessary to explore why that pain is so severe prior to treatment. If it is due to higher levels of catastrophizing, then TENS can be part of a multimodal treatment. When patients have neuropathic and/or intermittent pain, TENS can be considered as a treatment option.

- We suggest that TENS should only be used as a mono-treatment in patients with chronic pain who want to stop or lessen pain medication, since it appears to be an appropriate substitute for pain medication and/or other pain treatment.

- The fact that the use of TENS in the long term resulted in positive effects regarding feelings of control and physical and mental functioning, means that it could be integrated into a multimodal pain management programme in which patients learn to cope with their pain. In particular, the reduction of pain catastrophizing thoughts associated with use of TENS could support other treatments aimed at empowering patients in self management. Combining treatment for pain relief and learning to cope with pain (self management) could be more effective [32].

- When TENS is offered to a patient, preferences regarding stimulus sensation and expectancies about effects should first be assessed. In this regard, exploring the expectancies of effectiveness should not be restricted to pain relief only. Since caregivers can influence expectations by their style of communication, a positive approach (I think this will work for you) as opposed to a neutral one (It may or may not work for you) is recommended [18].

- When evaluating the effectiveness of a test period with TENS treatment, effectiveness must be evaluated from a patient's point of view. 


\section{Implications for future research}

Based on the results of this study, we do not currently recommend that studies comparing the effectiveness of different types of TENS in patients with chronic pain should be undertaken. It would seem to be more important to discover whether or not an electrical stimulus has a potential (dose-related) effect in inhibiting nociceptive transmission throughout the pain system in humans.

- Measurement of pain reduction in future TENS studies should not be solely based on the subjective changes in pain reported by patients. Objective measures of changes in transmission and/or the activation of pain processing neurophysiologic pathways, for example, by evoked potentials [47], should be conducted to establish whether TENS stimulus really modulates nociceptive transmission in humans.

- In this study, we noted that pain-related variables were associated with the outcome of TENS. Whether these pain-related variables reflect differences in pain aetiology is unknown. In future research, a more detailed examination of specific pain patterns (severity of pain, multi-sited, fluctuations pattern) should be taken into account in order to discover what type of pain profile can or cannot be positively influenced by electrical stimulation.

- As well as specific pain patterns, the influence of 'central sensitisation' on the effectiveness of TENS must be considered when designing new trials. The concept of 'central sensitisation' has recently been proposed as a possible explanation for chronic pain in general [51]. We suggest measuring these sensitisation phenomena by quantitative sensory testing in order to establish several thermal pain and mechanical pain thresholds and/or tolerance thresholds. The results of this could provide us with information on the type of hypersensitivity that is related to the effectiveness of TENS.

- The influence of psychological factors needs further elaboration. More detailed assessments of constructs related to expectations, catastrophizing, control of pain, and/or selfefficacy in coping with pain, could enhance our knowledge of how TENS works and how to instruct patients to use it.

- Use of TENS together with other treatments, aimed at increasing daily functioning and/ or coping with pain, seems to be worthwhile since combining treatments appears to enhance the overall effect [10; 32]. Research should be undertaken into which combination works the best.

- Future research on defining the success of treatment should be based on patients' perception of what is an important change in relation to the negative aspects of the treatment. Designing strategies to assess pre-treatment expectations of outcome in more than one area, in combination with designing methods for evaluation of treatment results, is also necessary for establishing which and when treatment is considered successful. 


\section{References}

[1] Andersson HI, Ejlertsson G, Leden I, Rosenberg C. Characteristics of subjects with chronic pain, in relation to local and widespread pain report. A prospective study of symptoms, clinical findings and blood tests in subgroups of a geographically defined population. Scand J Rheumatol 1996;25(3):146154

[2] Arnstein P, Caudill M, Mandle CL, Norris A, Beasley R. Self efficacy as a mediator of the relationship between pain intensity, disability and depression in chronic pain patients. Pain 1999;80(3):483-491

[3] Barrett B, Brown D, Mundt M, Brown R. Sufficiently important difference: expanding the framework of clinical significance. Med Decis Making 2005;25(3):250-261

[4] Barrett B, Brown R, Mundt M, Dye L, Alt J, Safdar N, Maberry R. Using benefit harm tradeoffs to estimate sufficiently important difference: the case of the common cold. Med Decis Making 2005;25(1):47-55

[5] Bennett M. The LANSS Pain Scale: the Leeds assessment of neuropathic symptoms and signs. Pain 2001;92(1-2):147-157

[6] Bingel U, Wanigasekera V, Wiech K, Ni Mhuircheartaigh R, Lee MC, Ploner M, Tracey I. The effect of treatment expectation on drug efficacy: imaging the analgesic benefit of the opioid remifentanil. Sci Transl Med 2011;3(70):70ra14

[7] Bouhassira D, Attal N, Alchaar H, Boureau F, Brochet B, Bruxelle J, Cunin G, Fermanian J, Ginies P, GrunOverdyking A, Jafari-Schluep H, Lanteri-Minet M, Laurent B, Mick G, Serrie A, Valade D, Vicaut E. Comparison of pain syndromes associated with nervous or somatic lesions and development of a new neuropathic pain diagnostic questionnaire (DN4). Pain 2005;114(1-2):29-36

[8] Chen CC, Johnson MI. An investigation into the effects of frequency-modulated transcutaneous electrical nerve stimulation (TENS) on experimentally-induced pressure pain in healthy human participants. J Pain 2009;10(10):1029-1037

[9] Chen CC, Johnson MI. Differential frequency effects of strong nonpainful transcutaneous electrical nerve stimulation on experimentally induced ischemic pain in healthy human participants. Clin J Pain 2011;27(5):434-441

[10] Chiu TTW, Hui-Chan CWY, Cheing G. A randomized trial of TENS and exercise for patients with chronic neck pain. Clinical Rehabilitation 2005;19:850-860

[11] Claydon LS, Chesterton LS, Barlas P, Sim J. Dose-specific Effects of Transcutaneous Electrical Nerve Stimulation (TENS) on Experimental Pain: A Systematic Review. Clin J Pain 2011

[12] de Vet HC, Terwee CB, Knol DL, Bouter LM. When to use agreement versus reliability measures. J Clin Epidemiol 2006;59(10):1033-1039

[13] Dworkin RH, Turk DC, Farrar JT, Haythornthwaite JA, Jensen MP, Katz NP, Kerns RD, Stucki G, Allen RR, Bellamy N, Carr DB, Chandler J, Cowan P, Dionne R, Galer BS, Hertz S, Jadad AR, Kramer LD, Manning DC, Martin S, McCormick CG, McDermott MP, McGrath P, Quessy S, Rappaport BA, Robbins W, Robinson JP, Rothman M, Royal MA, Simon L, Stauffer JW, Stein W, Tollett J, Wernicke J, Witter J. Core outcome measures for chronic pain clinical trials: IMMPACT recommendations. Pain 2005;113(1-2):9-19

[14] Eggermont LH, Shmerling RH, Leveille SG. Tender point count, pain, and mobility in the older population: the mobilize Boston study. J Pain 2010;11(1):62-70 
[15] Ferreira ML, Herbert RD, Ferreira PH, Latimer J, Ostelo RW, Nascimento DP, Smeets RJ. A critical review of methods used to determine the smallest wothwhile effect of interventions for low back pain. 2011:accepted for publication

[16] Fields HL. Pain: an unpleasant topic. Pain 1999;Suppl 6:S61-69

[17] Foss JM, Apkarian AV, Chialvo DR. Dynamics of pain: fractal dimension of temporal variability of spontaneous pain differentiates between pain States. J Neurophysiol 2006;95(2):730-736

[18] George SZ, Robinson ME. Preference, expectation, and satisfaction in a clinical trial of behavioral interventions for acute and sub-acute low back pain. J Pain 2010;11(11):1074-1082

[19] Harris RE, Williams DA, McLean SA, Sen A, Hufford M, Gendreau RM, Gracely RH, Clauw DJ. Characterization and consequences of pain variability in individuals with fibromyalgia. Arthritis Rheum 2005;52(11):3670-3674

[20] Hill JC, Lewis M, Sim J, Hay EM, Dziedzic K. Predictors of poor outcome in patients with neck pain treated by physical therapy. Clin J Pain 2007;23(8):683-690

[21] Janssen SP, Truin M, Van Kleef M, Joosten EA. Differential GABAergic disinhibition during the development of painful peripheral neuropathy. Neuroscience 2011;184:183-194

[22] Jellema P, van der Horst HE, Vlaeyen JW, Stalman WA, Bouter LM, van der Windt DA. Predictors of outcome in patients with (sub)acute low back pain differ across treatment groups. Spine (Phila Pa 1976) 2006;31(15):1699-1705

[23] Johnson MI, Ashton CH, Thompson JW. An in-depth study of long-term users of transcutaneous electrical nerve stimulation (TENS). Implications for clinical use of TENS. Pain 1991;44(3):221-229

[24] Keefe FJ, Ahles TA, Porter LS, Sutton LM, McBride CM, Pope MS, McKinstry ET, Furstenberg CP, Dalton J, Baucom DH. The self-efficacy of family caregivers for helping cancer patients manage pain at end-oflife. Pain 2003;103(1-2):157-162

[25] Linde K, Witt CM, Streng A, Weidenhammer W, Wagenpfeil S, Brinkhaus B, Willich SN, Melchart D. The impact of patient expectations on outcomes in four randomized controlled trials of acupuncture in patients with chronic pain. Pain 2007;128(3):264-271

[26] Maeda Y, Lisi TL, Vance CG, Sluka KA. Release of GABA and activation of GABA(A) in the spinal cord mediates the effects of TENS in rats. Brain Res 2007;1136(1):43-50

[27] Manchikanti L, Singh V, Datta S, Cohen SP, Hirsch JA. Comprehensive review of epidemiology, scope, and impact of spinal pain. Pain Physician 2009;12(4):E35-70

[28] Mannion AF, Junge A, Taimela S, Muntener M, Lorenzo K, Dvorak J. Active therapy for chronic low back pain: part 3. Factors influencing self-rated disability and its change following therapy. Spine (Phila Pa 1976) 2001;26(8):920-929

[29] Marnie, Morabia A, Bernstein M, Klopfenstein CE, Forster A. Treatment efficacy is not an index of pain intensity. Can J Anaest 2000;47(12):1166-1170

[30] Mayer TG, Towns BL, Neblett R, Theodore BR, Gatchel RJ. Chronic widespread pain in patients with occupational spinal disorders: prevalence, psychiatric comorbidity, and association with outcomes. Spine (Phila Pa 1976) 2008;33(17):1889-1897

[31] Miles CL, Pincus T, Carnes D, Taylor SJ, Underwood M. Measuring pain self-efficacy. Clin J Pain $2011 ; 27(5): 461-470$ 
[32] Molloy AR, Nicholas MK, Asghari A, Beeston LR, Dehghani M, Cousins MJ, Brooker C, Tonkin L. Does a combination of intensive cognitive-behavioral pain management and a spinal implantable device confer any advantage? A preliminary examination. Pain Pract 2006;6(2):96-103

[33] Moran F, Leonard T, Hawthorne S, Hughes CM, McCrum-Gardner E, Johnson MI, Rakel BA, Sluka KA, Walsh DM. Hypoalgesia in Response to Transcutaneous Electrical Nerve Stimulation (TENS) Depends on Stimulation Intensity. J Pain 2011;12(8):929-935

[34] Myers SS, Phillips RS, Davis RB, Cherkin DC, Legedza A, KaptchukTJ, Hrbek A, Buring JE, Post D, Connelly MT, Eisenberg DM. Patient expectations as predictors of outcome in patients with acute low back pain. J Gen Intern Med 2008;23(2):148-153

[35] Pincus T, Burton AK, Vogel S, Field AP. A systematic review of psychological factors as predictors of chronicity/disability in prospective cohorts of low back pain. Spine (Phila Pa 1976) 2002;27(5):E109 120

[36] Quartana PJ, Campbell CM, Edwards RR. Pain catastrophizing: a critical review. Expert Rev Neurother 2009;9(5):745-758

[37] Radhakrishnan R, Sluka KA. Deep tissue afferents, but not cutaneous afferents, mediate transcutaneous electrical nerve stimulation-Induced antihyperalgesia. J Pain 2005;6(10):673-680

[38] Ren K, Dubner R. Descending modulation in persistent pain: an update. Pain 2002;100(1-2):1-6

[39] Rokugo T, Takeuchi T, Ito H. A histochemical study of substance $P$ in the rat spinal cord: effect of transcutaneous electrical nerve stimulation. J Nihon Med Sch 2002;69(5):428-433

[40] Rubinstein SM, Knol DL, Leboeuf-Yde C, de Koekkoek TE, Pfeifle CE, van Tulder MW. Predictors of a favorable outcome in patients treated by chiropractors for neck pain. Spine (Phila Pa 1976) 2008;33(13):1451-1458

[41] Sluka KA. Mechanisms and management of pain for the physical therapist. Seattle: IASP Press, 2009

[42] Sluka KA, Vance CG, Lisi TL. High-frequency, but not low-frequency, transcutaneous electrical nerve stimulation reduces aspartate and glutamate release in the spinal cord dorsal horn. J Neurochem 2005;95(6):1794-1801

[43] Sluka KA, Walsh D. Transcutaneous electrical nerve stimulation: basic science mechanisms and clinical effectiveness. J Pain 2003;4(3):109-121

[44] Smeets RJ, Vlaeyen JW, Kester AD, Knottnerus JA. Reduction of pain catastrophizing mediates the outcome of both physical and cognitive-behavioral treatment in chronic low back pain. J Pain 2006;7(4):261-271

[45] Spinhoven P, Ter Kuile M, Kole-Snijders AM, Hutten Mansfeld M, Den Ouden DJ, Vlaeyen JW. Catastrophizing and internal pain control as mediators of outcome in the multidisciplinary treatment of chronic low back pain. Eur J Pain 2004;8(3):211-219

[46] Staud R. Predictors of clinical pain intensity in patients with fibromyalgia syndrome. Curr Pain Headache Rep 2005;9(5):316-321

[47] Treede RD, Lorenz J, Baumgartner U. Clinical usefulness of laser-evoked potentials. Neurophysiol Clin 2003;33(6):303-314 
[48] van Wijk RM, Geurts JW, Lousberg R, Wynne HJ, Hammink E, Knape JT, Groen GJ. Psychological predictors of substantial pain reduction after minimally invasive radiofrequency and injection treatments for chronic low back pain. Pain Med 2008;9(2):212-221

[49] Westman AE, Boersma K, Leppert J, Linton SJ. Fear-Avoidance Beliefs, Catastrophizing, and Distress-A Longitudinal Subgroup Analysis on Patients With Musculoskeletal Pain. Clin J Pain 2011

[50] Williams DA, Gendreau M, Hufford MR, Groner K, Gracely RH, Clauw DJ. Pain assessment in patients with fibromyalgia syndrome: a consideration of methods for clinical trials. Clin J Pain 2004;20(5):348356

[51] Woolf CJ. Central sensitization: implications for the diagnosis and treatment of pain. Pain 2011;152(3 Suppl):S2-15

[52] Yelland MJ, Schluter PJ. Defining worthwhile and desired responses to treatment of chronic low back pain. Pain Med 2006;7(1):38-45 



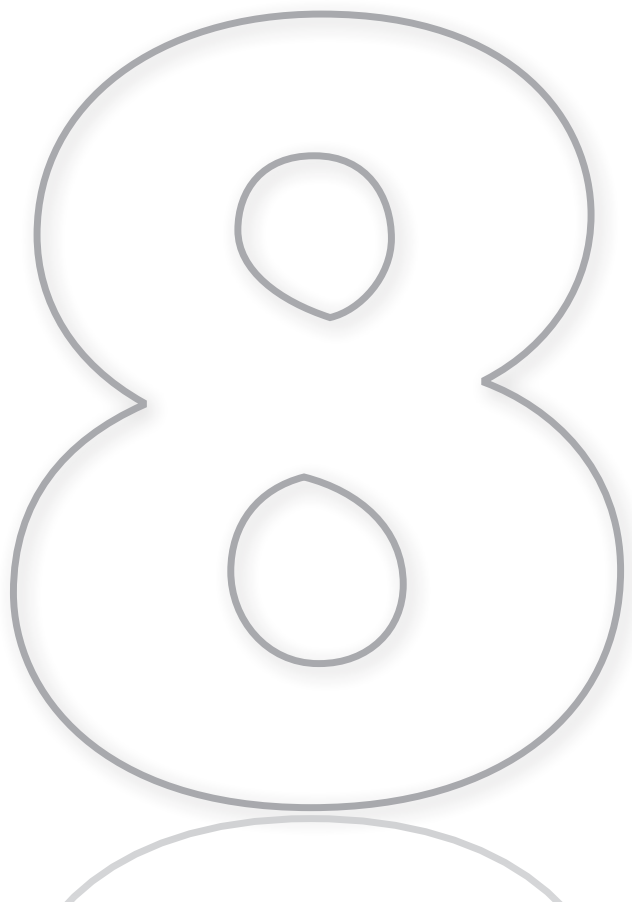

Summary 

Research in the past decades has made progress on the elucidation of causal mechanism, assessment and treatment of chronic pain. Nevertheless, several prevalence studies have been published showing that chronic pain is a very common condition, and is even increasing throughout the past decade. Most chronic pain patients persist in seeking treatment, although the effectiveness of all current treatments aimed at pain relief offered, remains limited. Chronic pain therefore is a highly refractory health problem resulting in increasing healthcare costs and prolonged patient suffering. Because of today's high prevalence and still unclear aetiology of chronic pain, there is a pressing need for effective low cost treatment with no or minor side effects. As Transcutaneous Electrical Nerve Stimulation (TENS) is a non invasive, inexpensive, safe, non-addictive, easy to use treatment with no or minor side effects (skin irritation), it seems worthwhile to examine its effectiveness. In this thesis the effectiveness of TENS in patients with chronic pain complaints is examined. The research was aimed at effectiveness of different types of TENS, for whom TENS may be a successful treatment and what factors are associated with prolonged use of TENS. Also the degree of pain reduction at which a patient considers the TENS treatment as successful was examined.

In chapter $\mathbf{2}$ the results of a randomized cross-over study of the pain reducing effect of three types of TENS is described. Type of TENS is based on a combination of pulse frequency (low (1-10 Hz) vs. high (50-100 HZ), pulse duration (50 ms - $250 \mathrm{~ms}$ ) and stimulus intensity (below threshold - pain tolerance). The three types of TENS studied were:

1) Conventional high frequency TENS (HFT), frequency of $80 \mathrm{~Hz}, 80$ microseconds pulse duration 80 and intensity at sensory threshold intensity. Patients were instructed to use TENS 4-6 times a day for 1 hour periods.

2) High frequency high-intense TENS group (HIT), frequency $80 \mathrm{~Hz}, 250$ microseconds pulse duration and intensity at maximum tolerance intensity level. Patients were instructed to use TENS 4-6 times a day for 30 minutes periods.

3) Control TENS group (COT), frequency $30 \mathrm{~Hz}, 250$ microseconds pulse duration and patients were free to choose stimulus duration and stimulus intensity as they preferred.

A total of 180 patients with various musculoskeletal pain complaints were included in the study. Each patient was received two out of three possible types of TENS. Type and order of TENS in time was randomized. A treatment period consisted of two weeks TENS treatment. Patients used their TENS, after instruction by a physical therapist, at home on daily basis. After the first treatment period, there was a period of 2 weeks with no treatment (wash out period). After the wash out period the second treatment period of 2 weeks was started.

At start and end of each treatment period, the severity of pain was measured with a $100 \mathrm{~mm}$ visual analogue scale (VAS). Also at the end of each treatment period patients were asked whether the effect of the treatment was sufficient to continue that type of TENS on long term.

After 6 months pain severity and use of TENS was measured again. 
After the two treatment periods 100 patients continued the TENS treatment No statistical significant difference was found in pain reduction between the three types used during the two treatment periods. A majority of the patients (62\%) stated to continue TENS with both types of TENS tested, as both types were found equally effective. At 6 months follow up data of 149 patients were available. Of these 149 patients 75 were still using TENS, whereas 74 patients did not. The TENS-users had statistical significant greater pain reduction compared to non-users ((28\% (SD 35\%) en 0\% (SD41\%)). The final conclusion of the study was that there is no difference in pain reducing effect between the three types of TENS. A relative large group of patients (42\%) continues to use TENS even after 6 months.

In chapter $\mathbf{3}$ the results of an analysis of factors that may predict the success of TENS are discussed. Pain is a multidimensional problem, in which there is a complex interaction between physical, cognitive, affective and behavioural factors. Due to differences in aetiology of pain and/or psychosocial factors, one cannot expect that each individual patient with chronic pain responds equally to TENS. What types of pain complaints and/or psychological factors are associated with positive outcome of TENS are not known. To gain more insight into possible factors predictive for long term outcome a number of pain related variables ( pain severity, pain quality, neuropathic pain, intermitted pain, and number of pain locations) psychosocial variables (catastrophizing, expectancies, locus of control, mental health) and factors related to functioning ( daily activities and work status) were measured at the start of treatment. Two type of positive outcome were used; 1) continuing TENS at 6 months and a pain reduction of $33 \%$ (measured with a VAS pain scale) at 6 months. Different results were found for each type of outcome in 149 patients who completed the questionnaires at 6 months follow-up. Higher expectancies that TENS could resolve pain prior to the start of treatment, having neuropathic pain, a pain severity score below 80 mm VAS were independently associated with continued use of TENS at 6 months. The factors 'intermittent pain' and 'more than 2 pain locations' were associated with the outcome pain reduction of $33 \%$ ore more.

Chapter 4 describes the factors contributing to the continued use of TENS in the longer term. The main purpose of TENS treatment is to reduce the severity of the pain. The degree of pain relief by TENS differs varies from patient to patient. Some patients continue to use TENS despite a little or no improvement in pain severity. The question therefore was whether TENS has other effects that can explain the continued use of TENS.

To answer this question at the start and the end of treatment several other outcomes were measured. Results showed that TENS-users at 6 months had, besides less pain, statistical significant improvements in daily functioning, catastrophizing, feelings of control and selfefficacy compared to non-users. However in group of TENS-users less people returned to work compared to non-users. Multivariate regression analysis showed that the decrease in catastrophizing and pain reduction were both independently associated with the continua- 
tion of TENS. Also less use of pain medication and health care (doctor visits) were associated with the use of TENS at 6 months. The results show that TENS has important effects in other domains than pain, and that these effects contribute to the use of TENS.

In chapter $\mathbf{5}$ the validation of a Dutch translation of the Chronic Pain Self-efficacy Scale (CPSS), to measure level of self-efficacy in coping with pain and disability in patients with chronic pain, is described.

Self-efficacy is considered to be one of the most important variables in understanding how patients adjust to pain. Self-efficacy refers to the belief that required behaviours can be successfully performed in given situations or domains. People with stronger self efficacy beliefs are thought to be more determined and persistent in performing certain behaviours to deal with pain and pain related disability. It is hypothesised that TENS can improve selfefficacy for pain as TENS is a treatment that can be self-administrated by the patient. The Englisch version of the CPSS consists of 22 items and can be divided into three subscales; self-efficacy in dealing with the pain, self-efficacy in dealing with symptoms and self-efficacy in dealing with physical functioning. The results of a confirmatory factor analysis with the Dutch CPSS, executed in 231 patients with chronic pain, did not confirm the original three factor structures. In an exploratory factor analysis 2 factors (self-efficacy for dealing with pain and self-efficacy for dealing with physical functioning) were found. Of all 22 items 2 did not contribute to either one of the factors found. Both items were therefore removed from the Dutch CPSS. Also construct validity en test-retest reliability of the Dutch CPSS were studied and found to be adequate. As both factors (pain self-efficacy and physical functioning selfefficacy) are independent but correlate highly (0.70) further research is necessary to confirm these findings in another pain population.

Chapter $\mathbf{6}$ presents the results of an analysis what amount of pain reduction patients consider relevant to define TENS treatment as successful. For this purpose the concept of 'minimally clinically important change' (MCIC) was used. A'minimal clinically important difference' is defined as the smallest difference in score in the domain of interest which patients perceive as beneficial and which mandates, in the absence of troublesome side effects and excessive cost, a change in the patient's management. The term 'minimally clinically important difference' is used to indicate differences between patients, for a change in health status within patients the term 'minimally clinically important change' (MCIC) is used. For pain research a 30\% decrease in pain for an individual patient has been recommended as a reasonable $\mathrm{MCIC}$ for all acute and chronic pain complaints irrespective of interventions provided. This recommended $30 \%$ pain reduction was based on a cut point chosen from the clinician's perspective and not from a patient's point of view. Furthermore, a MCIC is regarded as context-specific, which means that $\mathrm{MCIC}$ is specific for the intervention provided and the population under It is important to find out if the recommended MCIC can be generalized to treatments with no or only minor side effects, such as TENS. Patient might consider less pain reduction as successful 
in such type of treatments. The MCIC was therefore calculated from a clinician's and a patient's perspective. The results showed that MCIC from a patient's perspective (20\% pain reduction) was lower compared to a MCIC from a clinician's perspective (40\% pain reduction). The MCIC from a patient's perspective was also lower as the recommended 30\% pain reduction in pain research. Therefore one uniform standard value for clinically relevant change seems not applicable as treatments are different in amount of pain reduction, side effects and/or other inconveniences. The current methods for calculating such a standard are currently not sufficiently explicit and valid. 
Samenvatting 

De afgelopen decennia is er veel progressie geboekt op het achterhalen van de oorzaak van chronische pijn en de behandeling ervan. Desondanks, tonen diverse prevalentie studies aan dat het probleem chronische pijn groeiende is. De meeste patiënten met chronische pijn blijven zoeken naar een behandeling die de pijn wegneemt. De effectiviteit van het huidige behandelaanbod voor chonische pijn is echter maar beperkt effectief. Chronische pijn is een therapie resistent gezondheidsprobleem wat leidt to hoge gezondheidsgerelateerde en maatschappelijke kosten. Doordat de oorzaak vaak onduidelijk is en het voorkomen van chronische pijn stijgt, is er behoefte aan een effective, goedkopen behandeling met weinig bijwerkingen. Transcutane elektrische neuro stimulatie (TENS) is een niet invasieve, veilige, goedkope behandeling, met weinig tot geen bijwerkingen, die de patient zelf kan uitvoeren. Het onderzoek gepresenteerd in dit proefschrift is gericht op de behandeling met TENS van patiënten met chronische pijn. TENS is een behandeling voor pijn, waarbij via electrodes op de huid, zenuwvezels elektrisch gestimuleerd worden met als doel pijn te verminderen. Onderzocht is wat de effectiviteit van verschillende typen TENS is, voor wie TENS mogelijk een succesvolle behandeling is en wat factoren zijn die bijdragen aan een langdurig gebruik van TENS. Tevens is onderzocht bij welke mate van pijnvermindering patiënten de TENSbehandeling als succesvol beoordelen.

In hoofdstuk 2 zijn de resultaten van een gerandomiseerde cross-over studie naar het pijnverminderende effect van drie typen TENS beschreven. Het type TENS wordt gedefinieerd op basis van de in te stellen parameters; impulsfrequentie (laag $(1-10 \mathrm{~Hz}$ ) versus hoog (50-100 Hz)), de impulsduur (50 ms-250 ms) en de stimulus intensiteit( niet voelbaar tot over tolerantiegrens). De in onze studie onderzochte typen TENS waren:

1) conventionele high frequency TENS (HFT), frequentie van $80 \mathrm{~Hz}$, impulsduur $80 \mathrm{mi}-$ croseconden en een intensiteit van mitis (net voelbaar). HFT wordt $6 \times$ per dag gedurende 60 minuten toegepast.

2) high frequency, high intensity TENS (HIT), frequentie van $80 \mathrm{~Hz}$ impulsduur $250 \mathrm{mi}-$ croseconden, intensiteit tot tolerantiegrens. HIT wordt 4-6 per dag gedurende $30 \mathrm{mi}-$ nuten toegepast.

3) controle TENS (COT), frequentie van $30 \mathrm{~Hz}$, impulsduur 250 microseconden en de intensiteit is door de patiënt zelf te regelen (wat men prettig vindt). Dit type TENS mag door patiënt continue toegepast, of zo vaak hij/zij dit wil.

In totaal werden 180 patiënten met verschillende pijnklachten geïncludeerd in de studie. ledere patiënt kreeg 2 van de 3 mogelijke types TENS toegewezen als behandeling. De toewijzing van type TENS en de volgorde van behandeling werd gerandomiseerd. De behandelperiode bestond telkens uit twee weken TENS. TENS werd, na instructie door een fysiotherapeut, thuis door de patiënt zelfstandig toegepast. Na twee weken behandelen met een type TENS, was er een periode van 2 weken geen behandeling, waarna de 2e behandelperiode met een ander type TENS volgde. Bij start en aan het einde van elke behandelperiode werd 
de ernst van pijn gemeten met behulp van een $100 \mathrm{~mm}$ visuele analoge schaal (VAS). Aan het einde van elke behandelperiode werd de patiënt gevraagd of het effect van die periode voldoende was om de behandeling met dat type TENS voor langere tijd te continueren. Na 6 maanden zijn alle patiënten opnieuw gevraagd de ernst van de pijn te scoren werd gevraagd of ze nog altijd TENS gebruikten.

Na de twee testperioden gaven 100 patiënten aan de behandeling met TENS te willen continueren. Daarbij werden geen statistisch significante verschillen in pijnvermindering gevonden tussen de 3 verschillende typen TENS. Merendeel van de patiënten (62\%) die de TENS behandeling wilden continueren gaven aan beide TENS typen even effectief te vinden. Er werd geen verschil gevonden in he pijnvermindering tussen de verschillend typen TENS. Bij de vervolgmeting na 6 maanden waren van 149 patiënten dat beschikbaar. Van deze patiënten gebruikten 75 nog steeds TENS, tegenover 74 niet. De gebruikers van TENS hadden na 6 maanden een statistisch significant groter pijnvermindering dan de niet gebruikers ((28\% (SD 35\%) en 0\% (SD41\%)). De eindconclusie was dat er geen verschil in pijnverminderend effect is tussen de 3 typen TENS. Een redelijke grote groep patiënten (42\%) blijft TENS ook na 6 maanden gebruiken.

In hoofdstuk $\mathbf{3}$ zijn de resultaten gepresenteerd van een analyse naar factoren die mogelijk het succes van TENS kunnen voorspellen. Pijn is een multidimensioneel probleem, waarbij er sprake is van een complexe interactie tussen lichamelijke, psychologische en sociale factoren. De verwachting is daarom dat niet alle patiënten baat zullen hebben bij een behandeling met TENS. Wat de kenmerken zijn van patiënten met positieve behandelresultaten van TENS is niet bekend. Om meer inzicht te krijgen in mogelijke kenmerken die bijdragen aan het effect van TENS zijn bij start van de behandeling een aantal mogelijke factoren gemeten. De set variabelen bij baseline bestond uit een combinatie van metingen van a) pijn gerelateerde variabelen (ernst van pijn, kwaliteit van pijn, neuropatische pijn, het intermitterende karakter van pijn, het aantal pijnlocaties), b) psychologische variabelen (catastroferen, verwachtingen, interne en externe locus of control en mentaal functioneren) en c) het dagelijks fysiek functioneren. Als uitkomst voor een positief behandelresultaat werden 2 verschillende maten gebruikt: 1) het blijven gebruiken van TENS op lange termijn ( 6 maanden) en 2) een pijnvermindering van 33\% (gemeten met een VAS-schaal) na 6 maanden. De analyses van 149 patiënten, die de vervolgmetingen na 6 maanden hadden ingevuld, lieten verschillende resultaten zien per uitkomstmaat. Hoge verwachtingen dat TENS de pijn kan verhelpen voor de start van de behandeling, het hebben van neuropatische pijn en een pijnscore lager dan $80 \mathrm{~mm}$ op een visuele analoge schaal waren onafhankelijk van elkaar geassocieerd met het blijven gebruiken van TENS op lange termijn (6 maanden). De factoren 'intermitterende pijn'en "aantal pijnlocaties $(\leq 2)$ " waren onafhankelijk van elkaar geassocieerd met de uitkomst pijnvermindering van $33 \%$ of meer. 
In hoofdstuk $\mathbf{4}$ is beschreven welke factoren bijdragen aan het blijven gebruiken van TENS op langere termijn (6 maanden). Het hoofddoel van de TENS behandeling is het verminderen van de ernst van de pijnklachten. De mate van pijnvermindering kan verschillen van patiënt tot patiënt. Sommige patiënten blijven TENS gebruiken, ondanks een klein of zelfs geen pijnverminderend effect. De vraag is of TENS naast pijnvermindering ook nog ander effecten sorteert, die het blijven gebruiken van TENS kunnen verklaren. Om deze vraag te beantwoorden zijn bij aanvang van de TENS behandeling en na 6 maanden een aantal effectmaten gemeten. De TENS-gebruikers op 6 maanden hadden, naast minder pijn, statistisch significant betere resultaten op het gebied van dagelijks functioneren, catastroferen, gevoel van controle en self efficacy dan de niet gebruikers. Daarentegen gingen minder patiënten in de gebruikers groep weer aan het werk in vergelijking met de niet-gebruikers. Uit een multiple regressievergelijking bleek dat naast pijnvermindering ook een afname van catastroferen onafhankelijk geassocieerd was met het blijven gebruiken van TENS. Verder bleek dat een afname van medische consumptie (onder behandeling zijn van arts of therapeut en gebruik van pijnstillers) ook geassocieerd te zijn met blijven gebruiken van TENS. De resultaten laten zien dat TENS naast pijnvermindering ook op andere domeinen effecten sorteert die bij kunnen dragen aan het blijven gebruiken van TENS.

In hoofdstuk $\mathbf{5}$ is de validering van een in het Nederlands vertaald meetinstrument (Chronic Pain Self efficacy Scale (CPSS) om self efficacy bij patiënten met chronische pijn te meten toegelicht. Self efficacy wordt omschreven als het vermogen en de overtuiging om adequaat en efficiënt te handelen in een gegeven situatie. Binnen het domein chronische pijn wordt self efficacy als een belangrijke factor gezien die bijdraagt aan de manier waarop een patiënt zelfstandig omgaat met zijn pijn en/of de gevolgen van pijn in het dagelijks functioneren. De behandeling van TENS kan mogelijk bijdragen een betere self efficacy in het omgaan met pijn omdat TENS zelf door de patiënt op eigen wijze (die werkt voor de patiënt) kan worden toegepast. De Engelstalige CPSS heeft 22 vragen en bestaat uit 3 factoren; self efficacy in omgaan met pijn, self efficacy voor fysiek functioneren en self efficacy in omgaan met symptomen (anders dan pijn). De resultaten van een confirmatoire factor analyse met de Nederlandstalige CPSS, uitgevoerd bij 231 patiënten met chronische pijn, ondersteunden de oorspronkelijke 3 factoren structuur niet. In een daarop volgende exploratoire factor analyse vonden we 2 factoren: self efficacy in omgaan met pijn en self efficacy voor fysiek functioneren. Daarbij laden 2 van de 22 items op beide factoren door een onduidelijke formulering. Beide items zijn verwijderd uit de Nederlandse CPSS. De construct validiteit en de betrouwbaarheid van de Nederlandse CPSS bleken voldoende te zijn. De beide gevonden factoren pijn self efficacy in omgaan met pijn en self efficacy voor fysiek functioneren correleren hoog (0.70). Nader onderzoek naar de gevonden factor structuur van de Nederlandse CPSS is noodzakelijk. 
In hoofdstuk $\mathbf{6}$ is gekeken naar de mate van pijnvermindering die een patiënt relevant vindt om de TENS-behandeling als succesvol te duiden. Hierbij is gebruik gemaakt van het concept 'minimally clinically important change' (MCIC). Een MCIC is het kleinste verschil in een score op een voor patient belangrijke effectmaat dat de patiënt als waardevol ervaart en wat voortzetting van de behandeling rechtvaardigt, in de aanwezigheid van bijwerkingen en ongemakken of kosten die de behandeling met zich meebrengt. Voor chronische pijn wordt een $30 \%$ reductie van pijn aanbevolen als een standaardmaat om het succes van alle behandeling voor pijn te evalueren. Deze aanbeveling is gebaseerd op een methode waarin patiënten hun algemeen verbetering scoren op een globale maat voor herstel (volledig verbeterd - volledig verslechterd). Op basis van deze globale maat voor herstel kiest de onderzoeker of behandelaar, zonder inzicht in de mogelijke bijwerkingen en/of ongemakken, een afkappunt voor positief herstel. De vraag is of de aanbeveling van 30\% pijnvermindering toepasbaar is voor alle typen behandelingen. Behandelingen met weinig bijwerkingen en/of ongemakken kunnen mogelijk al bij minder pijnvermindering als succesvol beschouwd worden door een patiënt. In de studie is de MCIC berekend vanuit het perspectief van de patiënt (met in acht name van bijwerkingen etc.), vergeleken met de MCIC berekend vanuit het perspectief van de behandelaar/onderzoeker. Hieruit blijkt dat voor de behandeling van TENS de MCIC vanuit de patiënt lager ligt dan die van de behandelaar/onderzoeker (20\% voor gemiddeld pijn vanuit patiënt perspectief t.o.v. 40\% vanuit behandelaar perspectief). De MCIC vanuit patiënt perspectief is eveneens lager dan de aanbevolen MCIC van 30\%. Een uniforme maat voor pijnvermindering, zoals de aanbevolen pijnvermindering van 30\% lijkt ideaal om effecten van verschillende behandelingen met elkaar te kunnen vergelijken. De resultaten van deze studie tonen aan dat dit niet mogelijk is, aangezien iedere behandeling andere bijwerkingen, kosten en/of ongemakken met zich meebrengt. 


\section{Dankwoord}

Dit proefschrift kent een lange weg waaraan veel personen in meer of mindere mate aan hebben bijgedragen. Onderzoek doe je nooit alleen, je hebt input, inspiratie en steun van velen nodig om het af te ronden. Daarom wil ik van de gelegenheid gebruik maken om diverse personen te danken die op de een of andere manier de afgelopen jaren mij met raad en daad terzijde hebben gestaan.

De basis van dit proefschrift is gelegd begin jaren negentig van de vorige eeuw, door het inrichten van het TENS-spreekuur op de poli pijn en pijnbestrijding, destijds onder leiding van coöordinator drs. Wout Dingemans. Wout Dingemans, samen met Nico Groenman (psycholoog van het pijnteam destijds), hebben mij in de beginjaren van het pijnteam geinspireerd om me verder te verdiepen in de problematiek van chronische pijn. Ik wil hun dan ook danken voor hun steun en vertrouwen in mij om me op te nemen in het pijnteam en dat ze mij de grondbeginselen van 'omgaan met pijnpatiënten' hebben geleerd. Sindsdien hebben meerdere coördinatoren het pijnteam aangestuurd en de behandeling met TENS verder onwikkeld. Na Wout Dingemans werd Maarten van Kleef de nieuwe coördinator, mijn huidige promotor. Maarten, wij twee hebben waarschijnlijk de langste diensttijd van alle leden van het pijnteam en Pijnkenniscentrum van Maastricht. Jij was en bent een constante factor binnen de afdeling pijn en pijnbestrijding. Jij constateerde op een gegeven moment dat 'die TENS behandeling' het eigenlijk best aardig deed. Dat is onder meer de aanleiding geweest om dit onderzoek op te zetten. Ik wil je daarom bedanken voor de plezierige en constructieve samenwerking (niet alleen met het onderzoek) de afgelopen jaren en het mogelijk maken van mijn promotie.

Vervolgens heeft Wim Weber het coördinatorschap van het Pijnkenniscentrum overgenomen en vanuit zijn evidence based georiënteerde insteek extra impulsen gegeven aan het onderzoek. Wim je was (en waarschijnlijk bent nog steeds) sterk in het schrijven van artikelen. Daar heb ik veel van geleerd. Je nuchtere kijk en relativering op de problematiek binnen de gezondheidszorg heb ik altijd zeer op prijs gesteld. Als we elkaar tegenkomen ( meestal op de loopbrug tussen ziekenhuis en het Provisorium) is het altijd weer een feest om de laatste ontwikkelingen in het ziekenhuis met je door te nemen.

De laatste en huidige coördinator is Jaap Patijn, mijn co-promotor. Jaap, je kwam zag en overwon in het Zuiden. Je hebt de pijnbehandeling in Maastricht nog meer een multidimensioneel karakter gegeven (mede een beetje door mijn invloed hoop ik). Vanaf de eerste dag klikte het tussen ons, wat menigeen mischien wel eens heeft verbaasd (een echte Limburger en een echte Rotterdammer samen). Jij bent de grote animator geweest achter mijn promotie, zonder jou had ik hier niet gestaan. Je hebt er steeds in geloofd dat ik het zou gaan redden en me geduldig aangespoord met zeer kritische, maar telkens zeer basale 
vragen. Het heeft mijn manier van denken aangescherpt en verbeterd. Sinds mijn overstap naar Adelante in Hoensbroek mis ik dan ook onze discussies en vooral ook je speciale humor. Jaap, ik vind het daarom bijzonder prettig dat we onze samenwerking binnen het Spine Center kunnen blijven voortzetten.

Hoewel niet als coördinator van het Pijnkenniscentrum maar wel als hoofd van het Kennsicentrum Adelante wil ik Rob Smeets, mijn tweede promotor bedanken. Rob, jij hebt mij het uiteindelijke zetje gegeven om de laatste loodjes van mijn proefschrift af te ronden. Door jou komst naar Adelante heb ik de moed verzameld om er nog een keer vol voor te gaan. Je hebt met een frisse kijk de resultaten van de analyses bekeken en me van waardevolle adviezen voorzien. Ik kijk er dan ook naar uit om met jou, en de rest van de vakgroep/kenniscentrum, het speerpunt chronische pijn verder te ontwikkelen.

Mijn dank gaat ook uit naar de vele collegae waarmee ik heb mogen samenwerken in het pijnteam en het pijnkenniscentrum. Ik wil speciaal Johan Vlaeyen bedanken, die in het beginstadium nog betrokken is geweest bij het onderzoek en waarvan ik veel heb mogen leren over de psychosociale kanten van pijn. Verder wil ik mijn kamergenotes binnen het Pijnkenniscentrum, Inge, Jose, Marianne, Nelleke en Rachel, bedanken die met me meeleefden in mijn promotiestrijd. Een bijzonder woord van dank wil ik richten aan Sandra Reijnders, secretaresse vanaf het eerste uur van de oprichting van het Pijnkenniscentrum. Sandra, je staat altijd klaar om zaken te regelen, literatuur op te vragen, te kopieren of congressen/cursussen te regelen. Altijd is alles tot in de puntjes verzorgd en geregeld. Jammer dat ik je niet kon meenemen als secretaresse naar Adelante.

Verder moet ik een woord van dank richten aan mijn oud-collega's van de afdeling Fysiotherapie van het ziekenhuis. Allereerst George Roox, hoofd van de afdeling die het organisatorisch mogelijk maakte dat we de effectstudie konden uitvoeren. Dank aan mijn collega's Myriam Lamerichs, Ed Waltje, Jos Lipsch en Alex Waelen die destijds de TENS behandelingen hebben uitgevoerd. Verder wil ik al mijn oud-collega's van het azM bedanken voor het de enorme gezellige werksfeer die we samen hadden.

Veder wil ik Emiliene Christophe en Claire Philippeth, secretaresses van de 'oude' pijnpoli bedanken die destijds meegewerkt hebben om de patiënten voor deelname aan de studie te benaderen. Ook alle patiënten die hebben meegedaan aan het onderzoek wil ik danken voor hun deelname en het trouw invullen van vragenlijsten. Zonder hun was er immers geen onderzoek mogelijk geweest.

Ik wil de leden van de beoordelingscommissie Madelon Peters, Johan Vlaeyen, Rob de Bie, Wouter Zuurmond en Riekie de Vet danken voor het lezen en positief beoordelen van mijn proefschrift. 
Verder moet in mijn co-auteurs danken, Jan Schouten voor zijn bijdrage aan de verwerking van de resultaten van de crossover studie, Alphons Kessels en Bjorn Winkens voor hun statistische adviezen, Jeffrey Roelofs voor zijn hulp bij het valideren van meetinstrumenten, Roberto Perez voor de inhoudelijk verbeteringen en kritische reflecties op vrijwel al mijn artikelen en Raymond Ostelo voor zijn bijdrage aan mijn vragen over wat nu een klinisch relevante veranderscore is.

Door mijn overgang van azM naar Adelante in Hoensbroek ben ik een wat andere richting ingeslagen. Echter ook binnen Adelante ben ik gesteund om mijn proefschrift af te ronden. Ik wil daarom de managers van team pijn Roger Bastiaens en Sven Balk danken dat ze die ruimte hebben gecreëerd.

Een speciaal woord wil richten aan mijn beide paranimfen Ton Lenssen en Anita SchmeitzKerckhoffs. Ik ben blij dat jullie me ter zijde willen staan bij de verdediging van mijn proefschrift. Ton, we zijn ooit (heel lang geleden) samen begonnen om evidence based fysiotherapie te implementeren in het ziekenhuis. Ik kijk met veel genoegen terug naar die gezamelijke tijd en onze vele discussies over het vak. Ik heb veel respect voor jou manier van denken en doen. Je was een stuk sneller met promoveren dan ik. Ik had dan ook de eer een paar jaar geleden jou te mogen steunen bij jouw promotie. Ik ben blij en trots dat jij nu naast mij staat.

Anita, we hebben ons leren kennen in het $1^{\mathrm{e}}$ jaar van de opleiding fysiotherapie. Sindsdien hebben we elkaar vrijwel niet meer uit het oog verloren (dat kan ook niet anders als je na de studie in dezelfde straat gaat wonen). Jij en Wien hebben altijd veel belangstelling getoond in wat ik allemaal zogezegd wetenschappelijk uitspookte. Ik heb die belangstelling en waardering altijd zeer op prijs gesteld. Anita, ik vind het dan ook erg fijn om samen met jou mijn promotie nu af te ronden.

Verder wil ik iedereen bedanken die ik de laatste jaren op verschillende plekken in het land of tijdens congressen, steeds weer ben tegengekomen en die mij telkens weer op meer of minder subtiele wijze vroegen wanneer ik nou eindelijk zou gaan promoveren, of men al een datum kon prikken, of verhalen vertelden van een neef die binnen 1 jaar zijn proefschrift afhad. Wel nu Appie, Paul, Michael, Arno, Cindy, Maria, Eugene, Els, Erik, Sandra en Peter, het is zover! Dank voor jullie belangstelling al die jaren.

Tenslotte had ik dit niet natuurlijk kunnen doen zonder mijn familie. Op de eerste plaats mijn moeder en vader. Mam, bedankt dat jij en pap mij de kans en ruimte hebben gegeven om te mogen worden wie ik wilde zijn. Jammer dat pap dit nu niet kan meemaken. Verder wil ik mijn schoonmoeder, Roger, Birgit, Niels, Britt, Miranda, John, Claire en Roy en Lex danken voor alle leuke dingen die we samen doen. 
Dan als laatste mijn eigen gezin. Stan \& Paula en Ward. Jullie staan als jonge twintigers aan het begin van jullie eigen carrieres nu. Ik hoop dat jullie ook net zoveel plezier mogen beleven in jullie werk als ik. Ik ben trots op jullie en hoop dat jullie mijn af en toe afwezige blik, als ik aan het lezen of typen was, niet al te kwalijk hebben genomen. En traditiegetrouw wordt aan het eind van elk dankwoord de belangrijkste persoon bedankt. Lieve Evelyn, het klink als een cliche, maar het klopt als een bus. Ik had dit niet kunnen doen zonder jou. Doordat jij thuis alle zaken regelde had ik de de rust en mogelijkheden om me op mijn promotie te richten. Je zorgt met je "doe maar gewoon" houding er steeds voor dat ik me realiseer wat het belangrijkste is in het leven. En dat zijn jullie! 


\section{About the author}

Albère Köke was born on June 6, 1961 in Sittard, the Netherlands. After he obtained his VWO diploma at the Albert Schweitzer Scholengemeenschap in Geleen, he studied Physiotherapy at the Akademie voor Fysiotherapie in Heerlen and graduated in 1983.

After one year of work in Germany he started in 1984 working at the physiotherapy department of the University Hospital Maastricht (azM) and became a member if the 'pain team' of the hospital in 1986.

Between 1990-1995 he worked, as a research assistant for two clinical trials on the department of epidemiology at the Maastricht University. He started in 1995 his study in Health Sciences at Maastricht University and graduated in 1998. From 1999 till 2009 he was member of the editorial board of the Nederlands Tijdschrift voor Fysiotherapie. He is since 1997 involved in teaching health care professionals about chronic pain at the NPI -institute in Amersfoort en ITON-institute in Haarlem. In 2002 he started working at the pain department of Adelante Volwassenenrevalidatie en Arbeidsreintegrate in Hoensbroek. In 2009 he was assigned to the Kenniscentrum Adelante at the department Innovation. Since 2009 he is also working, as a lecturer at Hogeschool Zuyd in Heerlen. 



\section{Publications}

\section{International}

Lindeman E, Leffers P,Spaans F, Drukker J, Reulen J, Kerckhoffs M, Köke A. Strenght training in patients with myotonic dystrophy and heriditary motor and sensory neuropathy: a randomized clinical trial. Arch. Phys. Med. Reh 1995; 76:612-620

Beurskens A.J.H.M, Heijden van der G.J.M.G, de Vet H.C.W, Köke A.J.A, Lindeman E, Regtop W, Knipschild P.G. Efficacy of traction for low back pain. Design of a randomized clinical trial. J. Manipulative Physiol. Ther. 1995; 18:141-147

Beurskens A.J.H.M, de Vet H.C.W, Köke A.J.A, Lindeman E, Regtop W, van der Heijden G.J.M.G, Knipschild P.G. Efficacy of traction for non-specific low backpain. 5 week results of a randomized clinical trial. Lancet 1995; 346:1596-1600

Beurskens A.J.H.M, de Vet H.C.W, Köke A.J.A, van der Heijden G.J.M.G, Knipschild P.G. Measuring the functional status of patients with low back pain. Assesment of the quality of four disease-specific questionnaires. Spine 1995; 20:1017-1028

Beurskens A.J.H.M, de Vet H.C.W, Köke A.J.A. Responsiveness of functional status in low back pain. A comparison of different instruments. Pain 1996; 65:71-76

Beurskens A.J.H.M, de Vet H.C.W, Köke A.J.A, Regtop W, van der Heijden G.J.M.G, Lindeman E, Knipschild P.G. Efficacy of traction for non-specific low back pain. 12-week and 6-month results of a randomized clinical trial. Spine 1997; 22(23): 2756-2762

Beurskens A.J.H.M, de Vet H.C.W, Köke A.J.A, Lindeman E, van der Heijden G.J.M.G, Regtop W, Knipschild P.G. A patient-specific approach for measuring functional status in low back pain. J Manipul. Phys. Therap. 1999;22(3):144-148

Ostelo R.W.J.G., Köke A.J.A., Beurskens A.J.H.M., de Vet H.C.W., Kerckhoffs M.R., Vlaeyen J.W.S., Wolters P.M.J.C. Berfelo M.W., van den Brandt P.A. Behavioral-graded activity compared with usual care after first-time disk surgery: Considerations of the design of a randomized clinical trial. JMPT; 2000, 23(5):312-319

J. Bart Staal PT, Hynek Hlobil, Maurits W. van Tulder, Albere J.A. Köke, Tjabe Smid, Willem van Mechelen. Return-to-work interventions for low back pain: a descriptive review of contents and concepts of working mechanisms. Sports Med 2002;32(4): 251-267

Tymour Forouzanfar, M.D., Albere J. A. Köke, Ms.c., Maarten van Kleef, M.D, Ph.D., Wilhelm E.J. Weber, M.D, Ph.D. Treatment of Complex Regional Pain Syndrome Type I. Review Eur J Pain 2002; 6(2):105-122

Tymour Forouzanfar, M.D., Marius Kemler, M.D., Ph.D., Alfons G. H. Kessels, M.D., Albere J. A. Köke, Ms.c., Maarten van Kleef, M.D., Ph.D., Wilhelm E.J. Weber, M.D., Ph.D. Comparison of multiple against single pain intensity measurements in Complex Regional Pain Syndrome Type I: analysis of 54 patients Clin J. Pain Jul-Aug 2002;18 (4): 234-237

Lenssen A.F., Köke A.J.A., de Bie R.A. Continuous Passive Motion following primary total knee arthropsty: short- and long-term effects on range of motion Physical Therapy Reviews 2003;8:113-121 
Staal JB, Hlobil H, Twisk JW, Smid T, Köke AJ, van Mechelen W.Graded activity for low back pain in occupational health care: a randomized, controlled trial. Ann Intern Med. 2004 Jan 20;140(2):77-84

Köke AJ, Schouten JS, Lamerichs-Geelen MJ, Lipsch JS, Waltje EM, van Kleef M, Patijn J.Pain reducing effect of three types of transcutaneous electrical nerve stimulation in patients with chronic pain: a randomized crossover trial. Pain. 2004 Mar;108(1-2):36-42

Geraets JJ, Goossens ME, de Bruijn CP, Köke AJ, de Bie RA, Pelt RA, van den Heuvel WJ, van der Heijden GJ.A behavioural treatment for chronic shoulder complaints: concepts, development, and study design. Aust J Physiother. 2004;50(1):33-8

C. De Bruijn, R. de Bie, J. Geraets, M. Goossens, A. Köke, W. van den Heuvel, GJMG van der Heijden, GJ Dinant. Evaluation of an education and activation programme to prevent chronic shoulder complaints: design of an RCT [ISRCTN71777817] BMC Family Practice 2005, 6:7

Hlobil H., Staal JB., Twisk J., Köke AJ., Ariens G. Smid T., van Mechelen W.The effects of a graded activity intervention for low back pain in occupational health on sick leave, functional status and pain: 12-month results of a randomized controlled trial. J Occup Rehabil. 2005 Dec;15(4):569-80

Pool JJ., Ostelo RW., Köke AJ., Bouter LM., de Vet HC. Comparison of the effectiveness of a behavioural graded activity program and manual therapy in patients with sub-acute neck pain: Design of a randomized clinical trial. Man Ther. 2006 Nov; 11(4):297-305.

Gereats JJ., Goossens ME., de Brijn CP., de Groot IJ., Köke AJ., Pelt RA., van der Heijden G., Dinant GJ., van den Heuvel WJ. Cost-effectiveness of a graded exercise therapy program for patients with chronic shoulder complaints. Int J Technol Assess Health Care. 2006 Winter;22(1):76-83

Gereats JJ., Goossens ME., van Haastregt JC., de Groot IJ., de Bruijn CP., de Bie RA., Köke AJ., van den Heuvel WJ. Implications of process evaluation for clinical effectiveness and clinical practice in a trial on chronic shoulder complaints. Patient Educ Couns. 2006 Apr;61 (1):11725. Epub 2006 Jan 6

Veenhof C, Köke AJ, Dekker J, Oostendorp RA, Bijlsma JW, Van Tulder MW, Van den Ende CH. Effectiveness of behavioral graded activity in patients with osteoarthritis of the hip and/or knee: A randomized clinical trial. Arthritis Rheum. 2006 Nov 30;55(6):925-934

Veenhof C. van Hasselt T., Köke A., Dekker J., Bijlsma J. Active involvement and long-term goals influence long-term adherence to behavioural graded activity in patients with osteoarthritis: a qualitative study. Aust J Physiother. 2006;52(4):273-8

A.J.A Köke, J.W. Vlaeyen, R. Perez, M. van Kleef and J. Patijn TENS in chronic pain; just pain reduction as an outcome? European Journal of Pain, Volume 10, Supplement 1, September 2006, Page S218

P.H.T.G. Heuts and A.J.A. Köke Acceptance of pain: is it influenced by conventional cognitivebehavorial treatment? European Journal of Pain, Volume 10, Supplement 1, September 2006, Page S221 
De Bruijn C., de Bie R., Geraets J., Goossens M., Köke A., van den Heuvel W., Dinant GJ. General practitioners apply the usual care for shoulder complaints better than expected--analysis of videotaped consultations. BMC Fam Pract. 2007 Mar 29;8:13

Staal JB, Hlobil H, Köke AJ, Twisk JW, Smid T, van Mechelen W. Graded activity for workers with low back pain: who benefits most and how does it work? Arthritis Rheum. 2008 May 15;59(5):642-9

Leeuw M, Goossens ME, van Breukelen GJ, de Jong JR, Heuts PH, Smeets RJ, Köke AJ, Vlaeyen JW. Exposure in vivo versus operant graded activity in chronic low back pain patients: results of a randomized controlled trial. Pain. 2008 Aug 15;138(1):192-207.

Verbunt JA, Huijnen IP, Köke A. Assessment of physical activity in daily life in patients with musculoskeletal pain. Eur J Pain. 2009 Mar;13(3):231-42.

Vonk F, Verhagen AP, Twisk JW, Köke AJ, Luiten MW, Koes BW.Effectiveness of a behaviour graded activity program versus conventional exercise for chronic neck pain patients. Eur J Pain. 2009 May;13(5):533-41

Maas van der L., Köke A., Bosscher R. de Vet. H., Peters M. Psychometric properties of the Pain Self-efficacy Questionnaire. Dutch validation, prediction and discrimination quality. Accepted for publication in European Journal of Psychological Assessment

Smeets RJEM, Köke A, Lin CWC, Ferreira M, Demoulin C. Instruments measuring function among individuals with low back pain/disorders. Accepted for publication in Arthritis Care and Research 7-6-2011

\section{National}

Groenman N.H, Dingemans W.A, Köke A.J.A, Lousberg R. Behandeling van chronische benigne pijn vanuit het perspectief van het drie-factoren model. Bewegen en Hulpverlening 1990; 3:257-266

Heijden G.J.M.G van der, Bouter L.M, Terpsta E, Essers A.H.H, Waltjè E.M.H, Köke A.J.A, Waelen A.M.W. De effectiviteit van tractie bij lage rugklachten. NTVF 1991; 101:37-41

Beurskens A.J.H.M, de Vet H.C.W, Köke A.J.A, Regtop W, van der Heijden G.J.M.G, Lindeman E, Knipschild P.G. Het effect van tractie bij a-specifieke lage rugklachten. Resultaten van een gerandomiseerd experiment. Ned. Tijdschr. Man. Ther. 1996; 15(1):3-10

Samenwerkende Kenniscenta voor Pijn. Locale projectgroep. Multidisciplinair consensusrapport. Diagnostiek en behandeling van chronische lage rugpijn. 1997 Pijn Kennis Centrum Maastricht, Schrijen-Lippertz Voerendaal

Köke A.J.A. Ander aanpak chronische rugpijnklachten. Fysiopraxis 1997; 8:16-18

Beurskens S., Köke A., de Vet R. Onderzoek is meer dan resultaten genereren. Fysiopraxis 1997:3:12-13

Kerckhoffs M R, Vlaeyen J.W.S, Weber W.E.J, de Vet H.C.W, Köke A.J.A. De interdisciplinaire en gedragsgeorienteerde behandeling van chronische pijn: een evaluatie. NTPP 1998; 1:1-7 
Köke AJA, Beurskens AJHM, De Vet HCW. Meten van het activiteitenniveau bij patiënten met lage-rugklachten: de functionele status. Ned T Fysiother 2001;111(3)74-78

Lenssen AF, Köke AJA, De Bie RA. Effectiviteit van continuous passive motion in de klinische nabehandeling van patiënten met een totale knieprothese: een systematische review. Ned T Fysiother 2001;111(6):152-157

Beurskens AJHM, Köke AJA, De Vet HCW. Lesbrief: Een patiëntspecifieke benadering bij het meten. Ned T Fysiother 2001;111(6):165-167

Köke AJA. Fysiotherapie en chronische pijn. Ned T Fysiother 2002;111(2):

Patijn J, Zuurmond W., Köke A. Pijn bij ouderen: het probleem van de zeer nabije toekomst. NTPP 2002; 22(10):5-11

Goossens M., Köke AJA., Tilli D. Multidisciplinaire Pijnrevalidatie in Nederland NTPP 2002; 22(11):7-13

Ostelo RWJG, Köke AJA , Coppoolse R. Algemene inleiding in meten. Ned. T. Fysiother. 2003;113(1):11-6

Beurskens AJHM, Köke AJA, de VeT HCW. Het meten van veranderingen; responsiviteit van meetinstrumenten. Ned T. Fysiother. 2003;113(4):82-85

Köke. A., Patijn. J, van Kleef M. Het meten van pijn in Nederland. Een inventarisatie onder behandelaars en onderzoekers op het gebied van pijn. NTPP 2003 22(14) 6-12

Gereats J., de Bruijn C., Heijkers J., de Bruijn N., Pelt R., Köke. A., Goossens M., de Bie R., Dinant G. Mogelijkheden voor cognitief-gedragsmatige behandeling van schouderklachten in de eerste lijn. Stimulus 2003 (2):158-171

Köke A.J.A. Meten in de praktijk: De Quebec Back Pain Disability Questionnaire Ned Tijdsch Fysiother 2003;113(4):88

Köke A. Psycholoog of fysiotherapeut? Stimulus 2004-2 p.95-108

Palmen C.M., Meijden van der E., Nelissen Y., Köke A.J.A. De betrouwbaarheid en validiteit van een Nederlandse vertaling van de Disabilities of the Arm Shoulder and Hand (DASH) vragenlijst. Ned Tijdsch Fysiother 2004;114(2):30-35

Köke A.J.A., Swaan L., Brouwers M., Heuts P., Schiphorst Preuper R., Smeets R., Vlaeyen J. Resultaten van het consensusproject Pijnrevalidatie Nederland. NTPP 2004 23(20) p.13-18

Palmen C., Hoogervorst C. Köke A. Geen lichamelijke oorzaak voor de pijn - leg dat maar eens uit. Stimulus 2004-4 p. 368-384.

A.J.A. Köke, M. Geilen. Reactiverende behandeling bij Failed Back Surgery Syndrome. Conditie of gedrag? In: Failed Back Surgery Syndrome, December 2004 Pijn Info p. 27-37

A.J.A. Köke Meten van pijn en hinder. In Algometrie 2005 Pijn Info

Patijn J., Tibboel D., Versteegen G. Wolff A., Köke A. De Pijnkenniscentra na 2007: een absolute noodzaak! NTPP 2006; 25(28): 27-52

Wilgen van CP., Werkman SL., Köke AJA. De behandeling van chronische pijn in de fysiotherapie. Wat is er veranderd? NTPP 2006;25(27):12-15 
Köke A.J.A., Kugler K.E., Rohof O.J.J.M., Engelen M.M.H.. , Danen M., Janssen R., De Bruin, J., Tilman P.B.J. Multidisciplinaire aanpak van lage rugpijn in het Maaslandziekenhuis; implementatie van de CBO richtlijn aspecifieke lage rugklachten. Ned Tijdsch Pijn Pijnbestrijding 2007 26(29):6-8

Rooijen van S., Geelen R., Hendrix L., Köke A., Beurskens A. Fysiek functioneren direct meetbaar. Observatietests voor fysiotherapie, overzicht en inventarisatie van kwaliteit en normgegevens. Stimulus 26(2007)p 201-228

Van Poppel D., Köke A. ljskoud de beste? Literatuurstudie naar het effect van cryotherapie op circulatie en oedeemvorming bij acuut letsel. Ned Tijdsch Fysiother 2007;117(1):

Köke A.J.A. Meten in de praktijk: De Patiënt Specifieke Klacht Ned Tijdsch Fysiother 2007;117(4):88

Maiori R., Köke A., Geilen M., van Zundert J., Vissers C. Graded activity in cognitieve gedragstherapie bij chronische pijn patiënten Pijninfo 13 (2007) p 81-93

Köke A., Torenbeek M., Engers A, Boonstra A, Brouwer S., Pont M., Schreurs K., Swaan L., Smeets R. De Nederlandse Dataset Pijnrevalidatie NTPP 2007 dec(29) 41-45

Meij P, Köke A, J. Patijn J. Inventarisatie intramurale pijnzorg in Nederland NTPP 2008;33:6-21

Geilen M., Köke A. Gedragsgeorienteerde aanpak. Pijnbehandelaar in rol van coach. Tijdschrift voor Coaching 2008 maart (1) pag 17-19

Köke A. Meetinstrumenten voor pijn De NRS en de PSK nader bekeken. Fysiopraxis juli 2009

M. Reneman, Köke A. Drie theoretische modellen. Het functioneren met chronische pijn aan het bewegingsapparaat. Fysiopraxis juli 2009

Sandra Beurskens, Eveline van Engelen, Albere Köke, Anita Stevens. Patiënt Specifieke Klacht. Een instrument om de hulpvraag van de patiënt te verhelderen en scoren. Fysiopraxis oktober 2010 26-29

Hester R. Trompetter, Karlein M. G. Schreurs, Peter M. ten Klooster, Albère Köke. Aanvaarding van pijn: Psychometrische problemen bij de Nederlandse vertaling van de Chronic Pain Acceptance Questionnaire (CPAQ) Psychologie en Gezondheid 2011 geaccepteerd voor publicatie

\section{Books en book contributions}

Lindeman E, Köke A, Kerckhofs M: Oefentherapie bij spierziekte: zijn de doelstellingen reëel? In: Jaarboek Fysiotherapie Kinesitherapie, 1998, Houten; Bohn, Stafleu, Van Loghum

Köke A.J.A., Huynen J.M.G., Kerckhoffs-Hanssen M.R., Konings G.M.L.G., Waltje E.M.H., Weber W.E.J. Multimodaal reconditionerings programma voor patiënten met chronische pijn.1999 Pijn Kennis Centrum Maastricht ISBN90-805-054-2-0

Köke AJA, Heuts P.H.T.G., Vlaeyen J.W.S, Weber W.E.J. Meetinstrumenten chronische pijn. Deel 1 functionele status 1999, Pijn Kennis Centrum Maastricht ISBN 9080505412 
Köke A.J.A. Hoofdstuk 11 Chronische pijn en fysiotherapie.In: Gezondheidspsychologie voor de fysiotherapeut. Red. P. van Burken en J. Swank. Bohn Stafleu Van Loghum Houten 2000 ISBN 903133011

Köke A.J.A., Thomassen J. Hoofdstuk 4: Operante behandelingsstrategieën. In: Gedragsgeoriënteerde behandelingsstrategieën bij rugpijn. Red. Vlaeyen J.W.S., Heuts P.H.T.G. Cure en Care Developments ISBN 9031332097 Bohn Stafleu Van Loghum, 2000

Barendse G., Köke A.J.A., Kemler M. Hoofdstuk Pijnmodulatie en TENS. In: Handboek Pijnbestrijding. Red. Van Kleef M., Weber W., Winter F., Zuurmond W. 2000, De Tijdstroom, Leusden ISBN 9058980073

Köke A.J.A, Vlaeyen J.W,S., Crombez G. Hoofdstuk 4 Pijnmeting, klinimetrie van chronische pijn. In: Handboek Pijnbestrijding Red. Van Kleef M., Weber W., Winter F., Zuurmond W. 2000, De Tijdstroom, Leusden ISBN 9058980073

Ostelo RWJG en Köke AJA, Coppoolse R. Hfst 7: Algemene inleiding in meten.

Beurskens AJHM, Köke AJA, de VeT HCW. Hfst 8: Het meten van veranderingen; responsiviteit van meetinstrumenten. Beurskens AJHM, Köke AJA, De Vet HCW. Hfst 9: Een patiëntspecifieke benadering bij het meten. Köke AJA, Beurskens AJHM, De Vet HCW.Hfst 10: Meten van het activiteitenniveau bij patiënten met lage-rugklachten: de functionele status. In: Onderwijs in wetenschap. Lesbrieven voor de fysiotherapeut. Redactie: Ostelo R., Verhagen A., de Vet H. Bohn Stafleu van Loghum Houten/Diegem 2002

Köke A.J.A.. Gedragsgeoriënteerde aanpak van chronische pijn door de fysiotherapeut. p. 2233 In Jaarboek Fysiotherapie 2004 Redactie: G. Scholten-Peeters, P Dijkstra, P. Vaes, A. Verhagen 2004 Bohn Stafleu van Loghum, Houten.

Köke A.J.A., Brouwers M., Heuts P., Schiphorst Preuper R., Swaan L., Smeets R., Vlaeyen J, Patijn J. Consensus Rapport Pijnrevalidatie Nederland. Een beschrijvend overzicht van pijnrevalidatie programma's in Nederland met betrekking tot doelen en inhoud. Pijn Kenniscentrum Maastricht 2005

Peters M.L, Vlaeyen J.W.S., Köke A.J.A., Patijn J.Meetinstrumenten chronische pijn. Deel 5 pijn gerelateerde vrees en catastroferen. Pijnkenniscentrum Maastricht 2005

Köke A, van Wilgen P., Engers A., Geilen M. Graded Activity. Een gedragsmatige behandelmethode voor paramedici Bohn Stafleu van Loghum, Houten 2007 ISBN 9789031350940

Engers A, Köke A, Torenbeek M. Nederlandse Dataset Pijnrevalidatie. SRL, Hoensbroek 2007 ISBN 9090174222 
Köke AJA. en van Wilgen P. Hfst 5 Graded Activity: een andere kijk op het bevorderen van activiteiten bij patienten met chronische pijnklachten. Praktische gids bij de toepassing van graded activity. p 91-114. In: Als pijn chronisch wordt. Revalidatie van patienten met chronische pijn. Nijs J en Van Wilgen P.(red.) Standaard Uitgeverij Antwerpen 2009 ISBN 9789034193063

Köke AJA. Hfst 11 Chronische pijn en fysiotherapie. p265-278. In Gezondheidspsychologie voor de fysiotherapeut. P. van Burken (red.) 2e druk Bohn Stafleu van Loghum Houten 2010 ISBN 9789031381203

Boonstra A.M, Schiphorst Preuper H.R, Brouwer M., Weerdt de M., Knol D.L., Köke A. Classificatie van patiënten met chronische pijnklachten; onderzoek naar de betrouwbaarheid van de WPN niveaus. NTPP 2011;30(46): 5-1-2011 
